
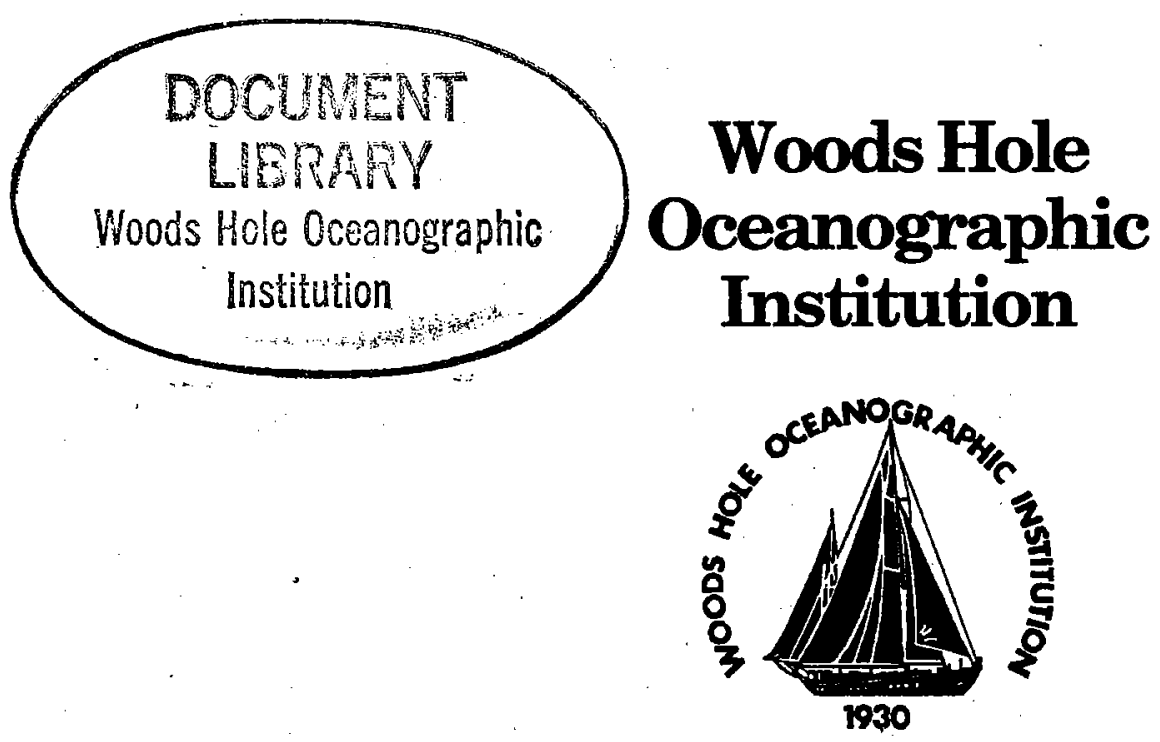

\title{
Winter 1993 Observations of Oceanography and Sediment Transport at the LEO-15 Site
}

\author{
by \\ *J.D. Irish \\ *J.F. Lynch \\ ${ }^{\star} A$.E. Newhall \\ ${ }^{\star} \mathrm{N}$. Witzell \\ *P. Traykovski \\ †S. Glenn \\ December 1995

\section{Technical Report}

Funding was provided by the National Oceanic and Atmospheric Administration through Contract No. 4-25020 to Rutgers/SUNY National Underseas Research Program.

Approved for public release; distribution unlimited.

"Woods Hole Oceanographic Institution

${ }^{\dagger}$ Rutgers University 
Winter 1993 Observations of Oceanography and Sediment Transport at the LEO-15 Site

by

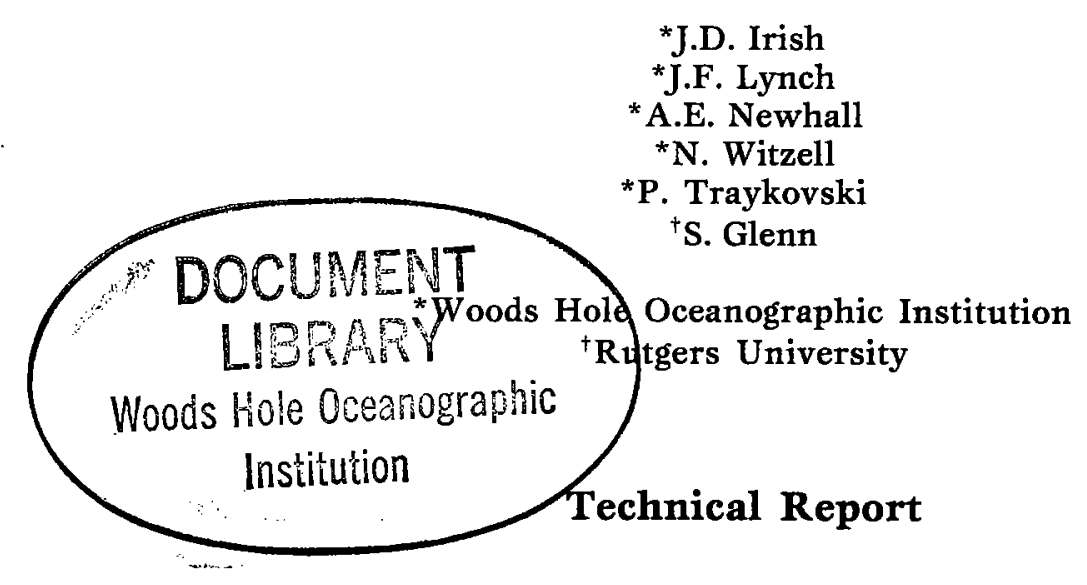

Woods Hole Oceanographic Institution

Woods Hole, Massachusetts 02543

December 1995

Funding was provided by the National Oceanic and Atmospheric Administration through Contract No. 4-25020 to Rutgers/SUNY National Underseas Research Program.

Reproduction in whole or in part is permitted for any purpose of the United States Government. This report should be cited as Woods Hole Oceanog. Inst. Tech. Rept., WHOI-95-17.

Approved for public release; distribution unlimited.

Approved for Distribution:
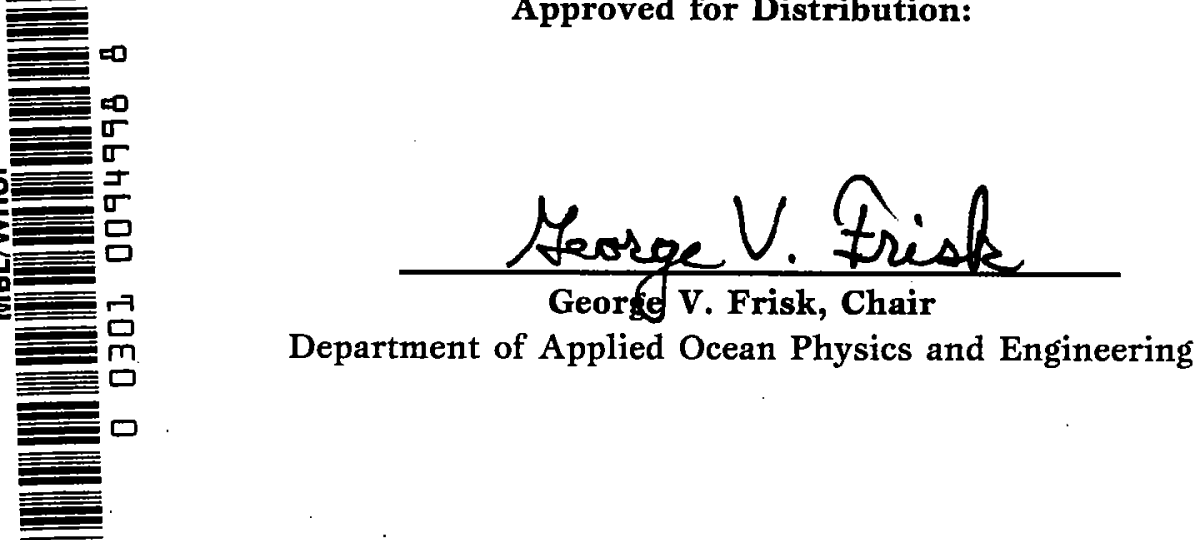


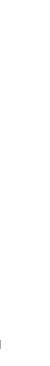

. 


\section{Table of Contents}

Table of Contents

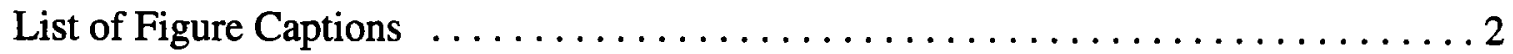

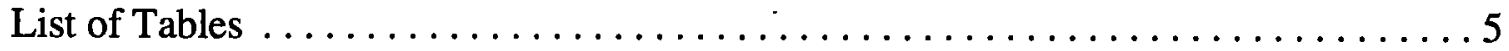

I. Objectives of the Winter 1993 WHOI Deployment at the LEO-15 Site $\ldots \ldots \ldots \ldots 6$

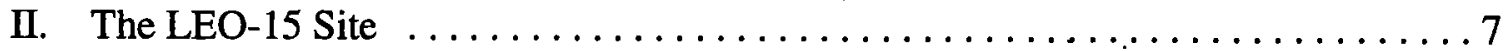

III. Instrumentation used in the Winter 1993 LEO-15 Deployment $\ldots \ldots \ldots \ldots \ldots$

A. Current Meter/OBS Instrument Sampling $\ldots \ldots \ldots \ldots \ldots \ldots \ldots \ldots \ldots \ldots \ldots \ldots \ldots$

B. Current Meter Measurements ......................... 12

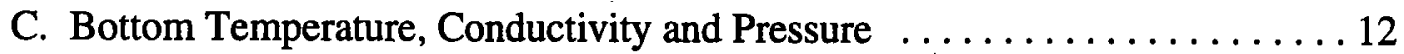

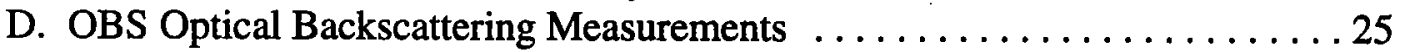

E. Acoustical Instruments ............................25

IV. LEO-15 Sediment Samples and OBS Calibrations $\ldots \ldots \ldots \ldots \ldots \ldots \ldots$

A. Sieving for course fraction and Coulter counter/SPECTREX

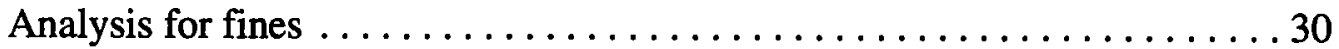

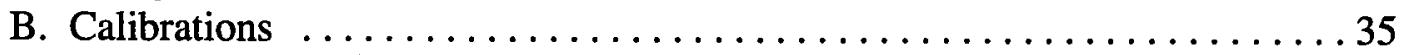

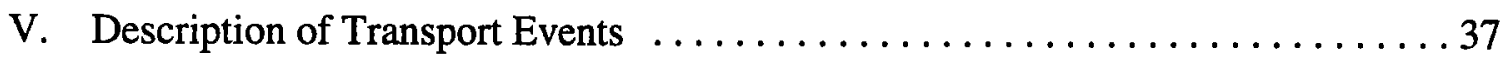

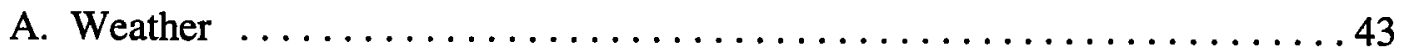

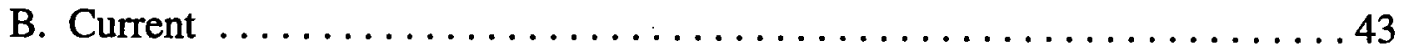

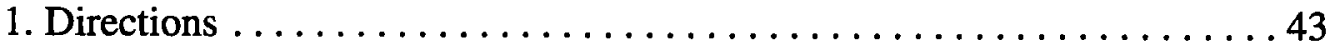

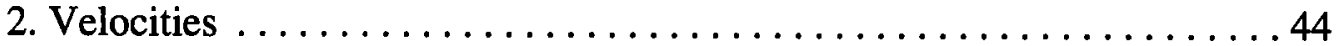

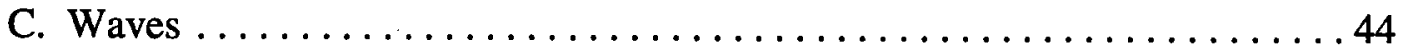

1. Wave Velocities .............................. 44

2. Wave Correlations $\ldots \ldots \ldots \ldots \ldots \ldots \ldots \ldots \ldots \ldots \ldots \ldots, \ldots, \ldots \ldots \ldots$

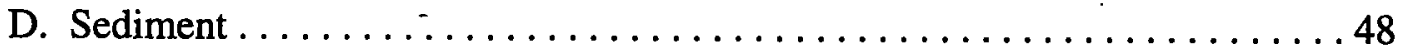

VI. Boundary Layer Structure and Size Dependent Transport at LEO-15 . . . . . . 49

A. Boundary Layer Models and Observations $\ldots \ldots \ldots \ldots \ldots \ldots \ldots \ldots . \ldots 49$

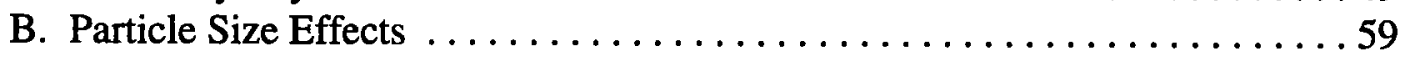

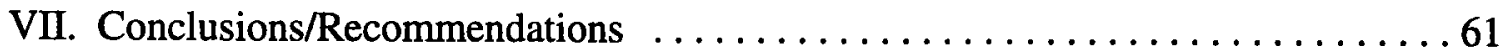

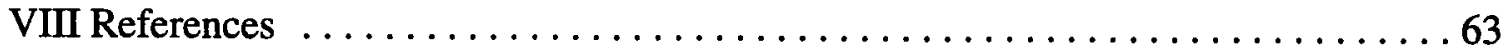

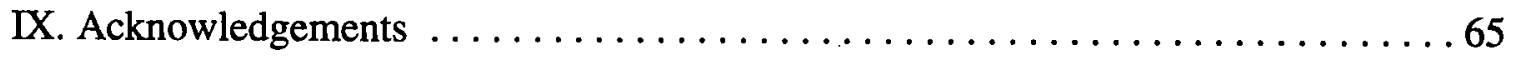




\section{List of Figure Captions}

Figure 1. LEO-15 study site is shown in relationship to the New Jersey Coast and the Rutgers Marine Field Station at Tuckerton, N.J.

Figure 2. Detailed bathymetry at the LEO-15 site from summer 1991 survey. The location of the New York Bight Undersea Research Center Stations are shown. Site 9 was occupied in December 1993 by WHOI instrumentation.

Figure 3. WHOI bottom instrument frame showing relative location of sensors.

Figure 4. Summary plot of data from December 1993 deployment along with NDBC buoy wave and weather data.

Figure 5. Savonius rotor speeds 2 meters above bottom. The solid line is the half-hourly averaged current speed which contains the mean and wave effects. The dots are from OBS triggered events with 3.5 second averages which indicate peak wave speeds are often twice averaged speeds.

Figure 6. The Eastgoing vector component of velocity at 2 meters above bottom. The solid line is the half-hourly averaged velocity component which should not have wave velocities. The dots are the OBS triggered events with 3.5 second averages which show the "instantaneous" velocity, including wave effects. The mean current peaks are typically one third of the instantaneous.

Figure 7. The Northgoing vector averaged and instantaneous velocity as in Figure 6.

Figure 8. End cap temperature showing the steady decrease of temperature with winter cooling over the first four days.

Figure 9. Comparison of the two pressure sensors (with the mean removed), showing the dominant tidal signal. The differences between the two sensors, due to drift, is also shown for comparison.

Figure 10. Comparison of the two pressure record spectra showing slight disagreement at low frequency (sensor drift) and high frequency (sensor noise and response). The pressure is dominated by the semi-diurnal (M2) tide.

Figure 11. Comparison of event (3.5156 second samples) of the two pressure sensors, showing the difference between the 3.5156 second averages of the Paroscientifc sensor, and the instantaneous A/D measurement of the Druck (analog) pressure sensor.

Figure 12. The burst wave spectrum from 20:23 GMT on 11 December 1993. Two frequency waves are present: with about 6 and 9 second period.

Figure 13. The attenuation of pressure or current velocity as a function of frequency at 12 meters depth.

Figure 14. The D\&A OBS sensor at $10 \mathrm{cmab}$ ( $\mathrm{cm}$ above bottom). The solid line is the 
unnormalized, half-hourly averaged OBS output in volts. the dots are the OBS triggered events sampled every 3.5 seconds. Again the instantaneous samples are many times the averaged signal indicating that high-frequency the wave effects dominate the signal at $10 \mathrm{~cm}$.

Figure 15. The D\&A OBS sensor at $30 \mathrm{cmab}$ plotted as Figure 14. The event signals are not as dominate above $10 \mathrm{~cm}$.

Figure 16. The OBS sensor at $100 \mathrm{cmab}$ as in Figure 15.

Figure 17. The OBS Sensor at $200 \mathrm{cmab}$ as in Figure 15.

Figure 18. Plot of the sieved sediment samples from the LEO-15 site in early December 1993 (3a and $3 \mathrm{~b}$ ) and early January 1994 (4a) indicating an increase in fine same fraction (125 to $500 \mu \mathrm{m})$.

Figure 19. Plot of the SPECTREX particle size spectrum from the water sample in early December 1993 at the LEO-15 site. The average is shown at the top, and two individual 90 second averaged samples from the Sample Bottle Number 1 are shown at the bottom.

Figure 20. The individual calibration points for OBS\#1 (SN107) from the weighted samples are shown as the * and least squares quadratic fit shown as the line. The parameters for the fit to the calibration are given in the equation.

Figure 21. OBS\#2 (SN145) Calibration as in Figure 20.

Figure 22. OBS\#3 (SN146) Calibration as in Figure 20.

Figure 23. OBS\#4 (SN147) Calibration as in Figure 20.

Figure 24. Cross correlations of wind, wave, current, and sediment concentration time series.

Figure 25. Tidal ellipses during NW wind event (period 2 in Fig. 4 wind time series).

Figure 26. Spectra of wind, wave, current, pressure, and sediment concentration time series. .

Figure 27. Modification of the GGM model of eddy viscosity vs height above bottom in which the eddy viscosity does not decrease, thus insuring continuity of the vertical current gradient.

Figure 28. Output of GGM model for $U_{*}^{C}$ and $U_{*}^{c w}$.

Figure 29. Wave boundary layer thickness calculated from the GGM model output.

Figure 30. Height of the "transition boundary layer" from the modified GGM eddy viscosity model of Figure 27.

Figure 31 . OBS output at $10 \mathrm{cmb}$ vs $C$ calculated at $10 \mathrm{cmab}$ using $C(z)=C\left(z_{r}\right)\left(\frac{z}{z_{r}}\right)^{-\omega_{s} / K v_{\bullet}^{e}}$ for $z_{r}$
$=200 \mathrm{cmab}$. (OBS output at $200 \mathrm{cmab}$ gave $C\left(\mathrm{z}_{\mathrm{r}}\right)$ ). 
Figure 32. OBS output at $10 \mathrm{cmab}$ vs $C$ calculated at $10 \mathrm{cmab}$ using $C(z)=C\left(z_{r}\right)\left(\frac{z}{z_{r}}\right)^{-\omega_{z} / \varepsilon v_{*}^{c m}}$ for
$\mathrm{z}_{\mathrm{r}}=200 \mathrm{cmab}$. (OBS output at $200 \mathrm{cmab}$ gave $\left.C\left(\mathrm{z}_{\mathrm{r}}\right)\right)$.

Figure 33. Calculated particle diameters for 1993 LEO-15 deployment using slope of Rouse profile fit to the 30,100, and 200 cmab OBS sensor's outputs. A Stoke's law fall velocity is assumed. 


\section{List of TABLES:}

Table I:

Table II:

Table III:

Table IV:
LEO-15 Sediment Samples

LEO-15 Sieving and Filtering OBS Calibrations - Part 1

OBS Calibrations - Part 2 


\section{Objectives of the Winter 1993 WHOI Tripod Deployment at the LEO-15 Site}

NOAA has the overall responsibility "to establish programs for the assessment, protection development, and utilization of U.S. underwater resources". In responding to this mandate, NOAA initiated the National Undersea Research Program (NURP), which consists of regional centers for support of in-situ research and technical development. The work being reported here was performed under the auspices of the Middle Atlantic Bight National Undersea Research Center administered jointly by the Institute of Marine and Coastal Sciences at Rutgers University and the Marine Sciences Research Center at the State University of New York, Stony Brook. This center is establishing long-term Ecosystem Observatories (LEOs) to study changes in the marine environment. LEO-15 is an inner shelf site located in $15 \mathrm{~m}$ of water offshore of the Rutgers Marine Field Station at Tuckerton, N.J. The LEO-15 observatory project has as its primary objective "to distinguish between natural and anthropogenic changes in the marine environment". In support of that objective, measurements of the physical oceanography, geology, biology, and chemistry of the LEO-15 site have been undertaken by a number of investigators at different institutions with an emphasis on longterm, real or near-real time, state of the art data acquisition. During the winter of 1993, WHOI initiated the first of a series of short term observations to obtain information on the site for the design of long-term deployments, and to test new acoustical and optical instrumentation on its suitability for use at the LEO-15 site. The measurements discussed in this report deal mainly with the physical oceanography and sediment transport aspects of the LEO-15 project, though be a small biology component (plankton size measurements) eventually will be included in this project.

The objectives of our initial study were to answer the following question:

1) What mechanisms drive the sediment transport at the LEO-15 site? Possibilities include storm events, normal wave/tidal current stresses, upwelling and downwelling events, among others.

2) What is the magnitude and direction of the integrated sediment transport over the entire water column?

3) What is the size dependence of the sediment transport versus depth and time, and do fine particles or large particles dominate the transport?

4) How well do standard 1-D eddy diffusion transport models such as the Glenn, Grant, and Madsen models (Grant and Madsen, 1979; Grant and Madsen, 1988; Glenn, 1983; and Glenn and Grant, 1987) describe the measured transport at the LEO-15 site, where there is some local ridge structure and sediment non-uniformity (i.e. 3-D effects).

5) What is the biological activity in the water column in the zooplankton size range? Can acoustics combined with optics separate the sediment signal from the biological activity unambiguously, or must one resort to making periodic in-situ samples?

In order to begin work toward accomplishing these objectives, we deployed a bottom instrument with oceanographic and sediment transport sensors at the LEO-15 site during the period 9 December 1993 - 11 January 1994. Winter is a period of high storm activity, which is generally an important factor in initiating coastal sediment suspension, and so a "first look" winter deployment 
was a logical first step in examining transport at the LEO-15 site. The remainder of the report will deal with the results of that deployment.

\section{The LEO-15 Site}

The LEO- 15 site $\left(39^{\circ} 29^{\prime} \mathrm{N} \mathrm{X} 74^{\circ} 15^{\prime} \mathrm{W}\right)$ is located in about 15 meters of water depth about $5 \mathrm{~km}$ offshore of Little Egg Inset in New York Bight (Fig. 1). The site itself is relatively sandy, with a large coastal sand/gravel ridge (Beach Haven Ridge) extending NE-SW through the region (Fig. 2). The ridge is about 5 meters high, and about 10 meters deep at the crest. On the shoreward side of the ridge, large sand ripples have been observed. The LEO-15 site 9 ( on the southwest end of the ridge) was selected for the December 1993 deployment because ongoing current meter and optical backscatter observations at this particular site by Rutgers University (Scott Glenn, private communications) indicated that wave-induced sediment transport would be easily observed here.

The LEO-15 site is ideal for establishing a long-term ocean observatory for sediment transport studies on the inner continental shelf because:

1. it is located only $5 \mathrm{~km}$ offshore, so that it is possible to lay a fiber optic cable with power from the Rutgers Marine Station to the site. This enables long-term observations (years long), interactive sampling, and study of the results in real time,

2. it is located close to the Rutgers Marine Station so that logistical support (small boat, diver, meteorological observations, etc.) can be easily supplied from there by Rutgers University,

3. the 15 meter depth should allow most storms to generate waves which will penetrate to the bottom so that we will be able to study numerous examples of high wave stress events and sediment suspension. This enables comparisons of low-energy, fair weather conditions versus high-energy, stormy conditions,

4. oceanographically the site is exposed to the North Atlantic which has many storms which will generate waves which can propagate into the region,

5. there is a general alongshore flow to the southwest, which at times is dominated by either up or down coast wind-driven flow events,

6. upwelling is frequently seen in the region, which can strongly affect the biological activity, and finally, 


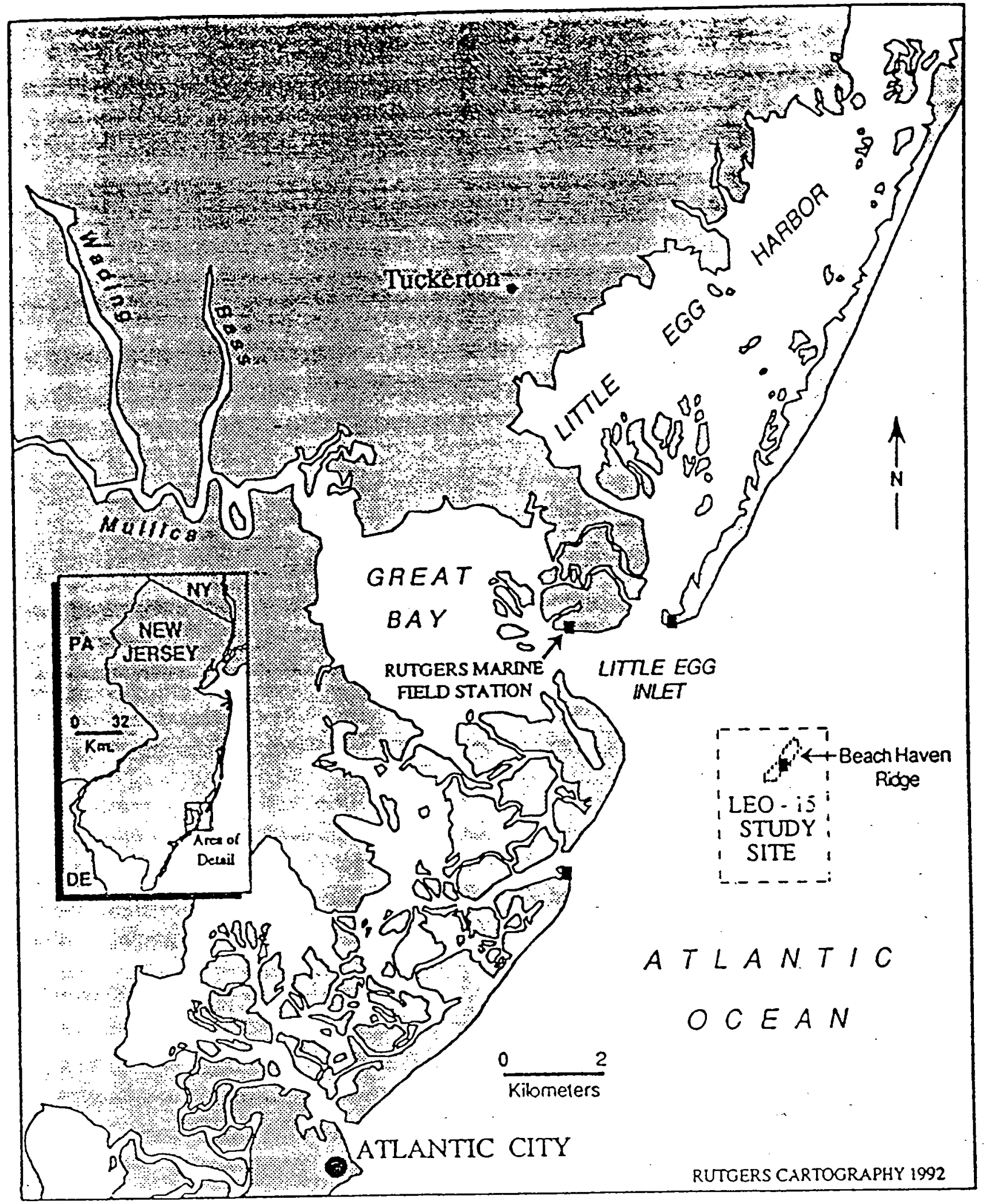

Figure 1. LEO-15 study site shown in relationship to the New Jersey Coast and the Rutgers Marine Field Station at Tuckerton, N.J. 


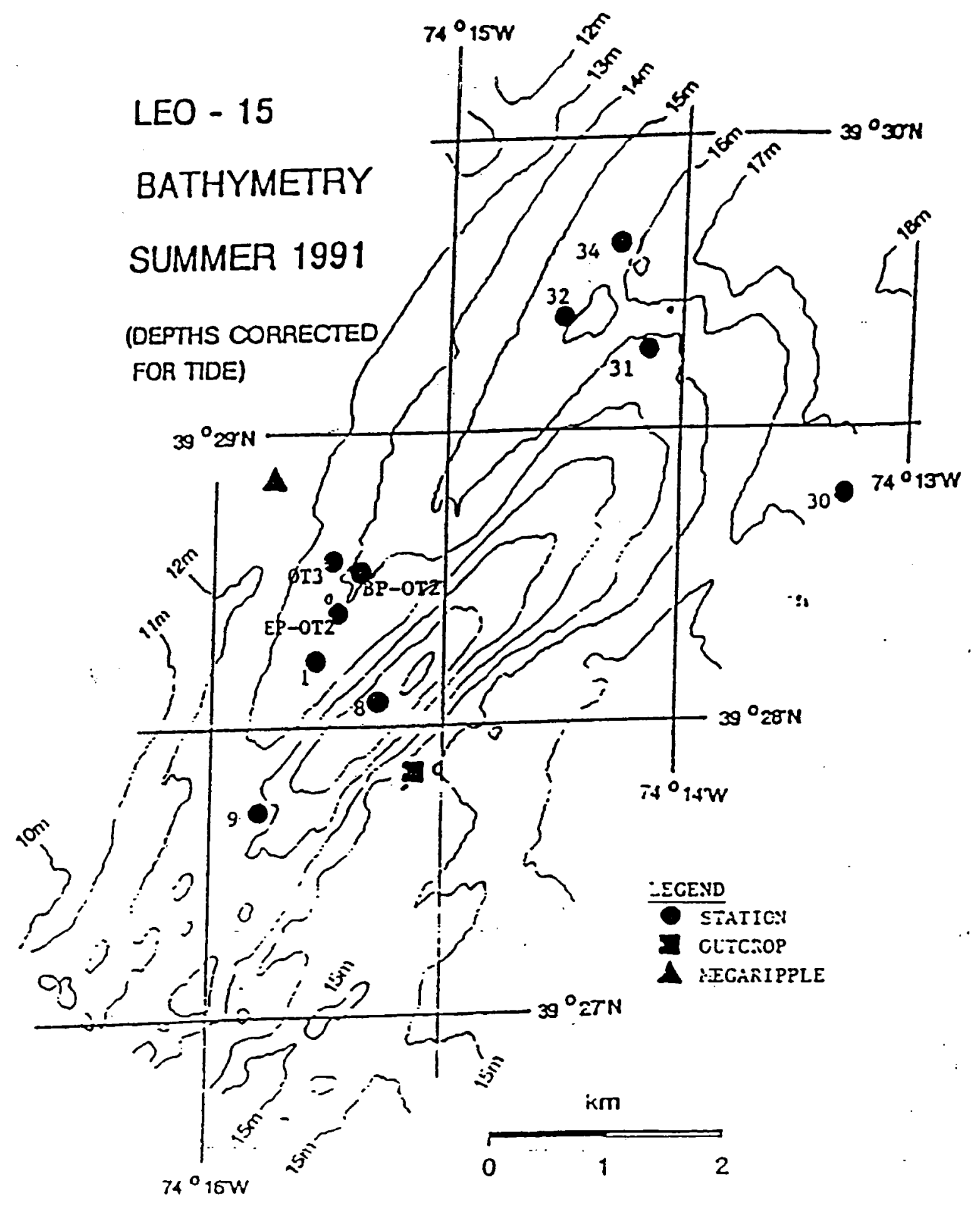

Figure 2. Detailed bathymetry at the LEO-15 site from summer 1991 survey. The location of the New York Bight Undersea Research Center Stations are shown. Site 9 was occupied in December 1993 by WHOI instrumentation. 
7. ongoing, interdisciplinary research is taking place at the site, so that other supporting observations, including satellite observations and modeling which are being conducted can help us determine the physical processes responsible for the suspension and transport of sediment on the inner continental shelf.

\section{III. 'Instrumentation Used in the Winter 1993 LEO-15 Deployment}

In order to study the sediment transport and oceanography at the LEO-15 site, a bottom instrument frame with a number of oceanographic sensors and sediment concentration monitoring sensors was deployed. This frame and the instrumentation it carried are shown Fig 3. For measuring the oceanography, the frame carried a Solid State Vector Averaging Current Meter (SSVACM, Irish et al, 1991) with rotor and vane at two meters above bottom (m.a.b.), a Sea Bird temperature and conductivity (salinity) sensor pair, and two Paroscientific pressure sensors. For measuring sediment concentration, both optical (single point) sensors at four heights and acoustical (continuous vertical profiling) instruments were employed. Unfortunately, the acoustic instrument's tape recorder failed, so that the only transport measurements that can be shown are from the Optical Backscatterance Sensors (OBS's). The bottom frame structure was designed squat and rugged for use as a dredged material site monitor (Baldwin, Irish \& Bokuniewicz, 1990). This was beneficial in protecting the instrumentation (in fact the frame was toppled by a string of winter storms during this deployment, despite being anchored by pipes to the bottom), but also caused some flow disturbance. We make no corrections or error estimates for the flow disturbance in this report. In the remainder of this section, we examine each of the sensors used in detail.

\section{A. Current Meter/OBS Instrument Sampling}

The SSVACM/OBS instrument (Fig. 3) ran for over one month, but filled the available data storage memory (1.2 MBytes) in about 10 days. The instrument sampled all sensors every 3.5156 seconds and summed the individual samples together to obtain half-hour averages to study the tides and average oceanographic conditions at the site. Additionally, the instrument conditionally sampled the four OBS sensors and if any one of them saw statistically high energy for more than 2 successive samples, the instrument then also recorded the 3.5156 second samples from all sensors for up to 7.5 minutes (128 samples), then waited 2 hours before recording additional event information. Finally, the instrument sampled bottom pressure with 256 point bursts at 0.8789 second intervals every day to measure the wave field. For a discussion of the revised conditional sampling techniques used in this deployment, see Irish (1993). 


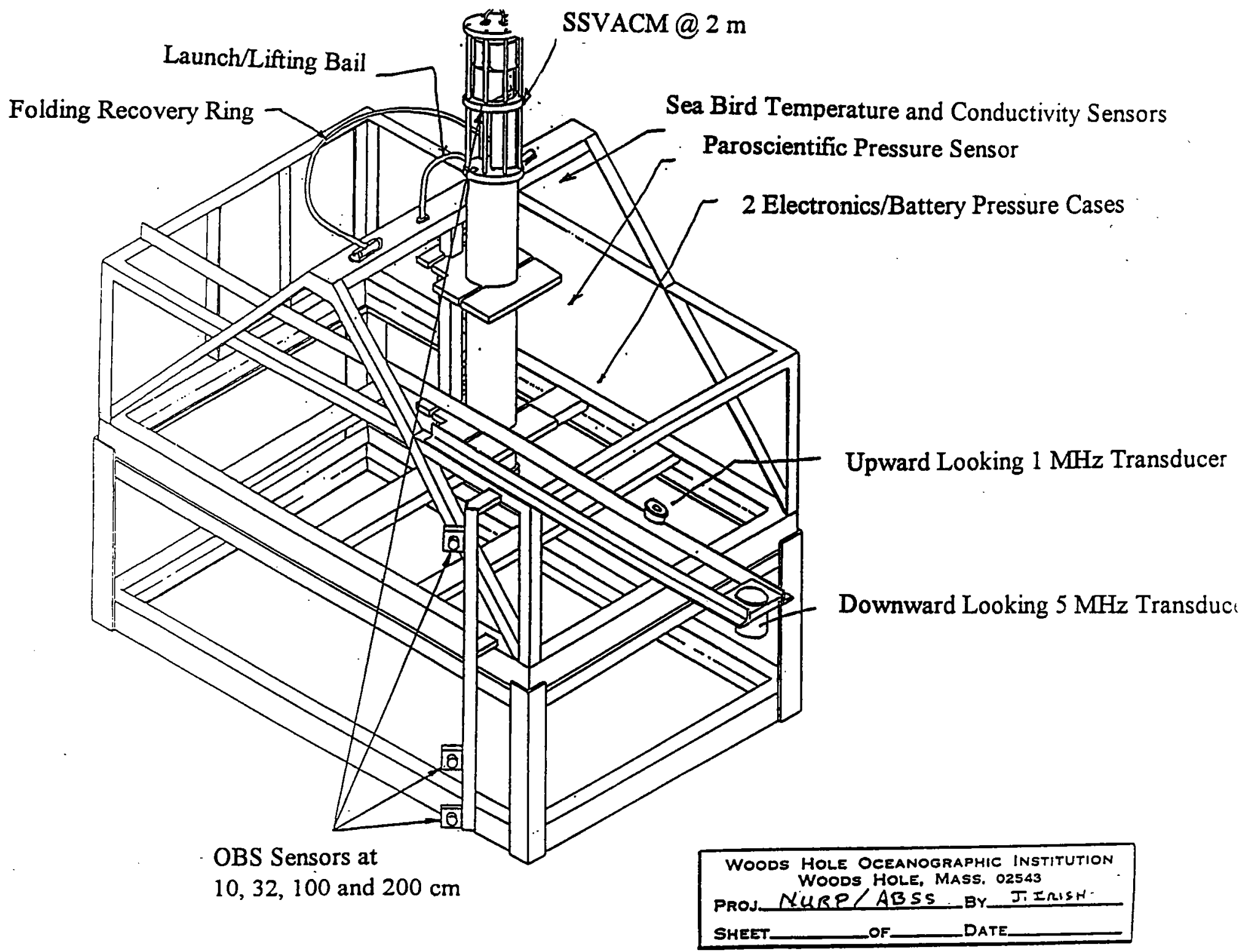

WHOI bottom instrument frame showing relative location of sensors.

Figure 3 


\section{B. Current Meter Measurements}

The current meter instrument measured sea water velocity with a Savonius rotor, vane and compass, calculated vector averages, and recorded the numbered rotor revolutions and two averaged velocity components (Irish et al 1991). Fig. 4f shows the flow generally to the south and west, except for specific events such as late on December 10 and 14, and early on the 18th when the flow changes to Northgoing. The velocities (Fig. 4e) are typical of shelf velocities, with magnitudes around 15 to $40 \mathrm{~cm} / \mathrm{sec}$. An estimate of the velocities in the wave field was also made. Since the Savonius rotor rectifies the wave energy, the rotor speed record contains some measure of the surface wave energy. The vector averaged velocity, however, averages out the wave oscillations (however, only as good as the vane can move back and forth with the waves). Therefore, the difference between the rotor speed squared and the speed squared calculated from the vector averages is a measure of the mean square wave activity (Beardsley, 1987). The square root of this is also shown in Fig. 4c. There are a number of periods of high wave activity, which aren't correlated with the lower frequency currents. The peak late in the morning of December 11 (marked "b" in Fig. 4c) is illustrative.

The current directions were estimated from the vector averaged velocities and are plotted in Fig. 4f. (The half-hourly average of the direction al vane from the instrument was not useful since the waves going back and forth gave a scatter in instantaneous direction with equal distribution between 0 and 360 , so the averages tended to be about 180 degrees.)

The high frequency (3.5156 second) samples were recorded when the OBS sensors saw high suspended sediment concentrations. These high-frequency rotor samples (dots) and the half-hourly (solid line) are shown in Fig. 5. The least count resolution of $5.6 \mathrm{~cm} / \mathrm{sec}$ in the $3.5156 \mathrm{~second}$ samples is obvious. There are much higher instantaneous speeds than are seen in the half-hourly averages, with the maximum 3.5156 second speed registered as $80 \mathrm{~cm} / \mathrm{sec}$, nearly twice the halfhourly maximum. Figs. 6 and 7 show the two components velocities with the half-hourly averages and the 3.5156 second samples. (Note that there is no vector averaging done in the high-frequency samples, as these are the basic samples taken and these samples are taken only $4 \%$ of the time during times of high OBS readings.)

\section{Bottom Temperature, Conductivity, and Pressure Observations}

Conductivity, temperature, pressure were also sampled by the bottom instrument. Two temperature sensors were used, a Sea Data Integrating thermometer (with YSI thermistor in the pressure case's end cap, and a Sea Bird SBE-3 thermometer (Pederson, 1969). The end cap temperature measurement has the time constant of the end cap, about 2 minutes (Levine, 1981), and an accuracy of $\pm 0.01^{\circ} \mathrm{C}$ over several months. The SBE-3's time constant is 0.5 to 1 second depending on the water velocity, and has an accuracy of better than $\pm 0.003^{\circ} \mathrm{C}$ over one year (Brown, Irish and Bratkovich, 1983). The Sea Bird sensor was used to sample the high frequency event signals, and compare with the end cap temperature for averaged samples. The Sea Bird 

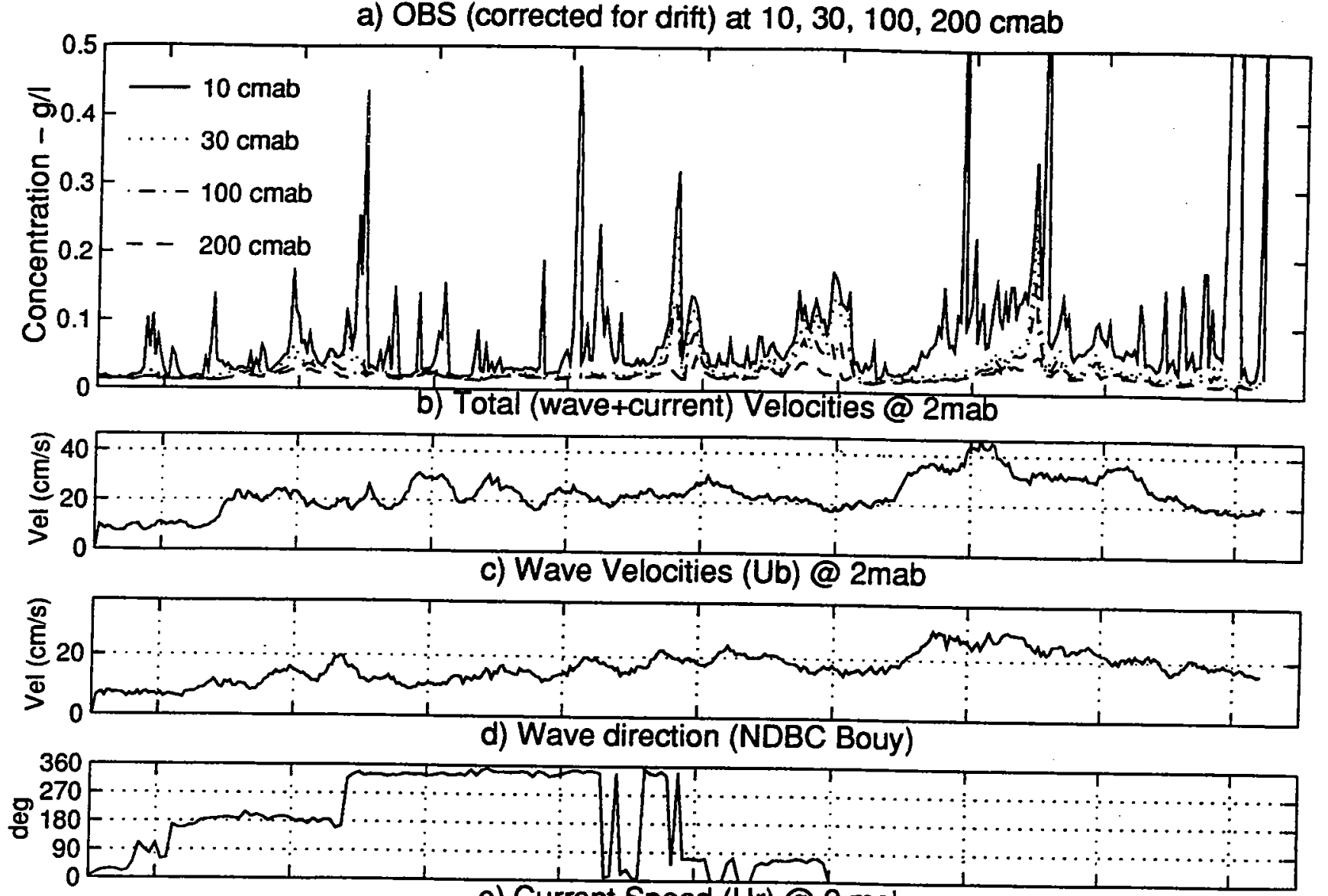

e) Current Speed (Ur) @ 2 mab
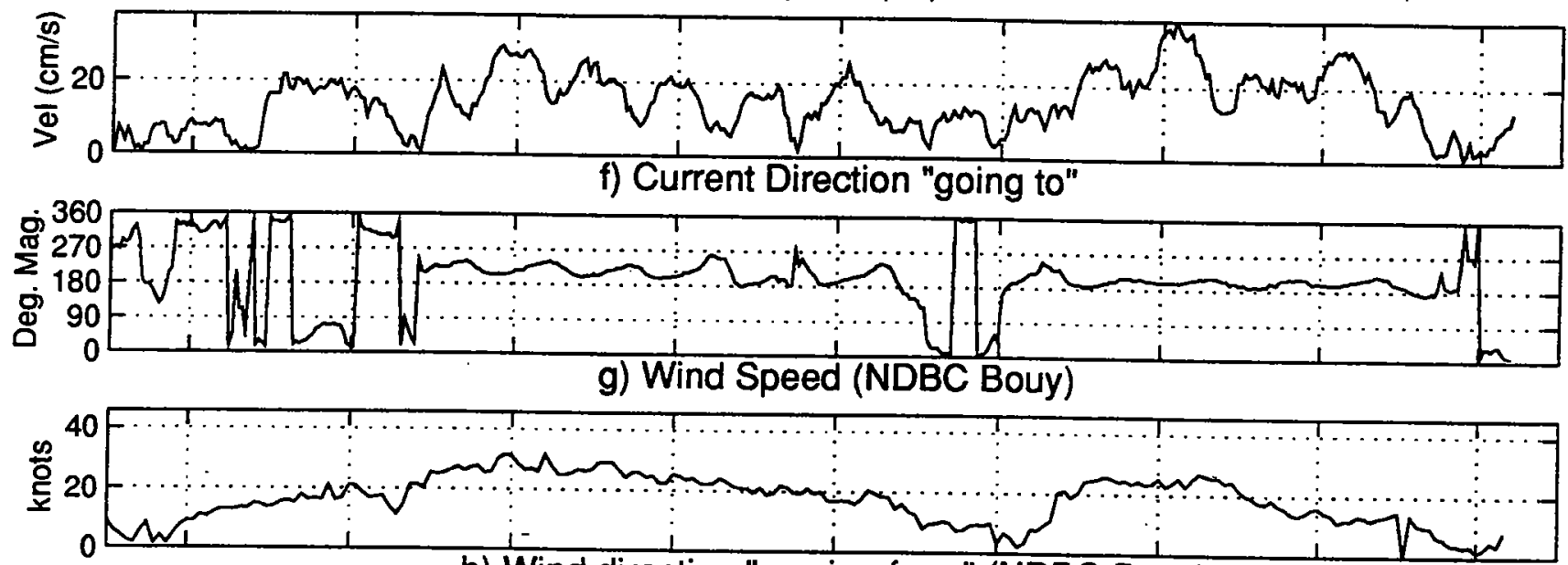

h) Wind direction "coming from" (NDBC Bouy)

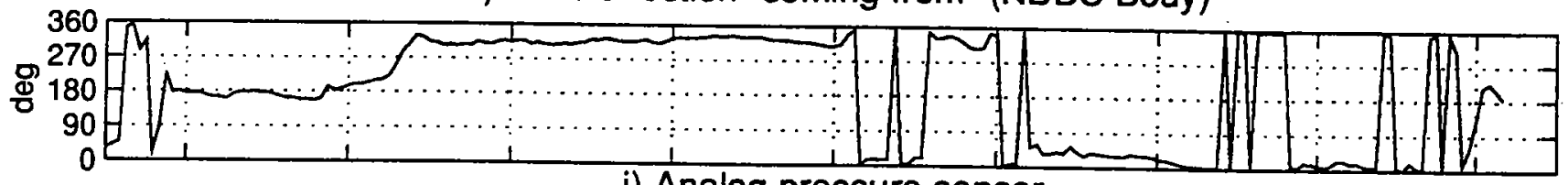

i) Analog pressure sensor

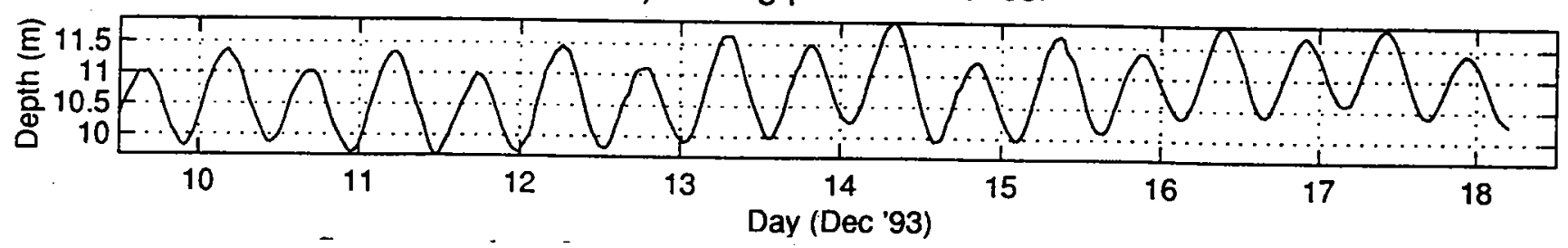

Figure 4. Summary plot of data from December 1993 deployment along with NDBC buoy wave and weather data. 


\section{LEO15 - Rotor Speeds}

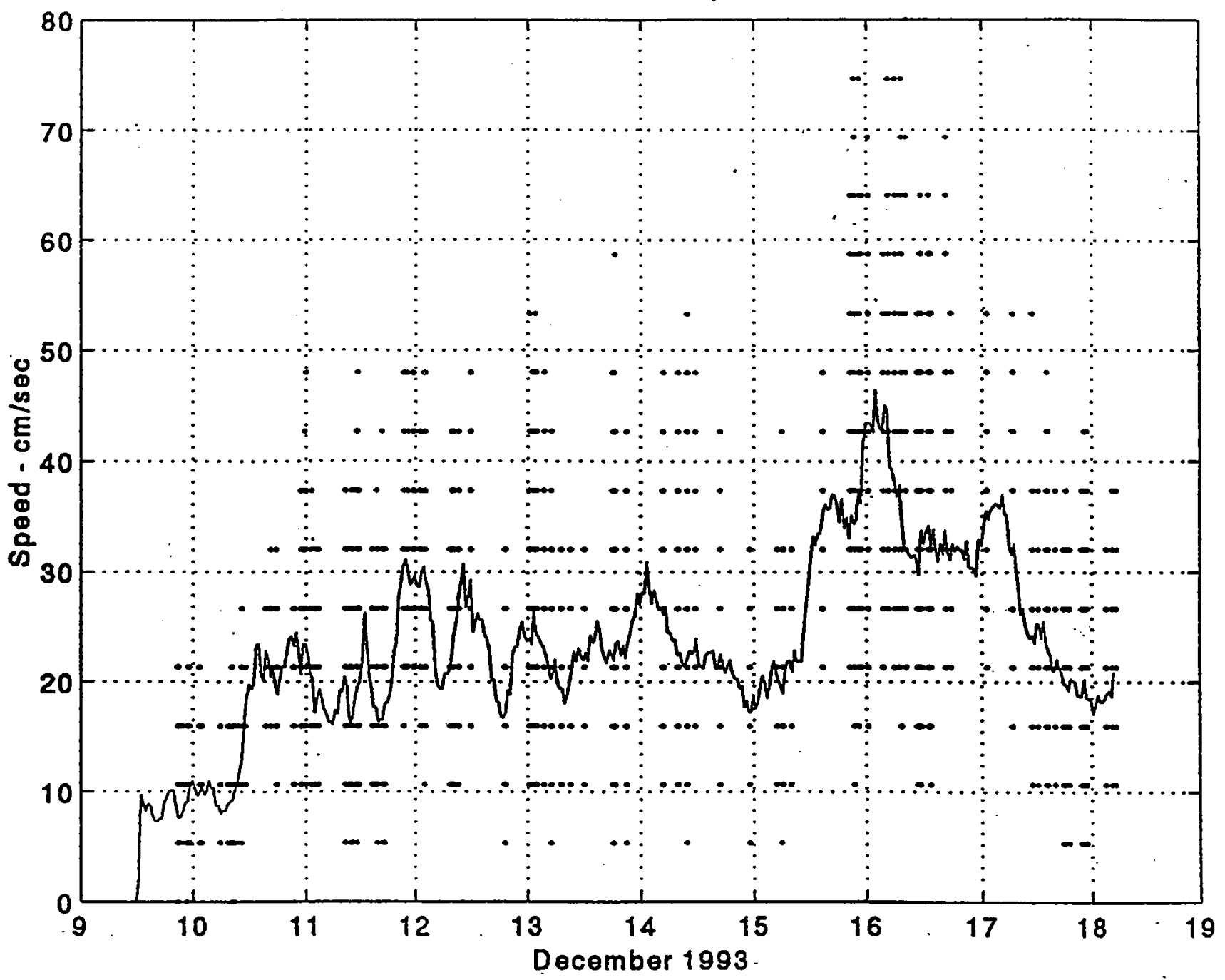

Savonius rotor speeds 2 meters above bottom. The solid line is the half-hourly averaged current speed which contains the mean and wave effects. The dots are from OBS triggered events with 3.5 second averages which indicate peak wave speeds are often twice averaged speeds.

Fig. 5 


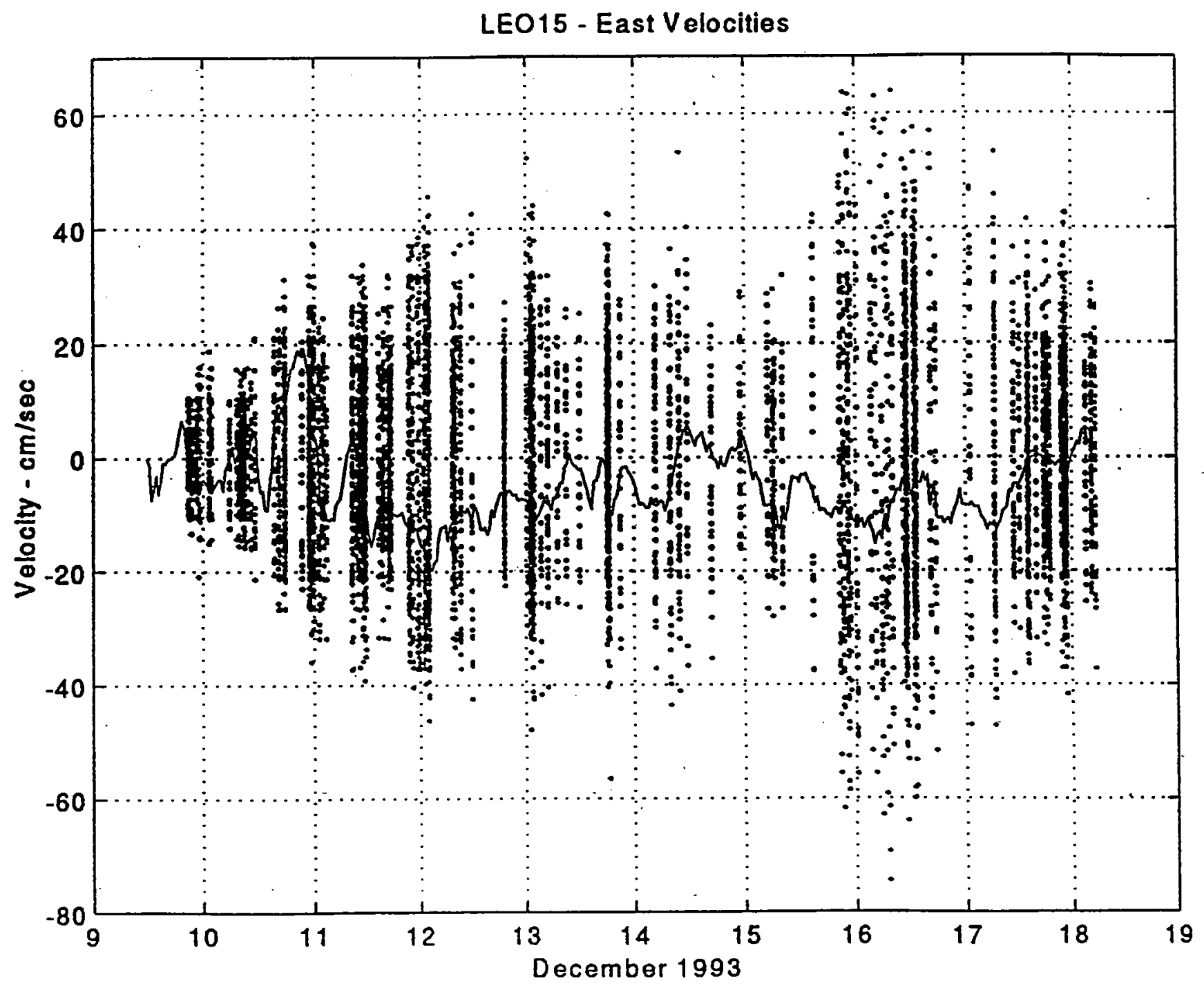

The Eastgoing vector averaged component of velocity at 2 meters above bottom. The solid line is the half-hourly averaged velocity component which should not have wave velocities. The dots are the OBS triggered events with 3.5 second averages which show the "instantaneous" velocity, including wave effects. The mean current peaks are typically one third of the instantaneous.

Fig. 6 


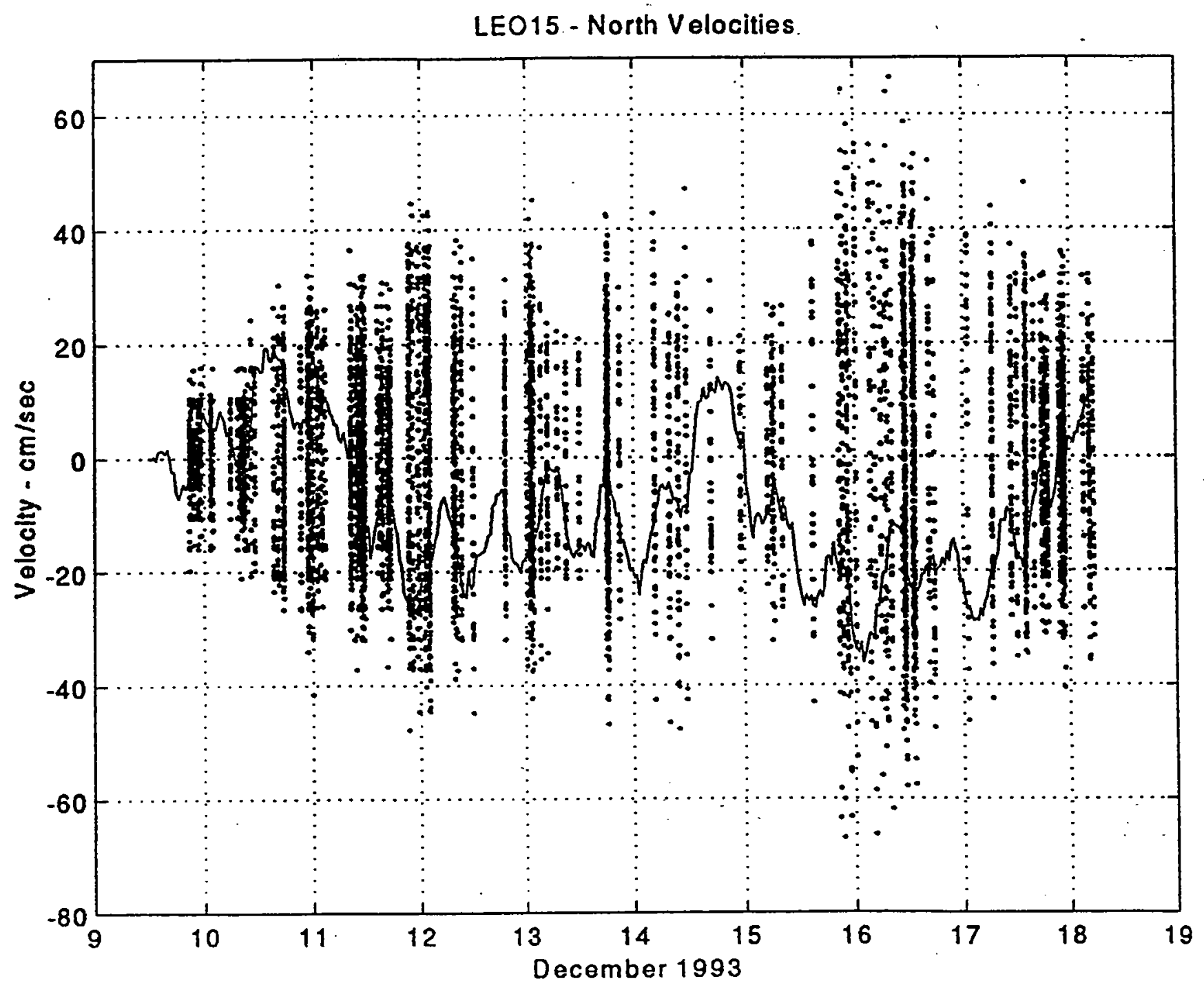

The Northgoing vector averaged and instantaneous velocity as in Figure 6.

Fig. 7 
temperature and conductivity sensors were noisy during this deployment due to bad ground wire in an underwater splice, which has since been fixed. Therefore, only the end cap temperature will be shown. The temperature signal, Fig. 8 decreased steadily from $10^{\circ} \mathrm{C}$ near the start to $8^{\circ} \mathrm{C}$ over the first four days due to winter cooling. This cooling is correlated with the increased wind from 10-14 December. The temperature then remains fairly constant for the last 4-5 days as seen in Fig. $4 \mathrm{~g}$.

Pressure was measured with a Paroscientific quartz pressure sensor (Busse, 1987, Brown, Irish and Erdman, 1983, Wearn and Marsen, 1982), and a Druck analog pressure sensor. Again a comparison was conducted to test the accuracy and noise level of the lower-cost analog sensor. A comparison plot (Fig. 9) shows the total record from the two sensors; clearly evident are the dominant semi-diurnal tide (M2 and S2). The spectra (Fig. 10) show nearly identical energy at the tidal frequencies. The difference at lower frequencies is probably largely due to relative sensor drift. . The increase at lowest frequencies is due to the weather forced sea surface fluctuations. Also at the highest frequencies resolved with the 0.5 hour samples, there appears to be significant differences in the records. Since these are the result of 512 point samples, there should be no aliasing to cause these differences.

The analog pressure sensor is sampled once every 3.5156 seconds and the individual samples averaged. In addition, the 3.5156 second instantaneous samples are recorded when the OBS sensors saw high suspended sediment concentrations. Fig. 11 shows a section of a high frequency record on 10 December 1993 with the 3.5156 second samples from the two pressure sensors compared. While the analog pressure is an instantaneous sample, the Paroscientific pressure signal is averaged over the 3.5156 second sample interval. This averaging tends to smooth the record which shows fewer large amplitude "spikes than the instantaneous analog sensors. Therefore, the observed differences are due to sampling differences. The indication is that the 3.5156 second interval is too long for this water depth as discussed below.

Finally, the analog pressure sensor was "burst sampled" at 0.8789 second intervals once a day. Samples were taken for 3.75 minutes (256 points) starting at 20:34 every day. Noise on the analog pressure sensor contaminated the spectra at just under $0.03 \mathrm{~Hz}$ (the 3.5156 second event sampling frequency) so the spectra (a representation one shown in Fig. 12) was cut off at 4 second period waves to eliminate this effect. This spectra shows 6 second and 9 second waves present as well as some longer $\sim 20$ second swell. To get the actual wave height from this spectrum, one must consider the attenuation with depth and frequency.

The ocean attenuates wind wave effects with depth. As one goes deeper the effects of the waves (velocity and pressure) decrease, and as one goes to higher frequencies, the effects at a fixed depth also decrease. The pressure attenuation for a 12 meter depth sensor (Fig. 13) indicates that a 10 second wave is attenuated to about 0.78 times its initial amplitude, and a 7 second wave (at the 3.5156 second Nyquist) is attenuated to about 0.6 of its initial amplitude. A 3 second wave is practically eliminated. Using a $90 \%$ attenuation in amplitude as the effective cutoff, then a 4 second wave is the highest frequency wave that we would see with reasonable 


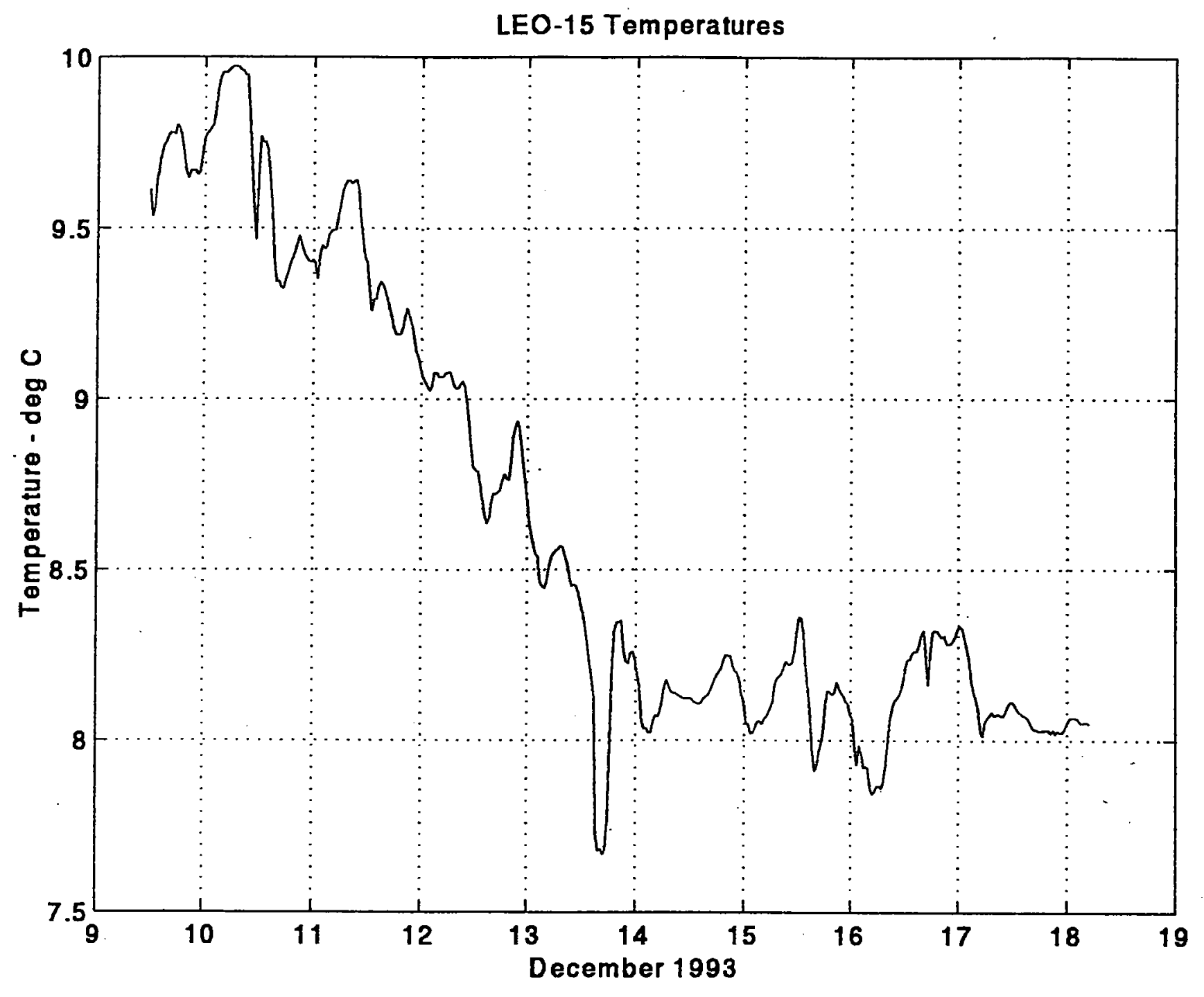

Figure 8. End cap temperature showing the steady decrease of temperature with winter cooling over the first four days. 


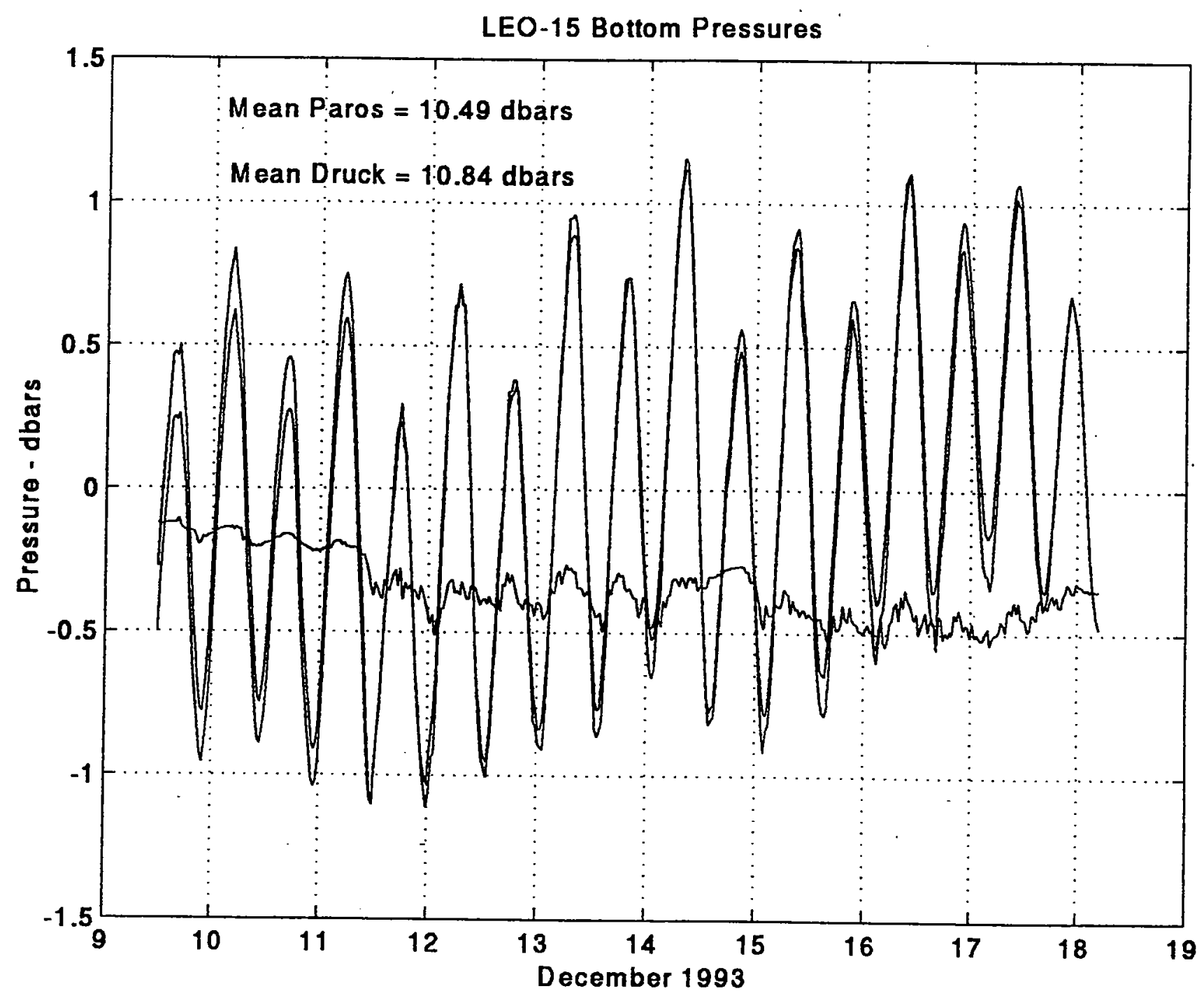

Figure 9. Comparison of the two pressure sensors (with the mean removed), showing the dominant tidal signal. The differences between the two sensors, due to drift, is also shown for comparison. 


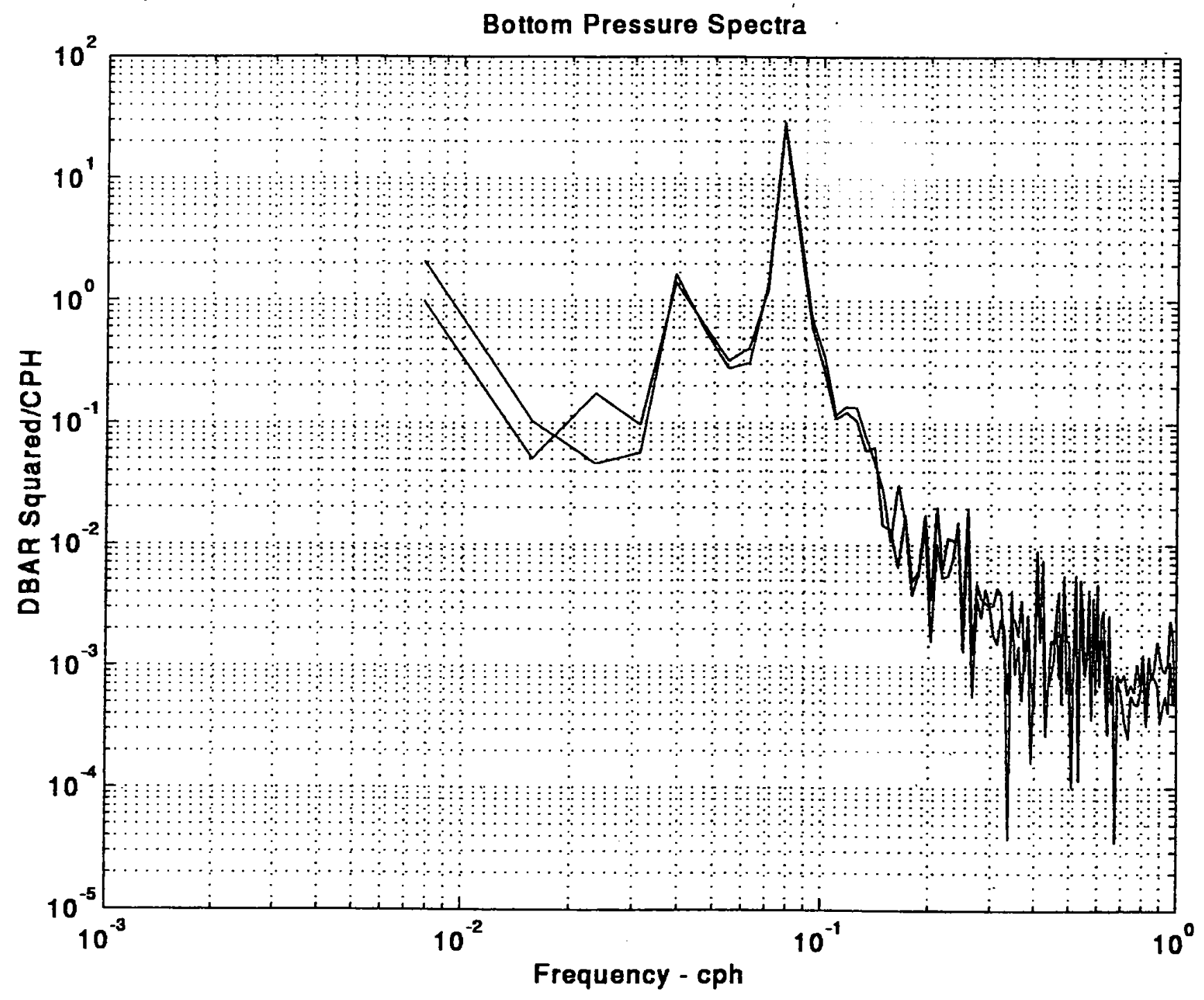

Comparison of the two pressure record spectra showing slight disagreement at low frequency (sensor drift) and high frequency (sensor noise and response). The pressure is dominated by the semidiurnal (M2) tide.

Fig. 10 


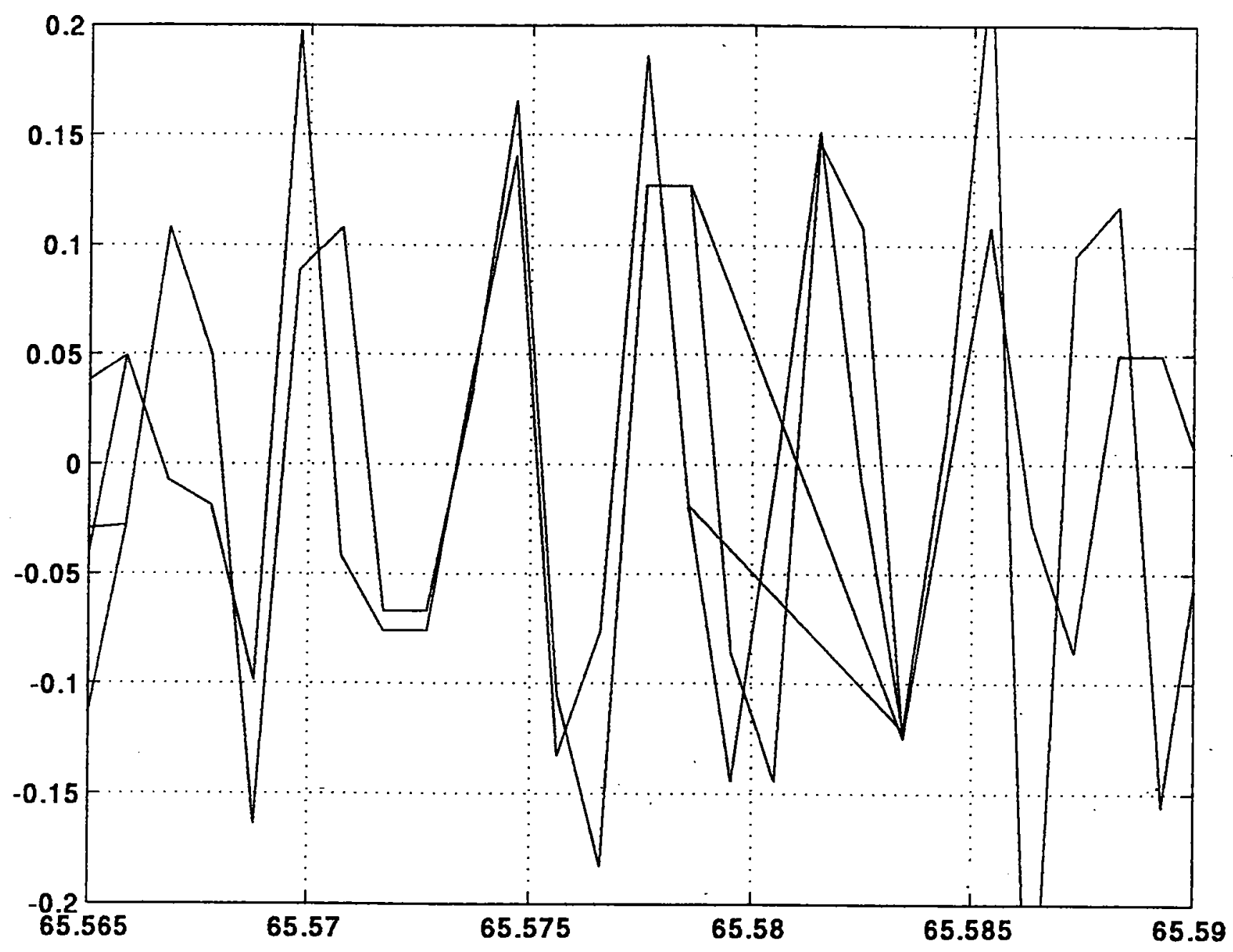

Comparison of event (3.5156 second samples) of the two pressure sensors, showing the difference between the 3.5156 second averages of the Paroscientific sensor, and the instantaneous A/D measurement of the Druck (analog) pressure sensor.

Fig. 11 


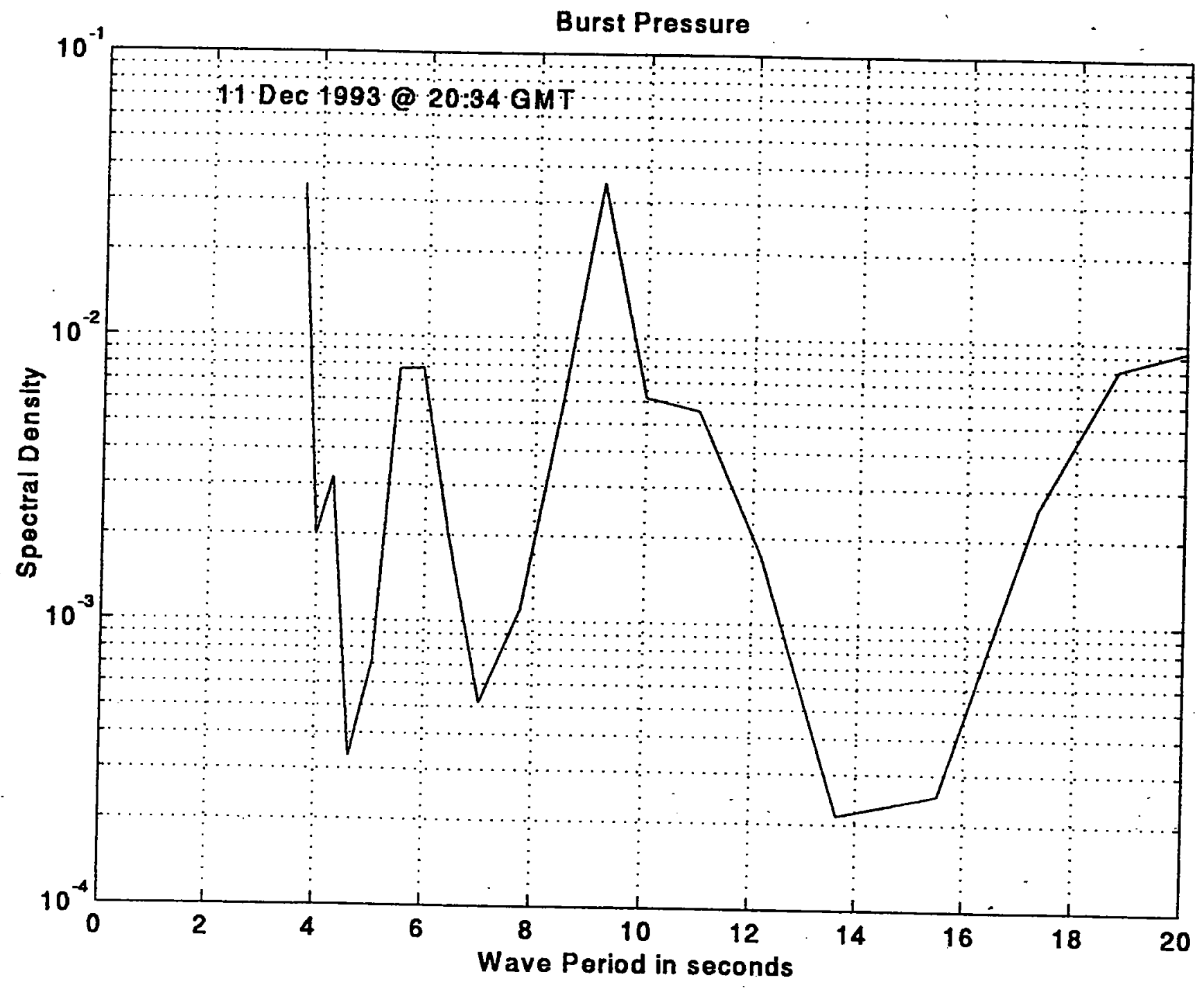

The burst wave spectrum from 20:23 GMT on 11 December 1993. Two frequency waves are present: with about 6 and 9 second period.

Fig. 12 


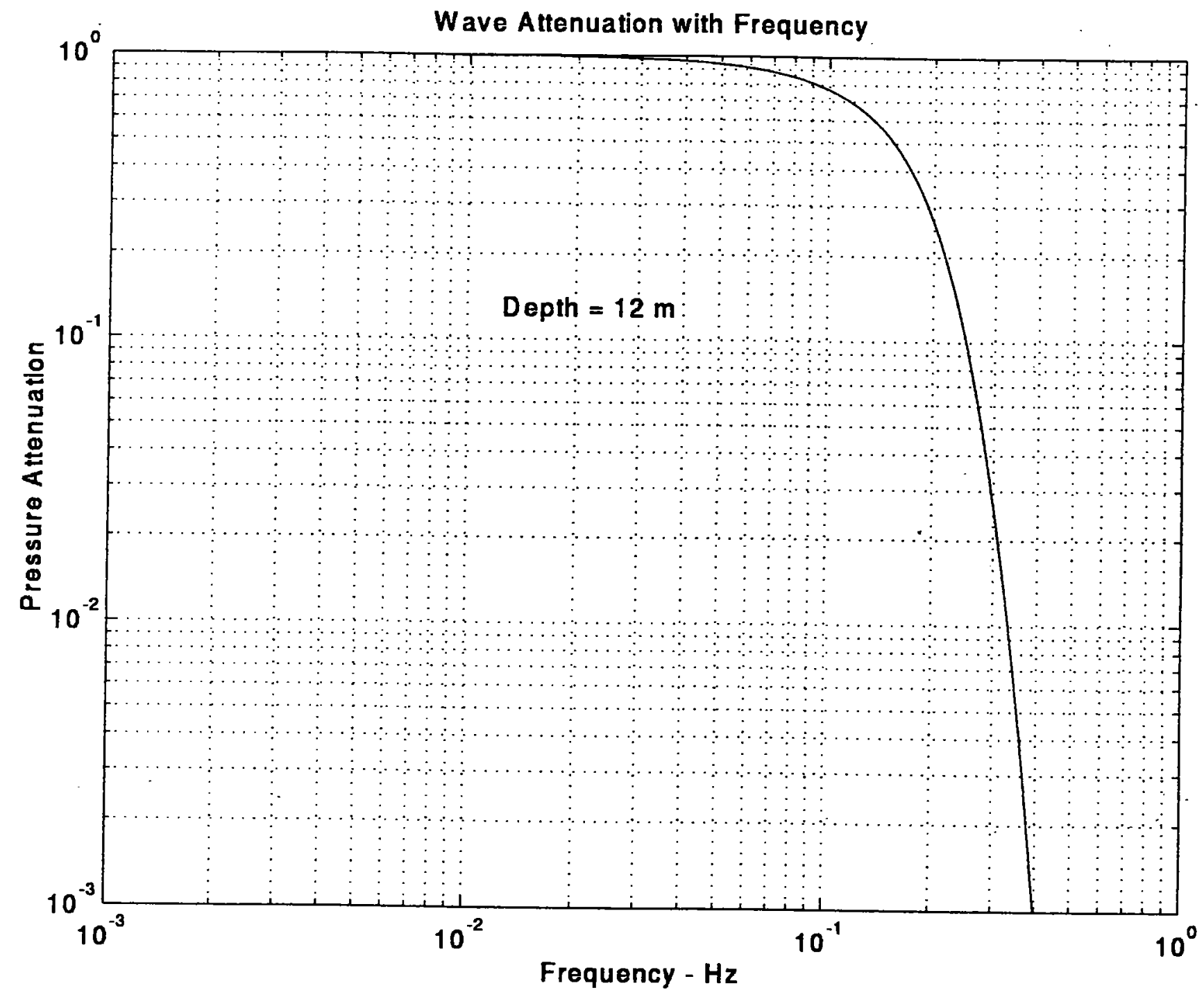

meters depth.

The attenuation of pressure or current velocity as a function of frequency at 12

Fig. 13 
amplitude at the bottom. Note that this wave may cause some slight aliasing at our 3.5156 second sample interval. The 3.5156 second interval was originally selected to match a 30 meter deep site. The sample rate will be increased to 2.0 seconds per sample for future work at the LEO- 15 site to better match it to the depth. However, it is unlikely that the data presented here contains much aliasing in the velocities. 


\section{OBS Optical Backscattering Measurements}

An array of four D\&A OBS-1 sensors (Downing, 1983) (see Fig. 3 for location on instrument) measured the optical backscattering at 10,30,100 and $200 \mathrm{~cm}$ above bottom. The sensors at $30,100,200 \mathrm{~cm}$ were calibrated during previous work and their gains adjusted so that they would read out in grams/liter of sediment from the Corps of Engineers Mud Dump Site in the New York Bight (Irish et al, 1990). The calibrated sensor at $10 \mathrm{~cm}$ was intermittent and replaced with a working sensor who's gain was not adjusted (increased). Thus it was expected to register lower voltage output than the other three, even though it was lower down and saw higher concentrations. This sensor's sensitivity was left lower so that very high concentrations near the bottom could be resolved without going off-scale. A summary plot of the normalized sensors is given in Fig. 4a. A linear drift was removed from each sensor by arbitrarily adjusting the minimum observed values to be about zero. This subjective method has worked in the past to remove biological drifts, although there is no real justification for using a linear drift. The drifts removed are as follows:

$$
\begin{aligned}
& \text { OBS1 }=\text { start at } 0.094 \text { and end at } 0.104 \\
& \text { OBS2 }=\text { start at } 0.120 \text { and end at } 0.134 \\
& \text { OBS3 }=\text { start at } 0.106 \text { and end at } 0.113 \\
& \text { OBS4 }=\text { start at } 0.105 \text { and end at } 0.135
\end{aligned}
$$

The unnormalized event samples of 3.5156 second data are plotted on the respective halfhourly records in Figs. 14, 15, 16, and 17. There are 419 points in the half-hourly averaged data and over 9,500 points in the event data series. Each point represents a 3.5156 second sample. The OBS1 sensors used reach a maximum of 3.5 volts if the signal is off-scale on the high end. This is seen in the $200 \mathrm{~cm}$ sensor, and is probably a fish or debris blocking the sensor momentarily. The high values seen at $10 \mathrm{~cm}$ reflect real sediment signals and shell hash being advected past the sensor by high wave activity. The records at 30,100 , and $200 \mathrm{~cm}$ indicate that the event midday on the 16 th was the largest. This is when the currents (waves plus mean current) reached a peak $80 \mathrm{~cm} / \mathrm{second}$ speed. Also, at this time the instrument tilt sensors indicated that the instrument was rocking back and forth $15^{\circ}$ to $20^{\circ}$, and the compass (frame orientation) shifted. It is obvious that there are significant forces acting on instrumentation at the LEO-15 site during the winter months and that careful attention must be given to securing instruments.

\section{E. Acoustical Instruments-}

Although the ABSS acoustical instrument did not produce a useful data set during the winter 1993 LEO-15 deployment, a small amount of data from within the buffer of the tape drive was retrieved after the instrument was recovered. Though the tripod was on its side when the acoustical measurements retrieved were taken, they still were useful in showing that the dynamic range of the ABSS instrument was well adjusted for the concentrations and particle sizes 


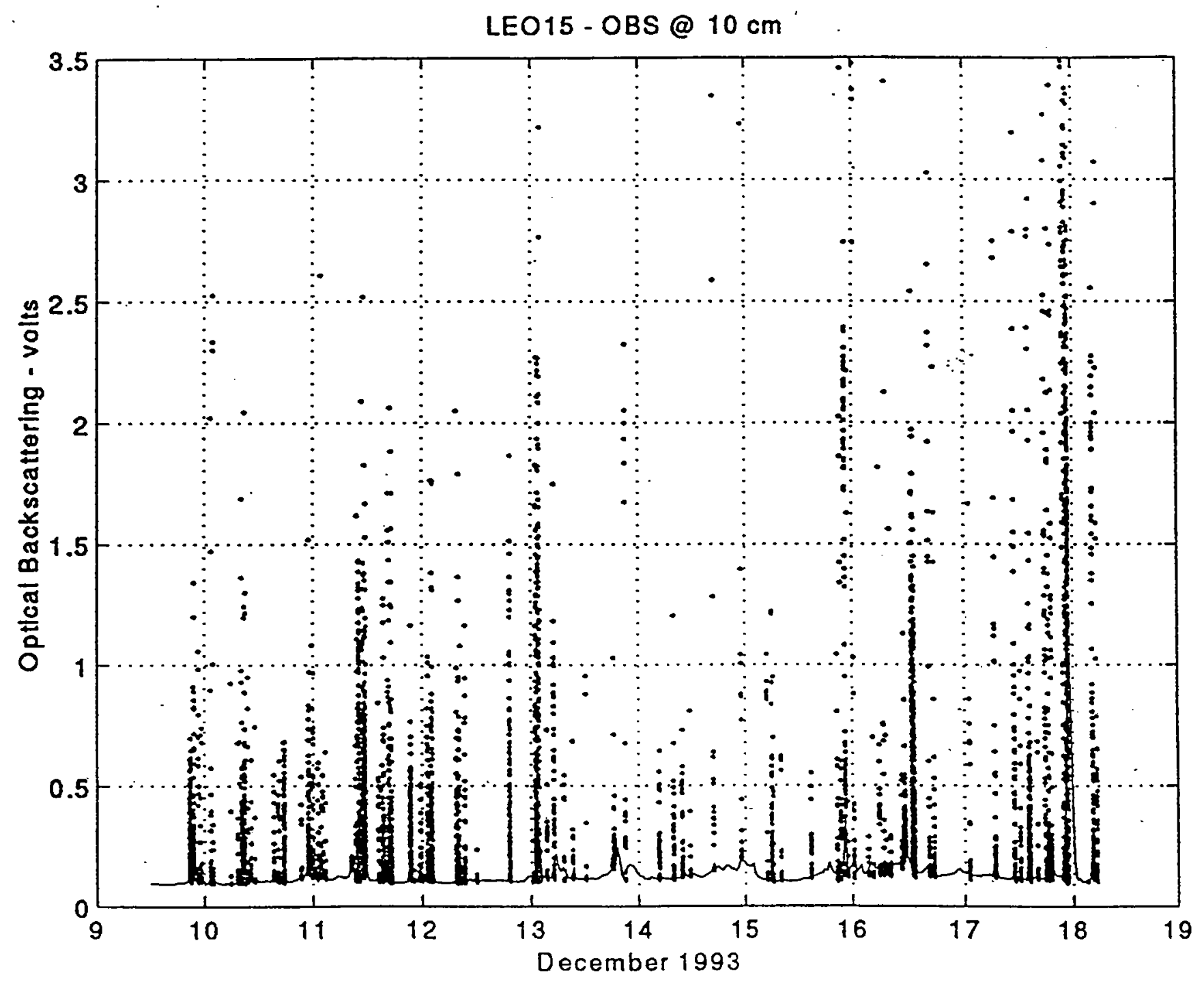

Figure 14. The D\&A OBS sensor at $10 \mathrm{cmab}$ ( $\mathrm{cm}$ above bottom). The solid line is the unnormalized, half-hourly averaged OBS output in volts. the dots are the OBS triggered events sampled every 3.5 seconds. Again the instantaneous samples are many times the averaged signal indicating that high-frequency the wave effects dominate the signal at $10 \mathrm{~cm}$. 


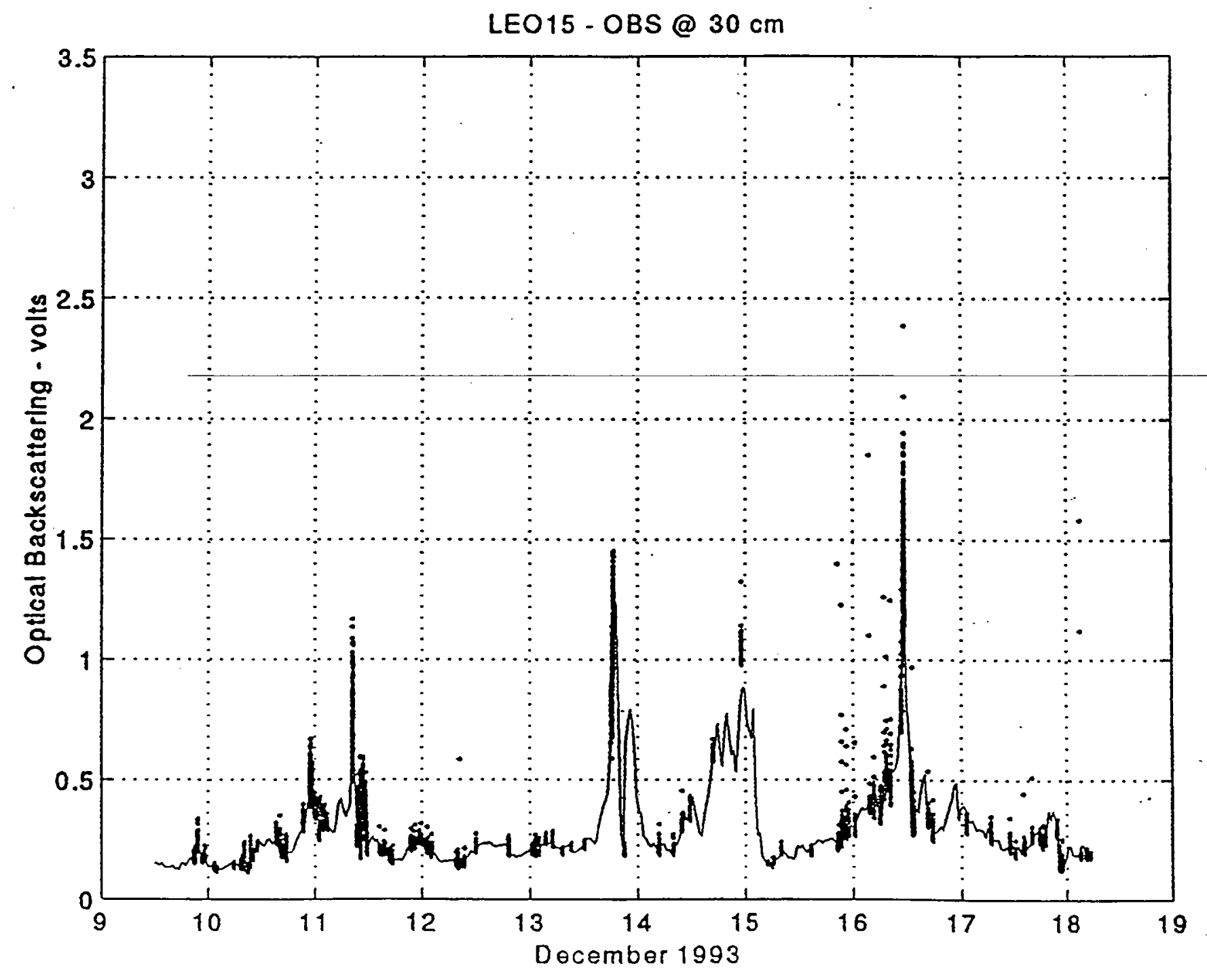

Figure 15. The D\&A OBS sensor at $30 \mathrm{cmab}$ plotted as Figure 14. The event signals are not as dominate above $10 \mathrm{~cm}$. 


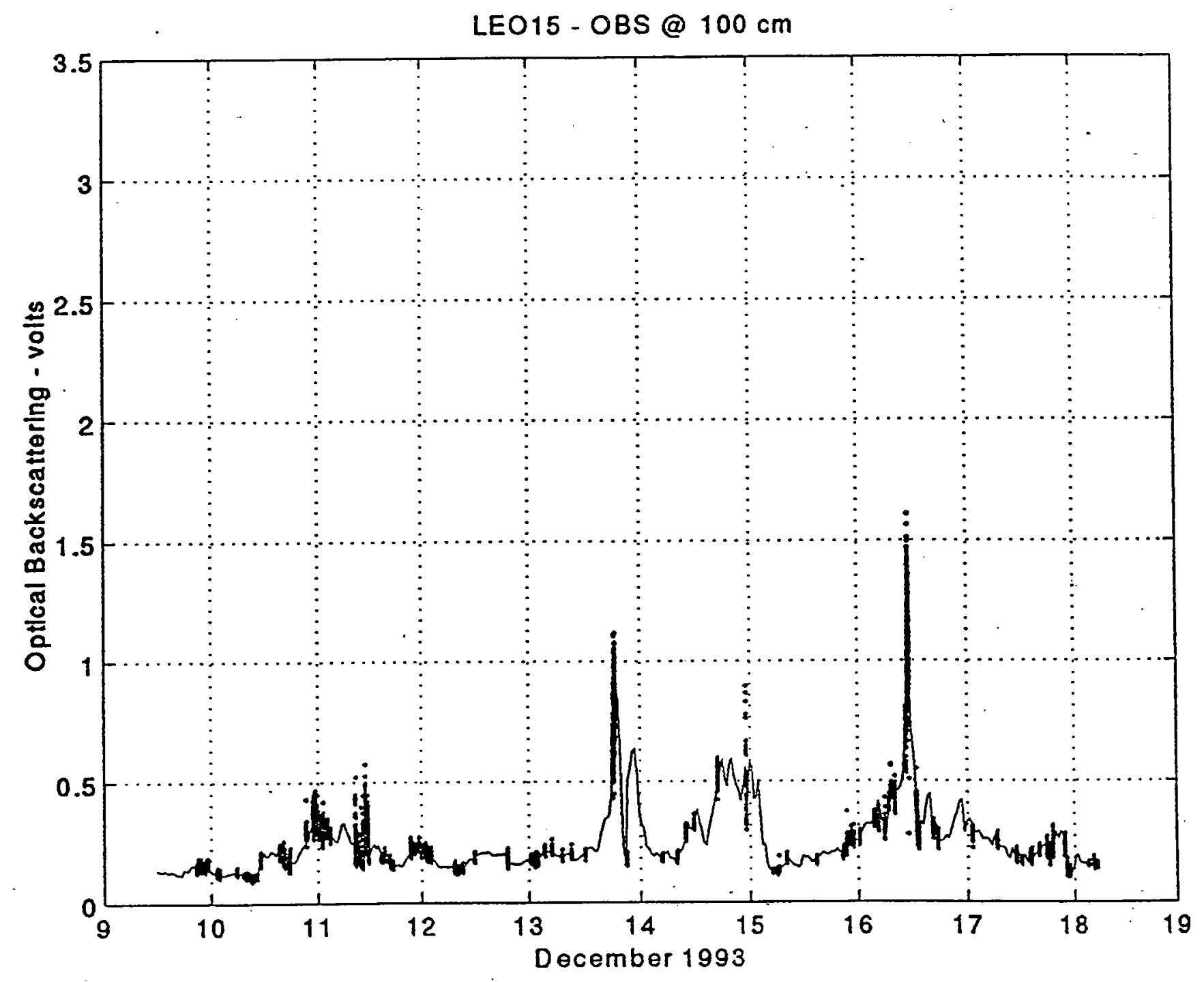

Figure 16. The OBS sensor at $100 \mathrm{cmab}$ as in Figure 15. 


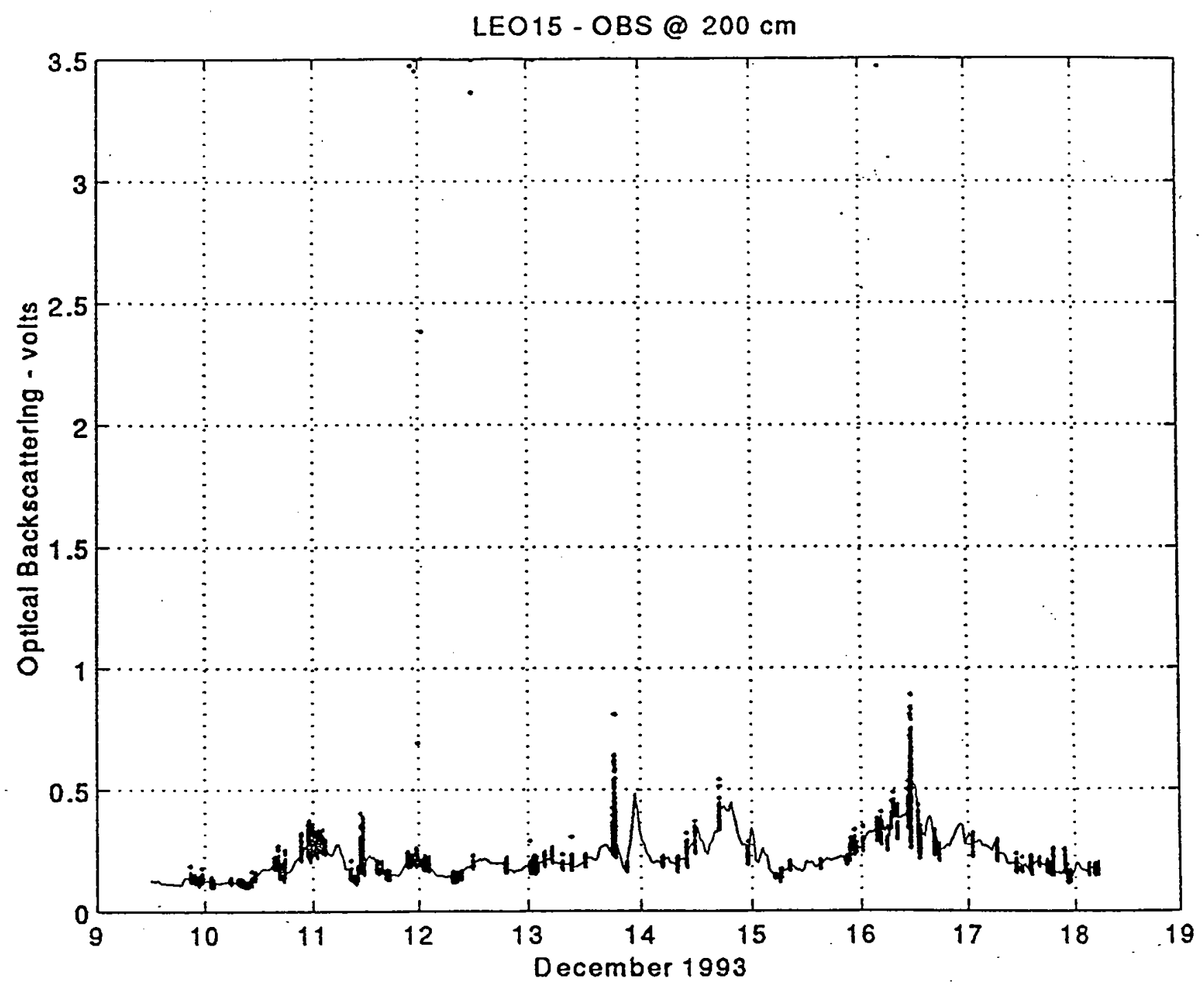

Figure 17. The OBS Sensor at $200 \mathrm{cmab}$ as in Figure 15. 
encountered at the LEO site. This was useful in planning the two spring 1994 deployments of ABSS, which were quite successful. The configuration of the ABSS transducers is seen in Fig. 3; the $5 \mathrm{MHz}$ transducer looks down $128 \mathrm{~cm}$ from the transducer face, with $1 \mathrm{~cm}$ resolution in height, while the $1 \mathrm{MHz}$ transducer looks upward $25.6 \mathrm{~m}$ above the transducer face with $0.2 \mathrm{~m}$ resolution in height.

\section{LEO-15 Sediment Samples and OBS Calibrations:}

To determine the bottom sediment size distributions and material available for transport, and to calibrate the Optical Backscattering Sensors (OBS's), sediment samples were taken at the LEO-15 site 9 on 9 December 1993 during the deployment operations, and on 10 January 1994 (the day before the recovery operation) by Rutgers University divers from the R/V CALETA. Two samples were taken from the bottom and two in the water column during each cruise. Half of these samples were studied and the other half reserved for later analysis if necessary. These samples are listed in TABLE I.

\section{A. Sieving for the Coarse Fraction and Coulter Counter/SPECTREX Analyses for Fines}

Samples of the bottom sediments from both the deployment and recovery cruises were selected for sieving (samples $3 \& 4$ ). Each sample was split by pushing a fiberglass board down into the sediments to isolate one side of the jar from the other, and the small part (about $40 \%$ ) of the sample removed into a beaker. This sample was then run through a series of sieves to separate the sample. A $1 \mathrm{~mm}$ sieve was used to remove the broken shells and larger debris. Then a standard set of sieves with openings of $500 \mu \mathrm{m}, 250 \mu \mathrm{m}, 125 \mu \mathrm{m}, 63 \mu \mathrm{m}$ and $45 \mu \mathrm{m}$ were used to separate the sample. The sediment was washed through the sieves with distilled water, and the water retained to measure the fine material less than $45 \mu \mathrm{m}$. The results of two sub samples of Sample \#3 from the deployment and Sample \#4 from the recovery are shown in TABLE $\mathrm{II}$ and Fig. 18. The samples

are largely coarse sand in the 500-1000 $\mu \mathrm{m}$ size range, with an appreciable fraction in the 250-500 $\mu m$ range. This fine fraction shows an increase in percent while the coarser fraction percent is decreasing! Since the large particles probably aren't transported out of the area before the smaller particles, it appears that during December, finer sand particles were brought into the region to cause this small observed increase.

An analysis of the smaller than $100 \mu \mathrm{m}$ fraction was made with a SPECTREX particle size analyzer. Sample \#1 taken $10 \mathrm{~cm}$ above bottom at deployment was used. The sample was shaken, and a few drops of the sample diluted with about $100 \mathrm{ml}$ of distilled water to reduce the concentration to that appropriate for the SPECTREX. Fig. 19 shows the two measurements from 


\section{TABLE 1: LEO 15 Sediment Samples}

\begin{tabular}{|c|c|c|c|c|}
\hline Sample Number & Type od Sample & Position of Sample & Date of Sample & Fate \\
\hline $\begin{array}{l}1 \text { - Sediment } \\
\text { Settles out }\end{array}$ & Water & $10 \mathrm{cmab}$ & $9 \operatorname{Dec} 1993$ & SEPCTREX \\
\hline $\begin{array}{l}2 \text { - Sediment } \\
\text { Settles out }\end{array}$ & Water & $60 \mathrm{cmab}$ & 10 Jan 1994 & SPECTREX \\
\hline $\begin{array}{l}3 \text { - Red Brown } \\
\text { Sandy Color }\end{array}$ & Bottom & Top $8 \mathrm{~cm}$ & $9 \operatorname{Dec} 1993$ & Sieve/OBS Cal \\
\hline $\begin{array}{l}4 \text { - Dark Grey } \\
\text { or Black Color }\end{array}$ & Bottom & Top $8 \mathrm{~cm}$ & 10 Jan 1994 & Sieved \\
\hline $\begin{array}{l}5 \text { - Sediment } \\
\text { Settles out }\end{array}$ & Water & $10 \mathrm{cmab}$ & $9 \operatorname{Dec} 1993$ & Saved \\
\hline $\begin{array}{c}6 \text { - Brown Sand } \\
\text { Color }\end{array}$ & Bottom & Top $8 \mathrm{~cm}$ & $9 \operatorname{Dec} 1993$ & Saved \\
\hline $\begin{array}{l}7 \text { - Dark Grey } \\
\text { Black Color }\end{array}$ & Bottōm & Top $8 \mathrm{~cm}$ & 10 Jan 1994 & Saved \\
\hline 8 & Water & $60 \mathrm{cmab}$ & 10 Jan 1994 & Saved \\
\hline
\end{tabular}

TABLE I 
Run \#1 Sample Jar \#3

Deployment Sample - Dec 9, 1993

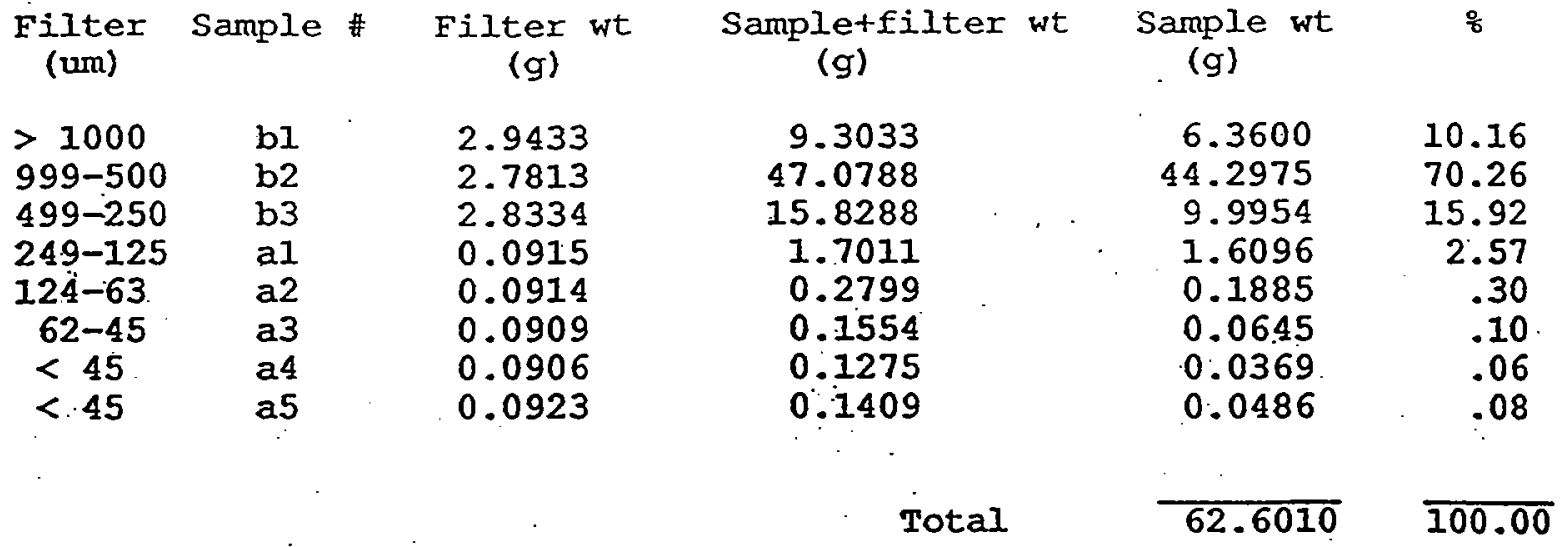

Run 2 Sample Jar \#3

Deployment Sample - Dec 9, 1993

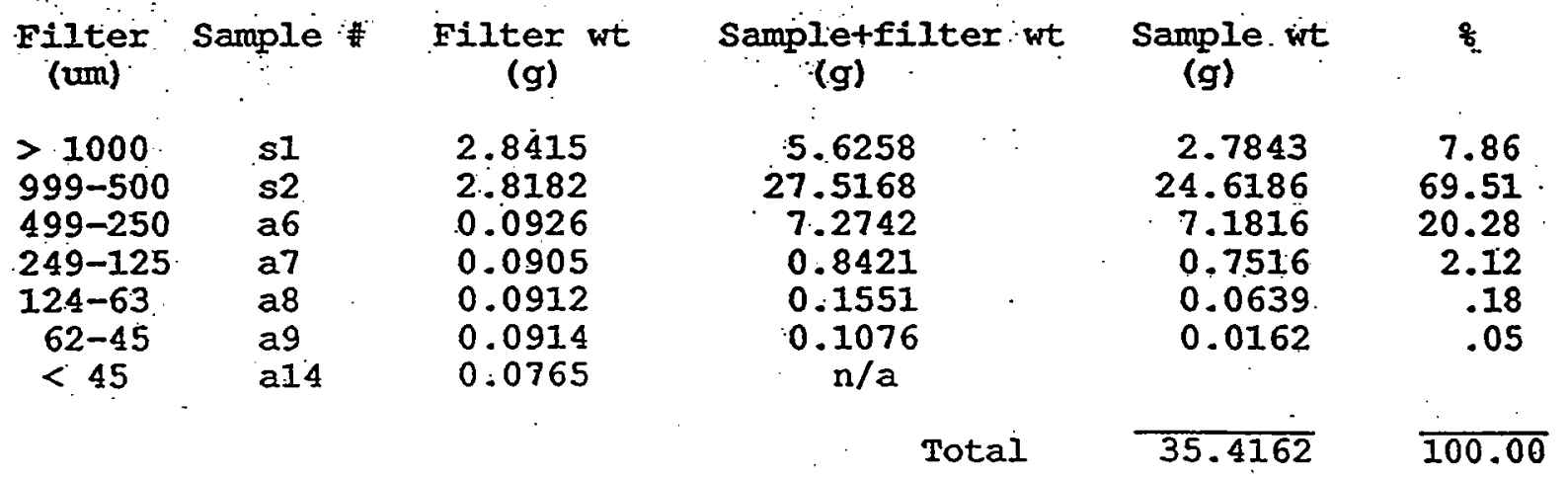

Run \#3 Sample Jar \#4

Recovery Sample - Jan 10, 1993

$\begin{array}{ccc}\begin{array}{c}\text { Filter } \\ \text { (um) }\end{array} & \text { Sample \# } & \begin{array}{c}\text { Filter } \\ \text { (g) }\end{array} \\ >1000 & \text { s3 } & 2.8160 \\ 999-500 & 54 & 2.8057 \\ 499-250 & \text { s5 } & 2.8250 \\ 249-125 & \text { al0 } & 0.0919 \\ 124-63 & \text { al1 } & 0.0917 \\ 62-45 & \text { al2 } & 0.0762 \\ <45, & \text { al3 } & 0.0764\end{array}$
Sampletfilter wt
(g)

$$
\begin{array}{r}
4.3964 \\
24.9251 \\
11.9267 \\
1.4281 \\
0.1710 \\
0.0907 \\
0.1067
\end{array}
$$$$
24.9251
$$

Sample wt (g)

$\begin{array}{rr}1.5804 & 4.61 \\ 22.1194 & 64.56 \\ 9.1017 & 26.57 \\ 1.3362 & 3.90 \\ 0.0793 & .23 \\ 0.0145 & .04 \\ 0.0303 & .09\end{array}$

Tolà
응

$\overline{100.00}$

TABLE II 


\section{LE015 Sediment}

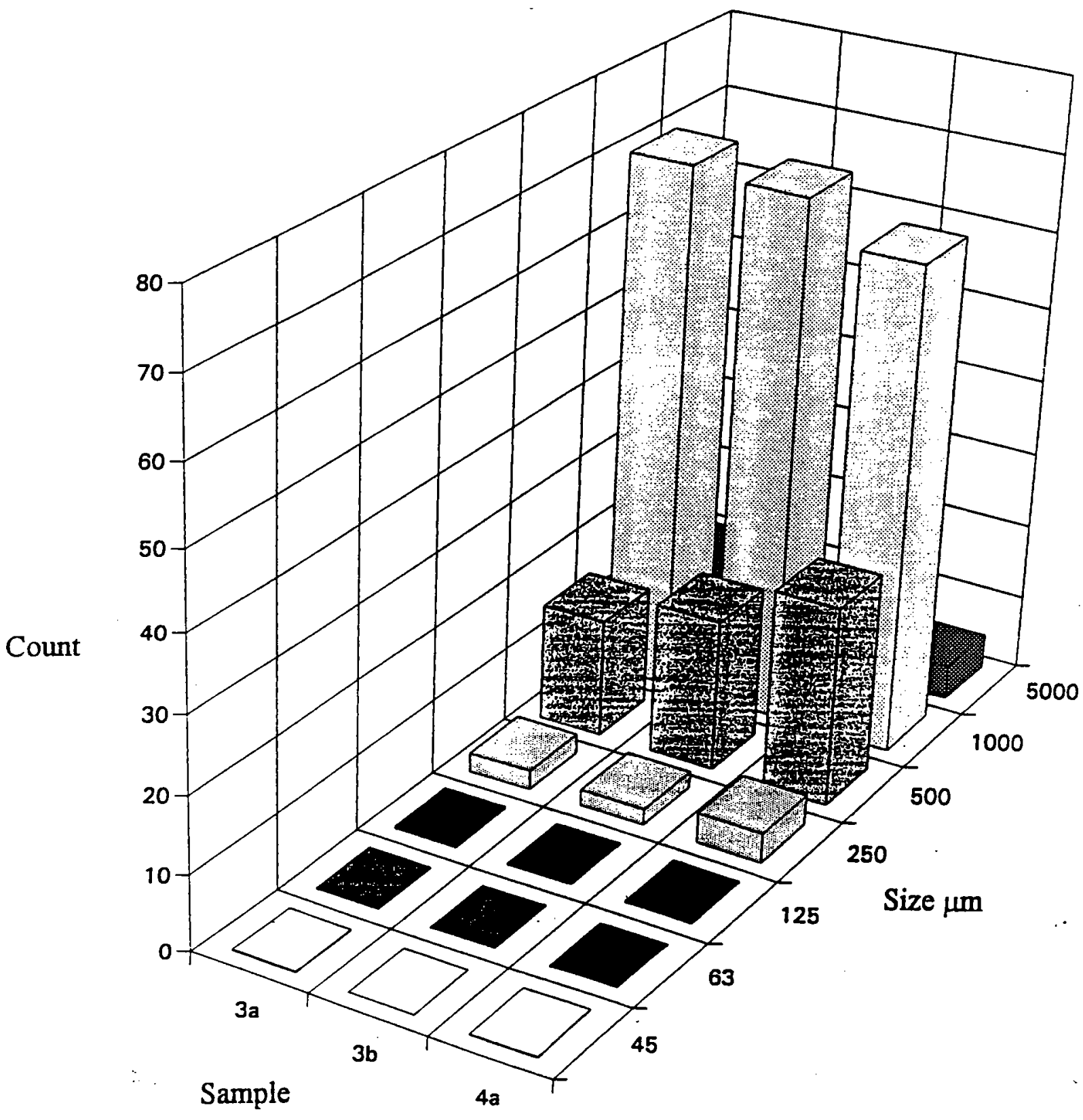

Figure 18. Plot of the sieved sediment samples from the LEO-15 site in early December 1993 (3a and 3b) and early January 1994 (4a) indicating an increase in fine same fraction (125 to $500 \mu \mathrm{m}$ ). 

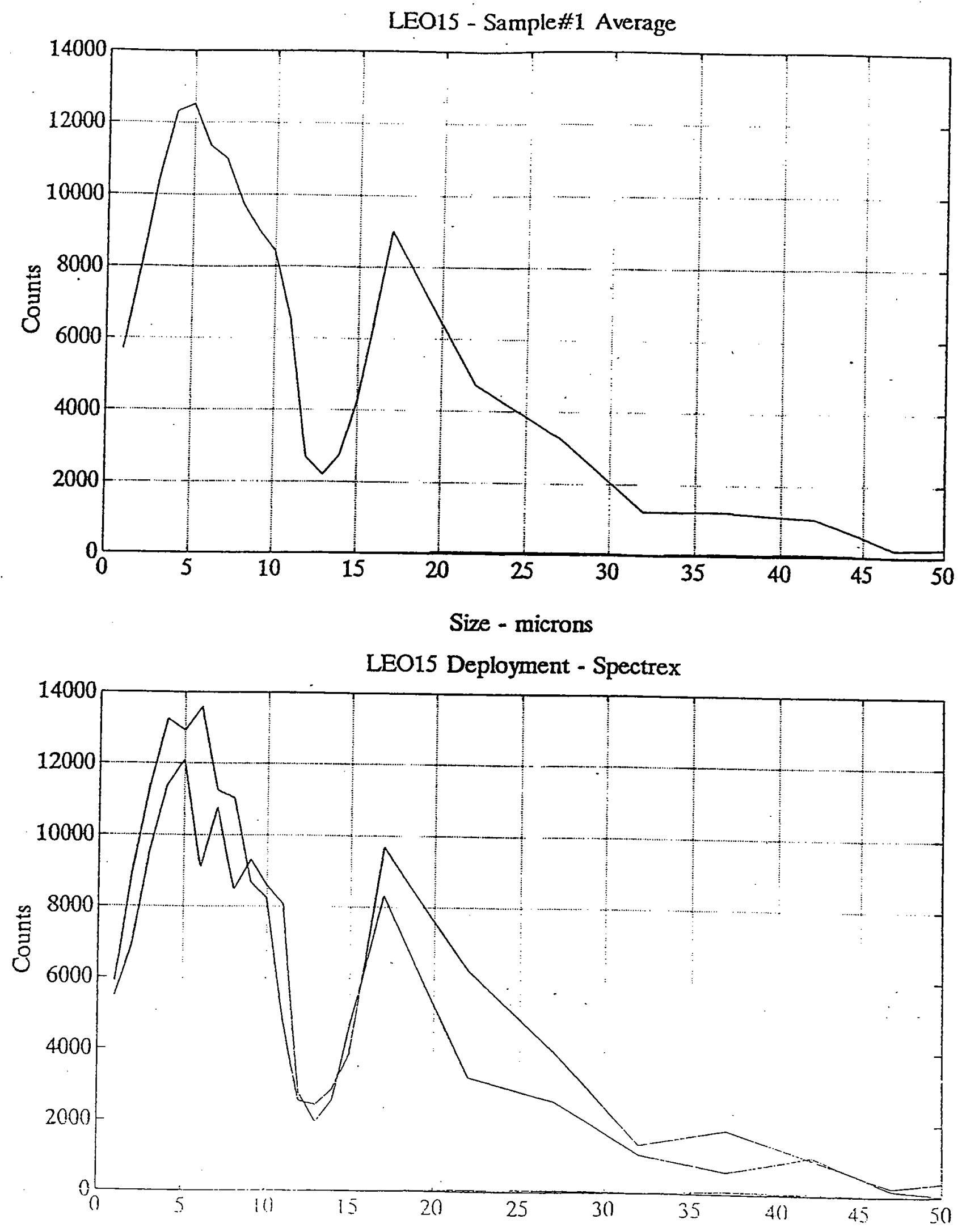

Sizé - microns

Figure 19. Plot of the SPECTREX particle size spectrum from the water sample in early December 1993 at the LEO-15 site. The average is shown at the top, and two individual 90 second averaged samples from the Sample Bottle Number 1 are shown at the bottom. 
the Sample \#1 bottle. There is a fine fraction below $10 \mu \mathrm{m}$ and a smaller, coarser peak around 18 $\mu \mathrm{m}$. The recovery sample looks similar. The residual from the filtering has the same fine grained fraction, and a smaller $18 \mu \mathrm{m}$ peak (or perhaps the same $18 \mu \mathrm{m}$ peak, and much more fine material). Sample \#1 was also run through a Coulter Counter, which showed a sharp increase in particle count as particle size decreased, but no real $18 \mu \mathrm{m}$ peak. (Was this due to not stirring the sample properly? The 18 peak settled out of the SPECTREX sample if one waited 10 minutes or so.)

\section{B. OBS Calibrations}

Part of the bottom sediment sample taken at the time of the instrument deployment (Sample \#3 from 9 December 1993) was sieved for sediment size, and the fine material from the other part of the sample was used for OBS calibrations. The sample was diluted with Falmouth tap water and ' the sample well shaken. The fine material was suspended by the turbulent mixing, and after waiting a few seconds for the coarse sand to settle, the fines were "decanted". This is probably nearly the process that happens in the environment when the sediment is moved by the waves, and the fine material is suspended while the coarse sand settles out quickly. The sample was then diluted and shaken again until the water and sand remaining was clear. This was the sample of material used for the calibration and doesn't contain any material that settled out of the sample within a few $(<10)$ seconds.

The OBS calibration was performed in a bucket. The opposite side of the bucket was just over $20 \mathrm{~cm}$ from the OBS sensor; far enough to be out of the view of the sensor. The depth of the water was about $20 \mathrm{~cm}$, and with the sensor held mid-depth, so no effects from the top or bottom were seen. (D\&A suggest that the vertical distance from any object be greater than $3 \mathrm{~cm}$, and the horizontal distance greater than $20 \mathrm{~cm}$.)

The four OBS-1 sensors used in the deployment were calibrated by taking the readings of their outputs with the recording system set up as it was used in the field. The system was powered on batteries, and switched power to the system and sensors as was done during the deployment. The AVD was 12 bits for a 5 volts range, or a value of 0.0012207 volts/bit. The bit counts were printed on a PC screen for feedback during the calibration, and the Hex values displayed were written in TABLE III. Falmouth tap water was used for the calibration, with the straight water used as a zero for the sensors. The results were listed in TABLE III, and a sample of the sediment concentration taken for weighing. Then some of the decanted sediment mixture was added to the water. Since only one OBS sensor could be in the tank at one time, the water-sediment mixture was well stirred, the sensor was placed in it, and a series of 8 to 12 values were recorded in TABLE III. The tank was also well stirred before the bottle samples of the suspended sediments were taken. The water removed from the tank by taking the sample was replaced as additional sediment was added. By monitoring one sensor as the sediment was added, 6 calibration points were made over the range of signals observed at the LEO-15 site. However, the sensors were not near their maximum signal, so additional sediment from the New York Bight, U.S. Army Corps of Engineer's Mud Dump Site was added to make two additional calibration 


\section{ABSS/NURP OBS Calibration \\ LEO-15 Bottom Sample \#3 \\ 18 January 1994}

\begin{tabular}{|c|c|c|c|c|c|c|}
\hline Description of sample & $\begin{array}{l}\text { Sample Time/ } \\
\text { Sample Number }\end{array}$ & $\begin{array}{l}\text { Sensor \#1 } \\
\text { S/N }-107\end{array}$ & $\begin{array}{l}\text { Sensor } \# 2 \\
\text { S/N }-145\end{array}$ & $\begin{array}{l}\text { Sensor \#3 } \\
\text { S/N }-146\end{array}$ & $\begin{array}{l}\text { Sensor \#4 } \\
S / N-147\end{array}$ & $\begin{array}{l}\text { WATER SAMPLE } \\
\text { BOTTLE NO. }\end{array}$ \\
\hline $\begin{array}{l}1 \text { - Falmouth Cold } \\
\text { Tap Water Outgassed }\end{array}$ & $\begin{array}{c}10: 05-10: 08 \\
476-531\end{array}$ & $\begin{array}{c}50,4 \mathrm{~F} \\
51 \\
(80=0.0975)\end{array}$ & $\begin{array}{c}55,57 \\
55 \\
(86)\end{array}$ & $\begin{array}{c}51,4 \mathrm{~F} \\
51 \\
(80)\end{array}$ & $\begin{array}{c}\mathrm{B} 5,84 . \\
\text { B4 } \\
(180)\end{array}$ & 33 \\
\hline $2-$ "Spiash of fines" & $\begin{array}{c}10: 24-10: 28 \\
803-867\end{array}$ & $\begin{array}{l}5 E, 5 E, \\
5 D \\
(94)\end{array}$ & $\begin{array}{l}\text { D1, C7, } \\
03, \mathrm{CD} \\
(206)\end{array}$ & $\begin{array}{c}\mathrm{DE}, \mathrm{E5} \\
\mathrm{DD}, \mathrm{DB}, \\
\mathrm{D} 6 \\
(221)\end{array}$ & $\begin{array}{c}12 F, 12 D \\
128,126 \\
(299)\end{array}$ & 27 \\
\hline $\begin{array}{l}3 \text { - Two Splashes of } \\
\text { gunk }\end{array}$ & $\begin{array}{c}10: 31-13: 36 \\
939-1023\end{array}$ & $\begin{array}{l}78,78 \\
7 A, 78 \\
\\
(120)\end{array}$ & $\begin{array}{c}1 \mathrm{D} 6,1 \mathrm{DB}, \\
1 \mathrm{E}, 1 \mathrm{E}, \\
1 \mathrm{D} 1,1 \mathrm{DB} \\
\\
(476)\end{array}$ & $\begin{array}{c}\text { IEE, 1EE, } \\
1 E B, 1 E 4 \text {, } \\
1 F 2,1 F 4, \\
\text { IF1 } \\
(494)\end{array}$ & $\begin{array}{l}22 \mathrm{~A}, 234, \\
22 \mathrm{~B}, 219, \\
237,219, \\
22 \mathrm{~B}, 228 \\
(553)\end{array}$ & 12 \\
\hline $\begin{array}{l}4 \text { - Another "lot" of } \\
\text { gunk }\end{array}$ & $\begin{array}{l}10: 42-10: 48 \\
1113-1226\end{array}$ & $\begin{array}{c}A B, A C, \\
A C, A D, \\
A A \\
(172)\end{array}$ & $\begin{array}{c}38 \mathrm{D}, 38 \mathrm{~F}, \\
38 \mathrm{~F}, 3 \mathrm{~A} 6 \text {, } \\
39 \mathrm{E}, 3 \mathrm{~A} 3 \\
39 \mathrm{E}, 3 \mathrm{A6}, \\
397 \\
(922)\end{array}$ & $\begin{array}{c}3 E 8,3 C 9, \\
3 D 3,3 E 3, \\
3 D 3,3 E 4, \\
3 E 4,3 C 5, \\
3 C 6 \\
(983)\end{array}$ & $\begin{array}{c}3 F 1,3 F 9, \\
3 E 9,3 F 9, \\
3 F 5,416, \\
3 E 0,404 \\
(1015)\end{array}$ & 06 \\
\hline $\begin{array}{l}5 \text { - Rest of sediment } \\
\text { fines from firs sift }\end{array}$ & $\begin{array}{l}10: 58-11: 05 \\
1378-1511\end{array}$ & $\begin{array}{l}E 5, E 7, \\
E 8, E 7, \\
E 6, E 9, \\
E 6, E 8 \\
\\
\text { (231) }\end{array}$ & $\begin{array}{c}5 F 6,5 F 4, \\
5 C A, 5 D 4, \\
5 D 7,604 \text {, } \\
5 C 8,5 F 2 \text {, } \\
607,5 A 5 \text {, } \\
5 C F, 5 B 1 \\
(1499)\end{array}$ & $\begin{array}{c}63 B, 625, \\
5 F F, 622, \\
614,5 E 5 \text {, } \\
5 D D, 620 \text {, } \\
630,60 E \text {, } \\
5 D E, 611 \\
(1550)\end{array}$ & $\begin{array}{c}63 \mathrm{~A}, 65 \mathrm{~B}, \\
62 \mathrm{E}, 610, \\
63 \mathrm{~B}, 63 \mathrm{E}, \\
61 \mathrm{~B}, 610, \\
632,634, \\
617,610 \\
(1579)\end{array}$ & 10 \\
\hline $\begin{array}{l}6 \text { - Washed out fines } \\
\text { from sand }\end{array}$ & $\begin{array}{l}11: 11-11: 19 \\
1611-1751\end{array}$ & $\begin{array}{l}F 3, F 4, \\
F 1, F 6, \\
F 2, F 3, \\
E F, F 3, \\
F 0, F 1, \\
E F, E D \\
(242)\end{array}$ & $\begin{array}{c}634,617, \\
641,621, \\
64 \mathrm{~B} .647, \\
628,641, \\
65 \mathrm{C}, 64 \mathrm{E}, \\
642,613 \\
(1593)\end{array}$ & $\begin{array}{c}\text { 6CE, 6BA, } \\
\text { 6EA, 6B7, } \\
\text { 6DE, 6EE, } \\
\text { 6CF, 6AA, } \\
\text { 6A7, 68D, } \\
\text { 6B7, 6A8 } \\
(1728)\end{array}$ & $\begin{array}{c}6 \mathrm{CO}, 6 \mathrm{AA} 7, \\
6 \mathrm{D} 3,6 \mathrm{DD}, \\
69 \mathrm{~B}, 6 \mathrm{B5}, \\
6 \mathrm{~B} 1,6 \mathrm{D} 8, \\
6 \mathrm{BE}, 6 \mathrm{D} 7 \\
68 \mathrm{C}, 6 \mathrm{C} 2 \\
(1724)\end{array}$ & 28 \\
\hline $\begin{array}{l}7 \text { - Added "mud" from } \\
\text { Mud Dump Site }\end{array}$ & $\begin{array}{l}11: 22-11: 30 \\
1811-1943\end{array}$ & $\begin{array}{c}143,138 \\
145,139 \\
130,136 \\
138,130 \\
13 \mathrm{C}, 13 \mathrm{~A} \\
(313)\end{array}$ & $\begin{array}{c}8 C 1,8 C D \text {, } \\
8 D F, 8 B C \text {, } \\
8 D D, 8 D 1 \text {, } \\
8 E D, 8 C B \text {, } \\
8 B 4,8 A E \text {, } \\
885,8 A F \\
(2243)\end{array}$ & $\begin{array}{c}98 \mathrm{D}, 97 \mathrm{E}, \\
985,956, \\
973,974, \\
937,9 \mathrm{E} 1, \\
93 \mathrm{C}, 936, \\
915,96 \mathrm{~B} \\
(2407)\end{array}$ & $\begin{array}{c}\text { 924, 939, } \\
907,959, \\
8 \mathrm{EA}, 937, \\
90 \mathrm{C}, 906, \\
8 \mathrm{C}, 90 \mathrm{E}, \\
8 \mathrm{FB}, 8 \mathrm{FD} \\
(2320)\end{array}$ & 30 \\
\hline $\begin{array}{l}8 \text { - Added another bit } \\
\text { of Mud Dump Site mud } \\
\text {. }\end{array}$ & $\begin{array}{l}11: 34-11: 39 \\
2008-2091\end{array}$ & $\begin{array}{c}1 \mathrm{~B} 6,1 \mathrm{~B} 7 \\
1 \mathrm{~A}, 19 \mathrm{~F}, \\
1 \mathrm{~A} 5,1 \mathrm{AD}, \\
1 \mathrm{A9}, 1 \mathrm{A4}, \\
19 \mathrm{1}, 1 \mathrm{A3} \\
(425)\end{array}$ & $\begin{array}{c}\text { B58, B58, } \\
\text { 859 } \\
\text { PEGGED } \\
(2904)\end{array}$ & $\begin{array}{c}\text { B54, B54, } \\
854 \\
\text { PEGGED } \\
(2900)\end{array}$ & $\begin{array}{c}\text { B6D, BCF, } \\
\text { BCD } \\
\text { PEGGED } \\
(3021)\end{array}$ & 34 \\
\hline
\end{tabular}

Callibration done with the instrument as it sampled the environment at the LEO-15 site with same A/O and same power cycling. Calitrations were made in a bucket with the far side $>20 \mathrm{~cm}$ from transducer, and the measurement mede at half depth, or about $10 \mathrm{~cm}$ from the top or bottom. Sediments Sample Number 3 was taken at the LEO-15 site at the time of instrument dephoyment (9 December 1993). Fines were separated from the coarse sands by slosting the sample and decarling the fines from the sands. These were then added to the bucket to make the calibration bath, and the sample were drawn after the OBS sensors were calibraled. The waler was vell stirs od between iach sensor's calibration and before the water sample was taken. 5 
points. The last point was at concentrations greater than could be measured by the OBS's at 30,100 , and $200 \mathrm{~cm}$ height (the electronics reached saturation), and so were not used in the curve fitting.

Once the calibrations were done and recorded in TABLE III, the values were averaged, converted to volts and recorded in TABLE IV. The top number in a box is the average of all the readings made, and the middle number is the standard deviation of the sample. The last number is averaged number converted to volts. This is the value used in fitting the calibration curves.

The water samples from the calibration were processed in the standard manner. The samples were measured for volume (about $300 \mathrm{ml}$ ) and then filtered through a $90 \mathrm{~mm}$ diameter 0.45 micron filter, dried and weighed. The values are also listed in TABLE IV, with the filter weight on top, the total sample and filter weight in the middle, and the volume of the sample on the bottom. Unfortunately, the filters were not dried before the initial weighting so they retained some moisture and weight as shown by the top right number in TABLE IV. Therefore, the other filtered weights were corrected by 0.0039 grams to correct for the initial filter moisture content. The corrected values are listed as the bottom number in the right hand box in TABLE IV, and used with the voltages for the calibrations.

The calibrations were not as linear as has been seen in the past. This may be due to uneven mixing of the sediment during the first 6 points, and the addition of different sediment for the seventh point. However, an attempt was made to mix the source between each addition, so this is probably not the cause. Therefore, the first 7 calibration points were fit by a quadratic, and the results shown in Figs. 20,21, 22, and 23. The fit is shown as the solid line and the asterisks are the individual calibration points. The eighth point was included in the OBS 1 calibration since it had a different sensitivity than the others. The calibrations constants are shown on the four figures and were used to normalize the data shown in Figs. 14, 15, 16, and 17 and finally plotted in Fig. 4a.

\section{Description of Transport Events}

One of our major goals in the NOAA-NURP work at LEO-15 is to understand the mechanisms driving sediment transport at the site. As is seen by looking at the OBS concentration measurement time series in Fig. 4, suspension and transport occur in series of reasonably discrete "events", which are labeled "a" through "f" in that figure. In this section of the report, we.will endeavor to relate these transport events to the meteorological and oceanic forcing functions, e.g. wind, waves, currents, tides, etc. Key in this description will be the "stacked" time series of concentration and the forcing variables shown in Fig. 4. To recap the other measurements in this figure briefly, the wave and current velocities are obtained from a vector averaging current meter and a rotor. The average current (S) was subtracted from the total horizontal water motion (R) as measured by the rotor to give an estimate of the wave velocities (W). This was performed as a incoherent subtraction by subtracting the squared quantities. A NDBC buoy located approximately 50 nautical miles SSW of the LEO-15 site provided wind speed and direction. 
ABSS/NURP OBS Calibration

LEO-15 Bottom Sample \#3

18 January 1994

\begin{tabular}{|c|c|c|c|c|c|c|c|}
\hline Description of sample & $\begin{array}{l}\text { Sensor \#1 } \\
\text { S/N- } 107\end{array}$ & $\begin{array}{l}\text { Sensor \#2 } \\
\text { S/N - } 145\end{array}$ & $\begin{array}{l}\text { Sensor } \# 3 \\
S / N-146\end{array}$ & $\begin{array}{l}\text { Sensor \#4 } \\
\text { S/N - } 147\end{array}$ & $\begin{array}{l}\text { WATER SAMPLE } \\
\text { BOTTLE NO. }\end{array}$ & $\begin{array}{c}\text { litter wt } \\
\text { total wt } \\
\text { volume } \mathrm{ml}\end{array}$ & $\begin{array}{c}\text { Sediment } \\
\text { Concentration } \\
(g / l)\end{array}$ \\
\hline $\begin{array}{l}1 \text { - Faimouth Cold } \\
\text { Tap Water Outgassed }\end{array}$ & $\begin{array}{c}80.00 \\
1.00 \\
0.09766\end{array}$ & $\begin{array}{c}85.67 \\
1.15 \\
0.10458\end{array}$ & $\begin{array}{c}80.33 \\
1.15 \\
0.09806\end{array}$ & $\begin{array}{c}180.33 \\
0.58 \\
0.22013\end{array}$ & 33 & $\begin{array}{c}0.2633 \\
0.2594 \\
294\end{array}$ & $\begin{array}{l}-0.0133 \\
0.00000\end{array}$ \\
\hline 2 - "Splash of fines" & $\begin{array}{c}93.67 \\
0.58 \\
0.11434\end{array}$ & $\begin{array}{c}206.00 \\
5.29 \\
0.25146\end{array}$ & $\begin{array}{c}221.00 \\
5.43 \\
0.26977\end{array}$ & $\begin{array}{c}298.50 \\
4.20 \\
0.36438\end{array}$ & 27 & $\begin{array}{c}0.2704 \\
0.2746 \\
287\end{array}$ & $\begin{array}{l}0.01463 \\
0.02822\end{array}$ \\
\hline $\begin{array}{l}3 \text { - Two Splashes of } \\
\text { gunk }\end{array}$ & $\begin{array}{c}120.5 \\
1.00 \\
0.14709\end{array}$ & $\begin{array}{c}475.83 \\
8.93 \\
0.58085\end{array}$ & $\begin{array}{c}494.00 \\
5.32 \\
0.60303\end{array}$ & $\begin{array}{c}552.63 \\
10.94 \\
0.67460\end{array}$ & 12 & $\begin{array}{c}0.2724 \\
0.2916 \\
250\end{array}$ & $\begin{array}{l}0.07680 \\
0.09240\end{array}$ \\
\hline $\begin{array}{l}4 \text { - Another "lot" of } \\
\text { gunk }\end{array}$ & $\begin{array}{c}171.60 \\
1.14 \\
0.20947\end{array}$ & $\begin{array}{c}922.33 \\
10.12 \\
1.12588\end{array}$ & $\begin{array}{c}982.78 \\
14.19 \\
1.19968\end{array}$ & $\begin{array}{c}1015.38 \\
16.48 \\
1.23947\end{array}$ & 06 & $\begin{array}{c}0.2754 \\
0.3281 \\
260\end{array}$ & $\begin{array}{l}0.20269 \\
0.21769\end{array}$ \\
\hline $\begin{array}{l}5 \text { - Rest of sediment } \\
\text { fines from firs sift- }\end{array}$ & $\begin{array}{c}231.40 \\
1.93 \\
0.28247\end{array}$ & $\begin{array}{c}1499.42 \\
31.67 \\
1.83034\end{array}$ & $\begin{array}{c}1549.67 \\
31.75 \\
1.89168\end{array}$ & $\begin{array}{c}1579.00 \\
23.60 \\
1.92748\end{array}$ & 10 & $\begin{array}{c}0.2752 \\
0.3735 \\
253\end{array}$ & $\begin{array}{l}0.38854 \\
0.40395\end{array}$ \\
\hline $\begin{array}{l}6 \text { - Washed out fines } \\
\text { from sand }\end{array}$ & $\begin{array}{c}241.50 \\
8.50 \\
0.29480\end{array}$ & $\begin{array}{c}1592.83 \\
22.95 \\
1.944368\end{array}$ & $\begin{array}{c}1728.08 \\
29.67 \\
2.10946\end{array}$ & $\begin{array}{c}1724.25 \\
25.57 \\
2.10479\end{array}$ & 28 & $\begin{array}{c}0.2741 \\
0.3996 \\
284\end{array}$ & $\begin{array}{l}0.44190 \\
0.45563\end{array}$ \\
\hline $\begin{array}{l}7 \text { - Added "mud" from } \\
\text { Mud Dump Site }\end{array}$ & $\begin{array}{c}313.40 \\
6.87 \\
0.382567\end{array}$ & $\begin{array}{c}2243.08 \\
27.87 \\
2.738128\end{array}$ & $\begin{array}{c}2407.25 \\
53.64 \\
2.93853\end{array}$ & $\begin{array}{c}2319.92 \\
38.63 \\
2.83193\end{array}$ & 30 & $\begin{array}{c}0.2823 \\
0.5173 \\
284\end{array}$ & $\begin{array}{l}0.82746 \\
0.84119\end{array}$ \\
\hline $\begin{array}{l}8 \text { - Added another bit } \\
\text { of Mud Dump Site mud }\end{array}$ & $\begin{array}{c}424.50 \\
8.67 \\
0.518187\end{array}$ & $\begin{array}{c}\text { PEGGED } \\
2904 \\
3.5449\end{array}$ & $\begin{array}{l}\text { PEGGED } \\
2900 \\
3.5400\end{array}$ & $\begin{array}{l}\text { PEGGED } \\
3021 \\
3.6877\end{array}$ & 34 & $\begin{array}{c}0.2760 \\
0.7222 \\
291\end{array}$ & $\begin{array}{c}1.53333 \\
1.54674\end{array}$ \\
\hline
\end{tabular}

Calibration done with the instrument as it sampled the environment at the LEO-15 site with same A/D and same power cycling. Calibrations were made in a bucket with the far side $>20 \mathrm{~cm}$ from transducer, and the measurement made at half depth, or about $10 \mathrm{~cm}$ from the top or bottom. Sediments Sample Number 3 was taken at the LEO-15 site at the time of instrument deployment (9 December 1993). Fines were separated from the coarse sands by sloshing the sample and decanting the fines from the sands. These were then added to the bucket to make the calibration bath, and the sample were drawn after the OBS sensors were calibrated. The water was well stirred between each sensor's calibration and before the water sample was taken.

Table IV 
LEO-15 OBS1 Calibration

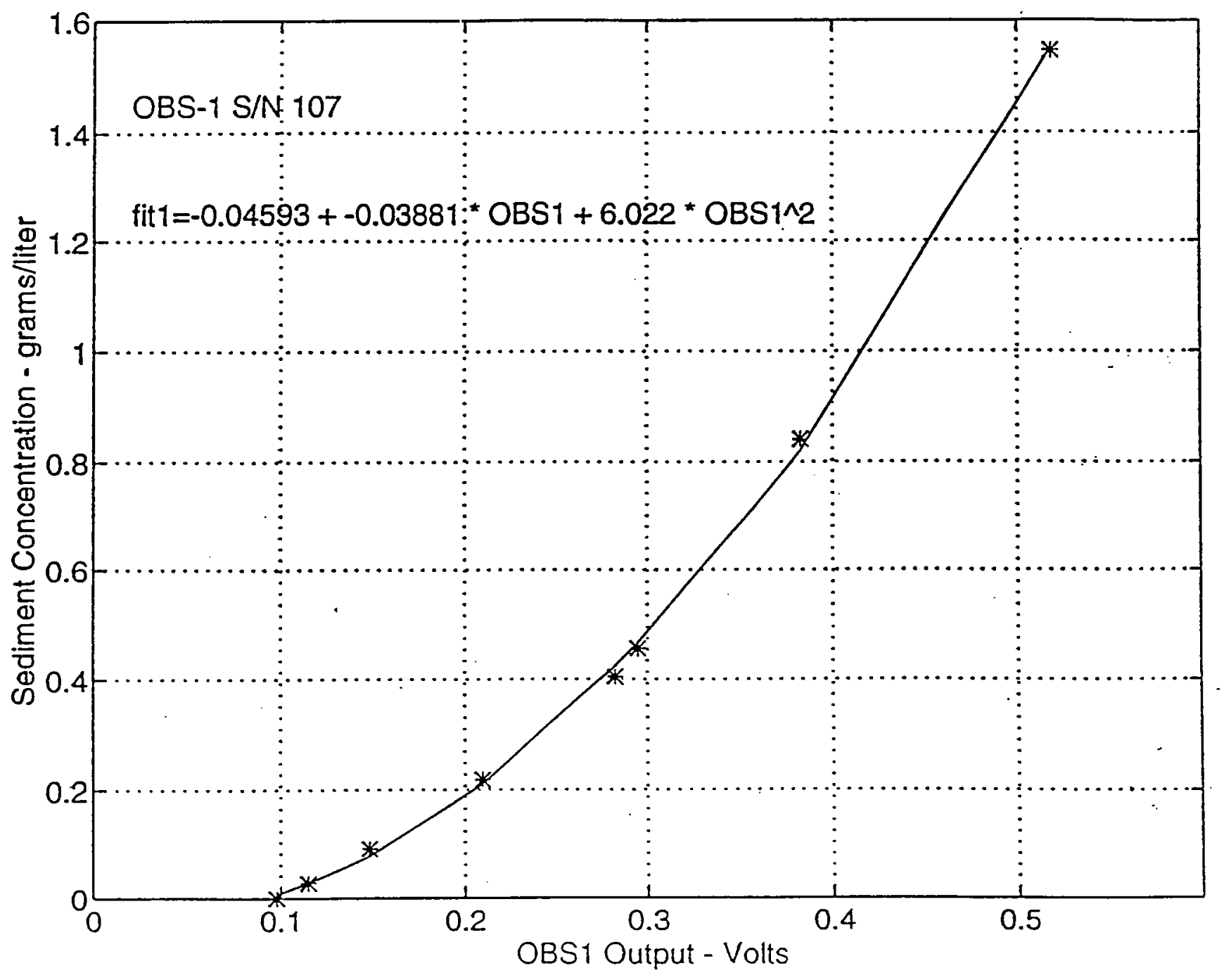

$$
\text { fit } 1=0.04593-0.03881 * \text { OBS } 1+6.022 * \mathrm{OBS}^{2}
$$

Figure 20. The individual calibration points for OBS\#1 (SN107) from the weighted smaples are shown as the * and least squares quadratic fit shown as the line. The parameters for the fit to the calibration are given in the equation. 


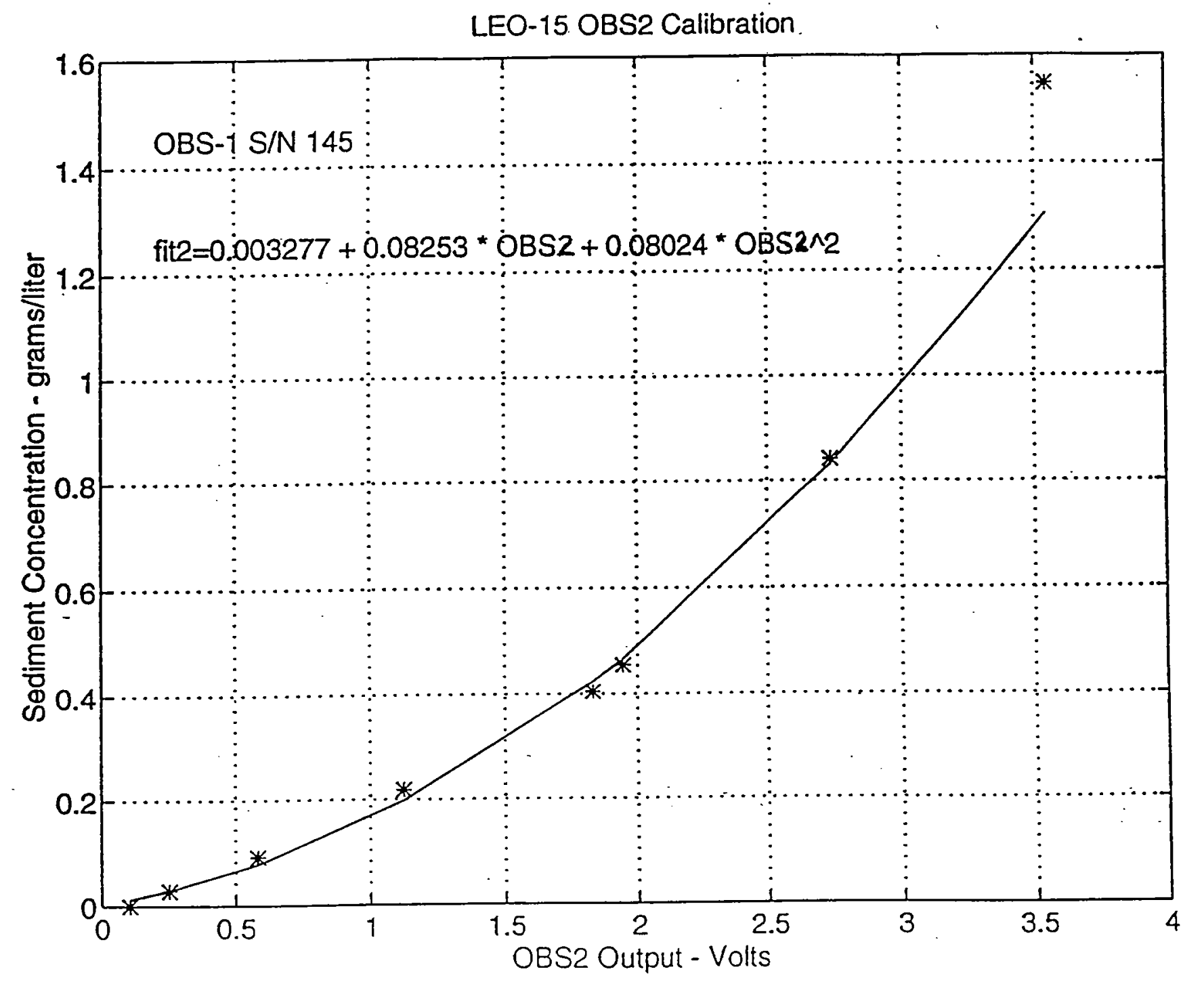

$$
f_{i t 2}=0.003277+0.08253 * \text { oBS } 2+0.08024 * \mathrm{OBS}^{2}
$$

Figure 21. OBS\#2 (SN145) Calibration as in Figure 20. 


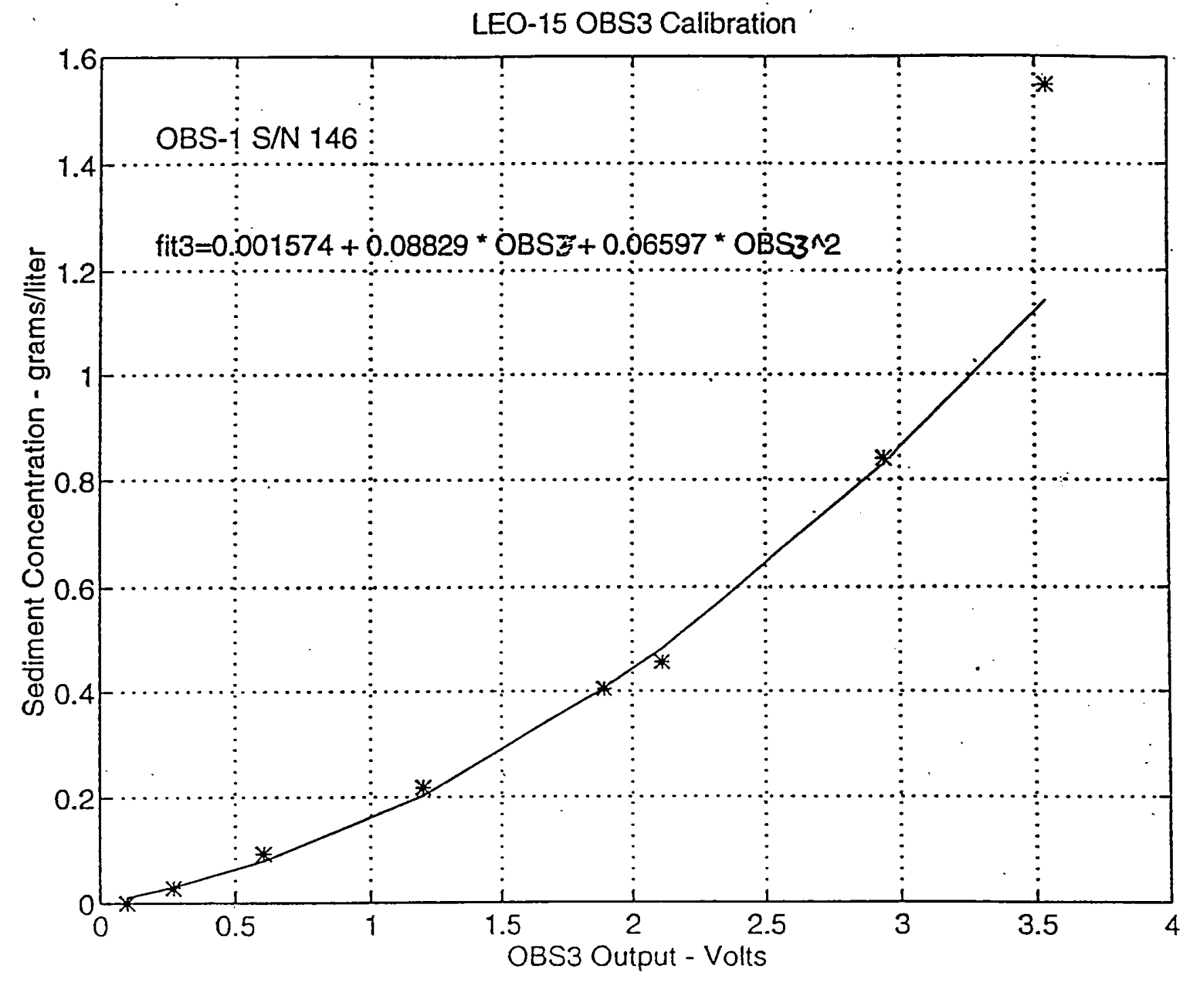

$$
\text { fit } 3=0.001574+0.0825 * \text { OBS3 }+0.09024 * \text { OBS3 }^{2}
$$

Figure 22. OBS\#3 (SN146) Calibration as in Figure 20. 


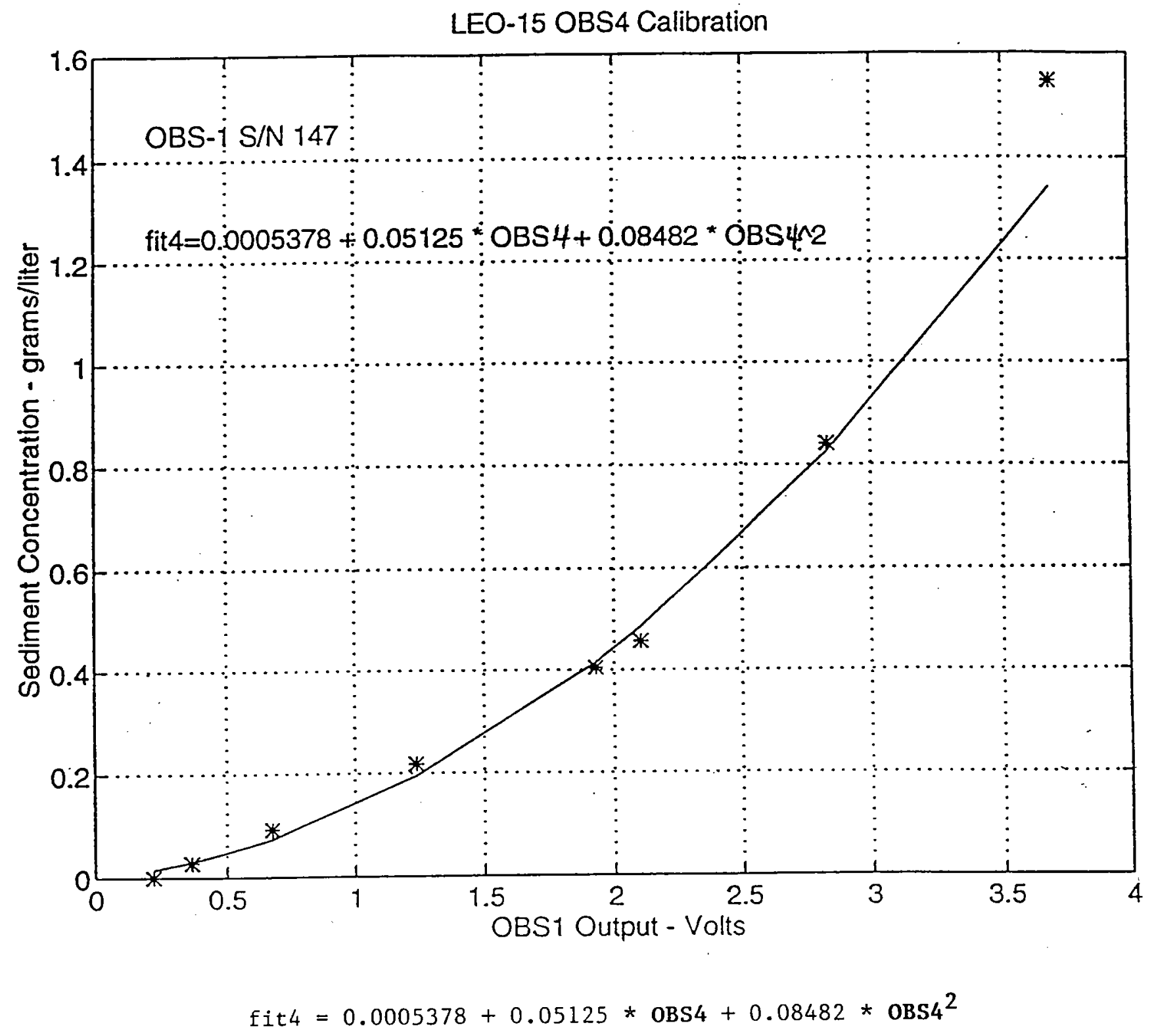

Figure 23. OBS\#4 (SN147) Calibration as in Figure 20. 
Although this is not exactly at the LEO site, it should provide a reasonable estimate. This buoy also recorded the principal wave period and direction.

\section{A. Weather}

The time series from December 9 to December 18, 1994 is divided into three distinct periods as labelled on the time series (Fig. 4g). These show a $S(1)$ wind followed by a NW (2) and then a NE (3) wind. The time series begins with the end of a north going (or South) wind.

1: From the evening of the 9th to the morning of the 11 th, a south wind blew and reached a maximum of 20 knots on midnight of the $10 \mathrm{th} / 11$ th.

2: On the morning of the 11 th the wind switched to the NW and reached a maximum of 30 knots by the midnight of the 11 th/12th. The northwest wind then decreased over the next three days and turned variable to the NE on the 14 th.

3: Early the morning of the 15 th, the wind increased to 25 knots from the NE. By midnight of the 17 th the $\mathrm{N}$ wind died and then began to increase again from the $\mathrm{SW}$.

\section{B. Current}

Some of the current structure can be explained by the wind forcing with semi-diurnal tidal cycle imposed on it. Other features can not be interpreted as easily.

\section{Directions:}

a: During the wind event from the South, the current goes primarily to the North with fluctuations going to the NW (onshore) during the flood tide and to the NE (offshore) during the ebb tide. During a S. Wind one may expect upwelling to occur due to net offshore Ekman transport. Examination of Sea Surface temperature data from the NDBC buoy did not show any dramatic decrease; a temperature/salinity profile at the LEO site would be a better indication if this is occurring.

bi: As the wind switches to the NW, the current flows primarily longshore to the SW with WSW (onshore) tidal fluctuations during the flood and SSW (offshore) during the ebb.

bii: As the wind dies and shifts variably to the NE during the 14th, the current takes a dramatic turn to a northgoing direction. The reason for this is not obvious, but may have to do with inertial oscillation in response to the removal of strong wind forcing since the period of this oscillation in 12 hours. $(2 * \mathrm{pi} / \mathrm{f}=11.3 \mathrm{hrs}$ here at $40 \mathrm{~N})$, and the disturbance is this order of time.

c: When the wind increases again from the NE on the 15th, the current returns to the SSW with less variation due to the tide than in the NW wind.

2. Velocities: 
The low frequency current velocities are generally well correlated to the wind, with maxima at the wind maxima of the three periods. This can be seen in the correlation plots (Fig. 24). The high frequency changes in the current are correlated to the tidal surface displacement with $1 / 4$ day lag time (Fig. 17b). This corresponds to half a tidal cycle; thus the largest currents are occurring at low water. This seems counter-intuitive; one would expect the largest velocities in between water times (ie. a lag of $1 / 4$ cycle or 1/8 day.) After looking at the semi-diurnal tidal ellipse (Fig. 25), however, this can be explained.

The semi-diurnal tidal ellipse was calculated by first filtering the north and east velocity vectors between 1.7 and $2.2 \mathrm{cpd}$. The position of the end of the velocity vector is then plotted on the $x$-y plane with the tidal displacement on the z-axis. From the ellipse it is evident that the largest tidal velocities occur at high and low tide. These velocities are in the north and south directions (longshore). This makes sense, as the tides on the shelf can be modeled to the first order by a Kelvin wave propagating around the North Atlantic basin and down the American east coast. The ideal Kelvin wave has only longshore (parallel to its propagation) velocity components which are in phase with surface displacement. If the Kelvin wave were travelling along a vertical wall it would only have longshore velocities. Here it is travelling along a coastal wedge or shelf wedge so the water surface rising and falling causes on and off shore velocity components. As seen in the tidal ellipse (Fig. 25) these velocities are smaller than the alongshore components and are out of phase with the surface displacement. This phase relation makes sense since the cross shelf velocities are forced by the surface displacement and the shelf structure itself. Also untrapped Poincare waves can contribute to the across shelf velocities at tidal frequencies.

The spectrum of the total currents (tidal plus mean, but without waves) (Fig. 26) reflects the dependence on both the wind with the low $(.25 \mathrm{cpd})$ peak and the tide with an approximate two cpd peak in both spectra.

\section{Waves}

Parts of the wave record can be related simply to the wind record. There are also contributions from wave sources far from the immediate area, but the principal wave direction from the buoy is the same as the wind direction during the periods of strong wind.

1. Wave Velocities:

a: At the maximum of the $\mathrm{S}$ wind there is a small wave velocity peak (a), but it is followed by a much larger peak (b) when the wind is dying and switching to the NW. This is difficult to explain from the local forcing data available, but could be interpreted in terms of a lag required to build a south swell associated with the long fetch on this section of coast. Also waves are very efficient propagators of energy from distant storms. 

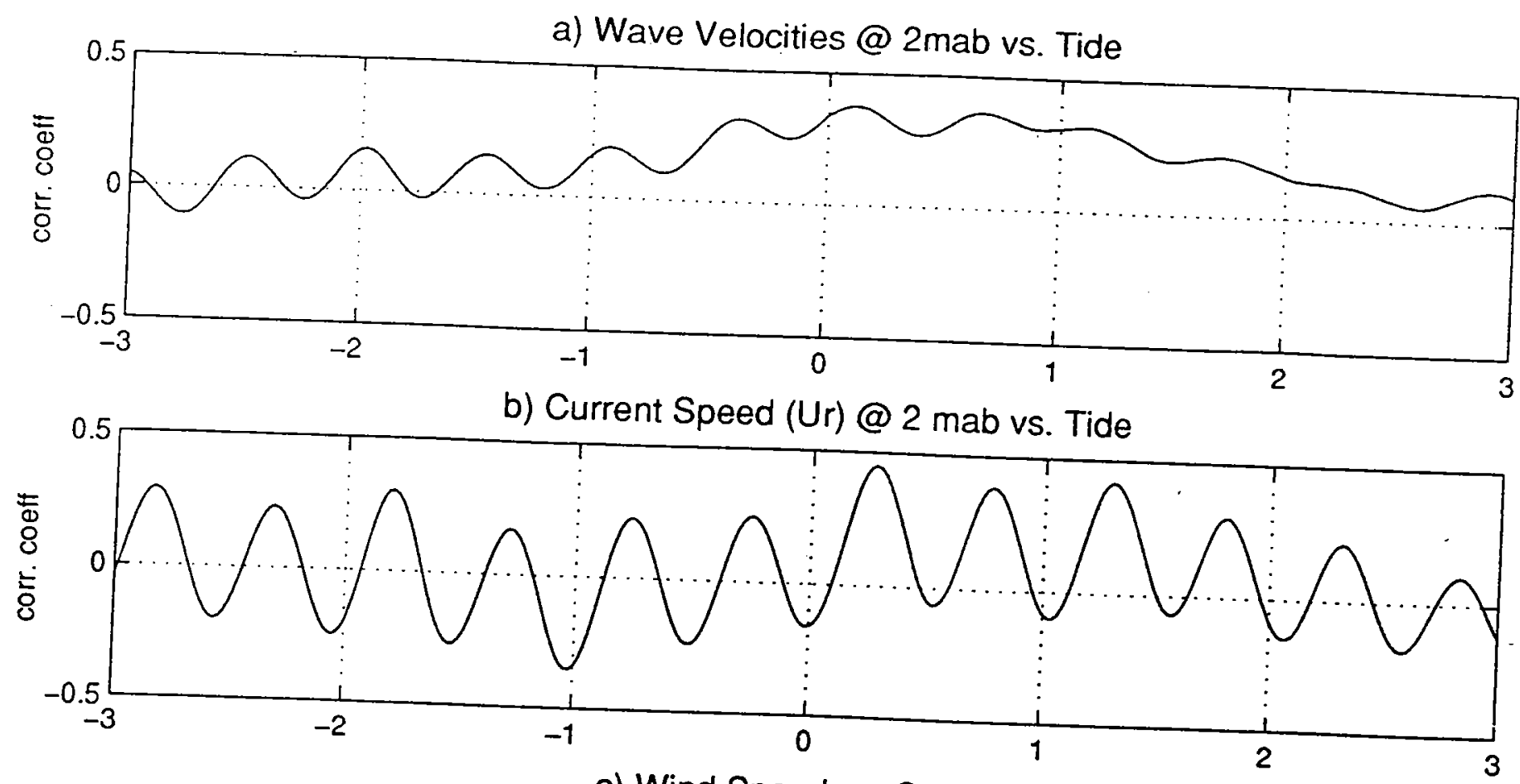

c) Wind Speed vs. Current
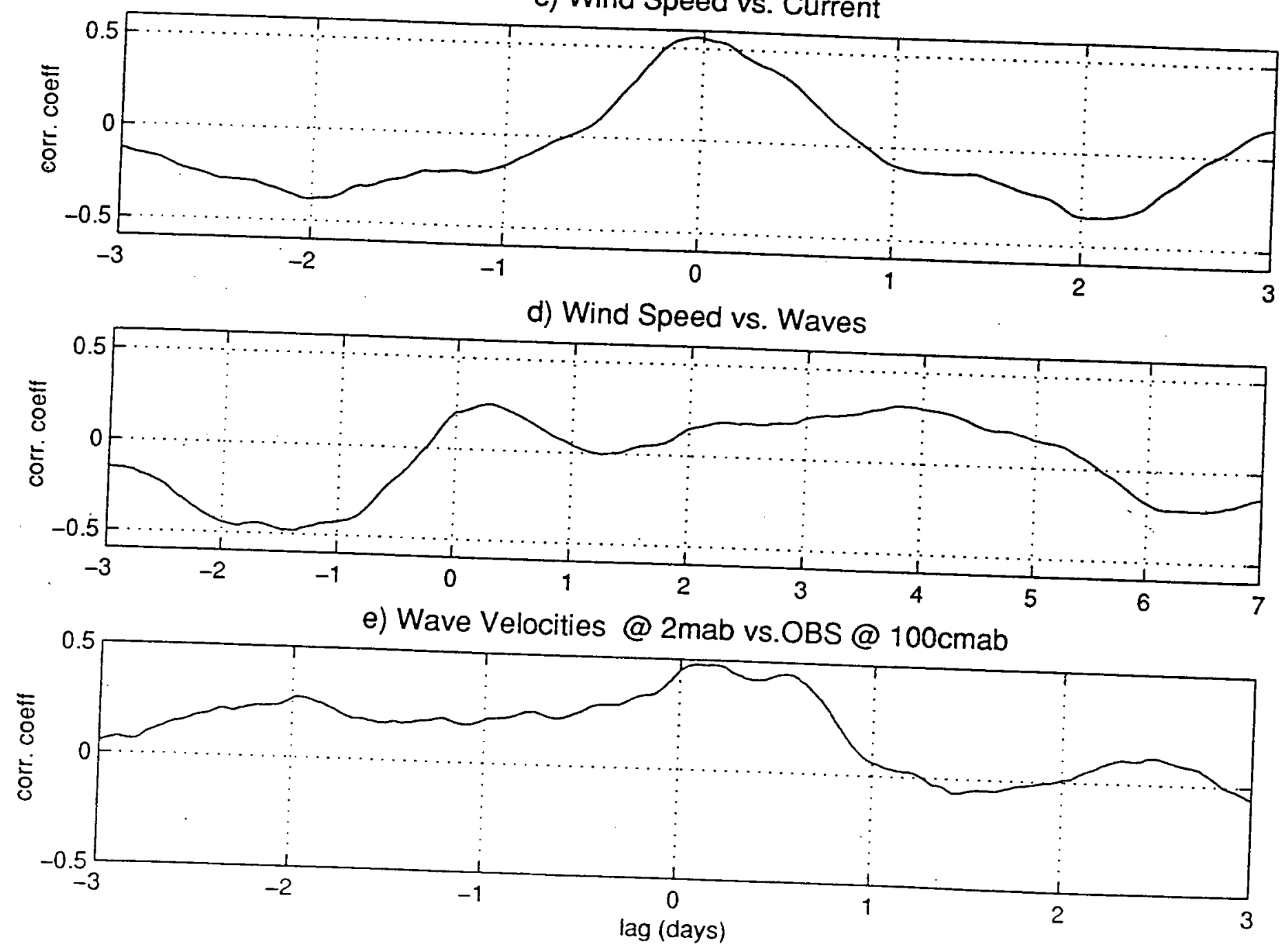

Figure 24. Cross correlations of wind, wave, current, and sediment concentration time series. 
Semidurnal (1.8 to 2cpd) tidal currents and elevation during NW wind period 2:(day 11.4 to 14.4)

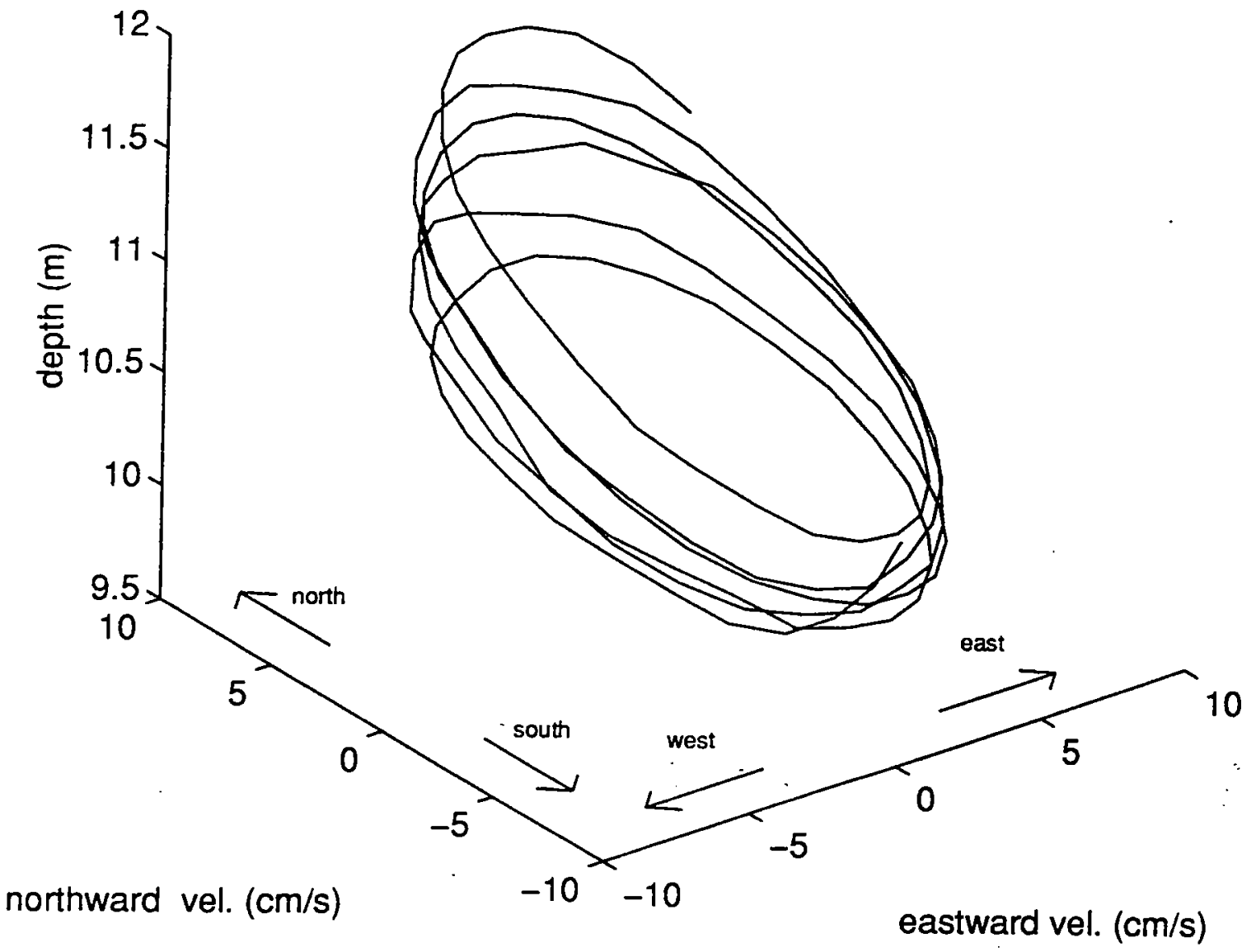

Figure 25. Tidal ellipses during NW wind event (period 2 in Fig. 4 wind time series). 
a) OBS Spectra (corrected for drift) at 10, 30, 100, $200 \mathrm{cmab}$
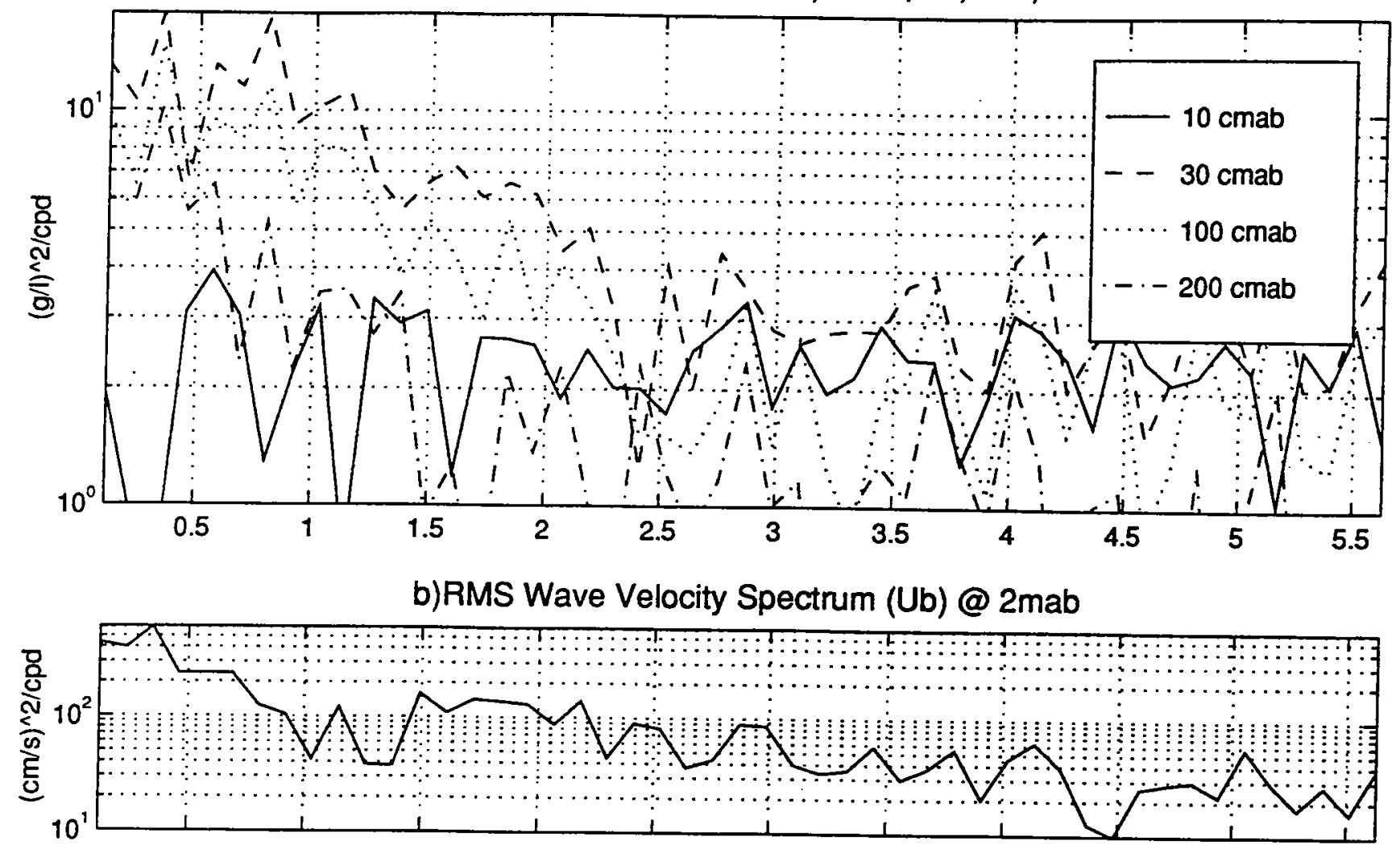

c) Current Speed Spectrum (Ur) @ 2 mab

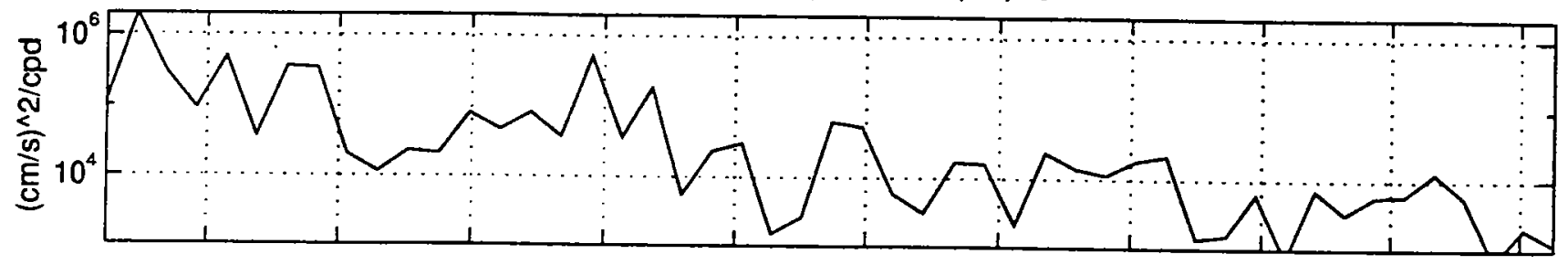

d) Wind Speed Spectrum

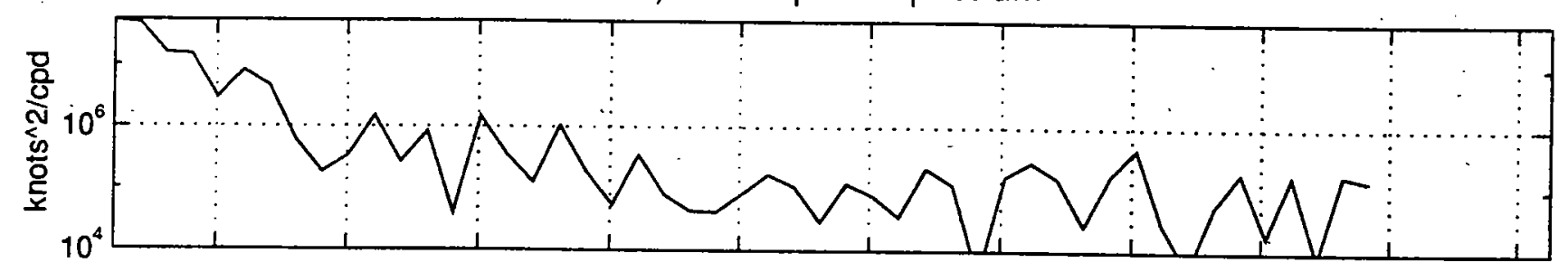

e) Analog pressure sensor spectrum

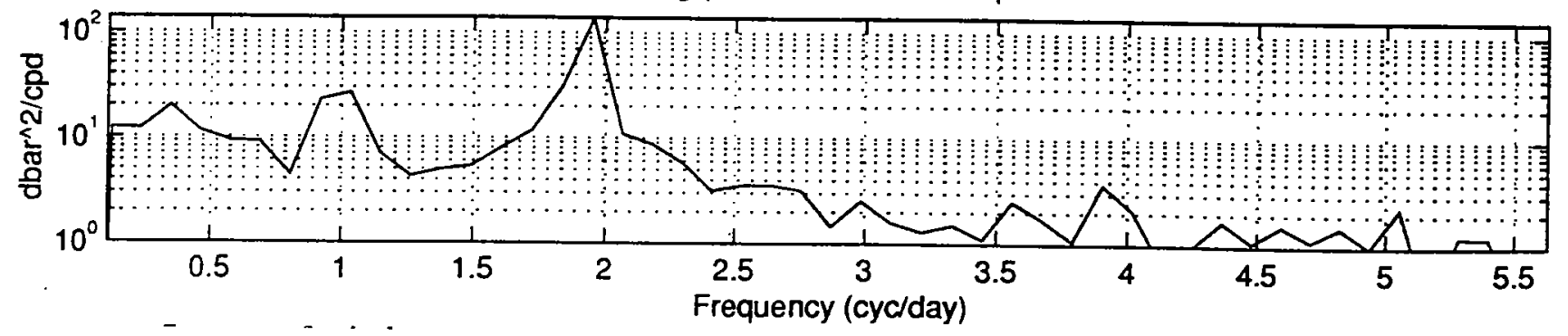

Figure 26. Spectra of wind, wave, current, pressure, and sediment concentration time series. 
b: Once the wind switches to the NW it takes 1 day for the wave velocities to increase and they reach a maximum after 2 days of $\mathrm{NW}$ wind. This lag is interpretable in terms the time required to generate the waves; the wind could be caused by a cold front going out to sea. Once the storm is offshore larger waves are generated. The two largest peaks during this period are indicated by (c) and (d) in Fig. 4c. This pattern is evident in the correlation structure of the wind and waves (Fig. 24d) where there is a subtle peak at 0 lag associated with seas and another beginning at 2 days associated with swell. The wind and waves have roughly the same low frequency spectral content, as seen in Fig. 26b and 26d.

c: $\quad$ During the NE wind there are two wave peaks ((e) and (f) on Fig. 2c) of similar magnitude corresponding to the peaks in the wind.

2. Wave Correlations:

There is a well known correlation between the wind and waves. We may also expect to see some correlation structure between the tides and the waves; correlations between the tides and the wind are not expected. There are four physical mechanisms that could correlate wave velocities to tides.

a. The changing depth of the water could cause the waves velocities to be greatest at low tide since there will be the least exponential decay (especially important for short/high amplitude waves.)

b. Changes in water depth also change the amount of friction dissipation a wave experiences as it travels into shallow water (especially important for long waves.)

c. Nonlinear steepening of the waves in shallower water could also cause corrections between tidal water depth and wave velocities.

d. Interactions between the tidal current and waves could cause changes in wave velocities. For this, the direction of wave propagation relative to the tidal current velocity vector must be considered.

The correlation between the waves and tide (Fig. 24a) indicates a broad peak (at roughly $1 / 4$ cycle lag). This would indicate that the tidal current velocities may be the most important tidal factor influencing the waves. 


\section{Sediment:}

Most of the notable sediment peaks (Fig. 4) can be directly related to the wave peaks with the exception of sediment peak (d) late on the 14th. Almost all of the wave peaks produce over 0.1 $\mathrm{g} / \mathrm{l}$ in the $10 \mathrm{cmab}$ OBS sensor, but not necessarily in the higher sensors. The exception to this is again on the 14th when the sediment peak (d) occurs after the wave peak (d). The peaks at (d) are of similar time durations at all heights so this may be indicative of an advective process. This sedimient peak (d) is also correlated to the dramatic change in current direction to the North at the end of the strong NW to NE wind. This could be indicative of an upwelling or advective event. Unfortunately, additional data (such as size distribution) to confirm this is not available.

The strongest wave peaks (b, c, f) cause sediment peaks $(b, c, f)$ in the higher sensors. The wave peak (e) is almost of the same magnitude as peak (f), but the sediment peak (e) is only visible on the $10 \mathrm{cmab}$ sensor while the sediment peak (f) appears on all sensors.

\section{Boundary Layer Structure and Size Dependent Transport at LEO-15.}

As stated, two of our major goals at LEO-15 are to understand how to model the boundary layer structure and how to calculate the size dependent sediment transport. The loss of the acoustic data in the winter 1993 deployment meant the loss of the high resolution vertical profiles of the bottom boundary layer, as well as the acoustics to optics backscattering ratio which can be used for size dependence studies. However, one may still study the boundary layer vertical structure using the four OBS sensors. By involving a boundary layer model, one may also study the size dependence of the transport. Of course, loss of the acoustic data means these studies will have less resolution -nonetheless, they are still viable and useful.

\section{A. Boundary Layer Models and Observations}

We begin our discussion with the (1-D) boundary layer model. We will look at two models here - the first the "original GGM model", i.e. the model by Grant, Glenn, and Madsen which consists of two portions, the "wave" and "current" boundary layers. The second model is the "modified" GGM model, which includes a "transition layer" between the wave and the current boundary layers. The latter model is suggested both by theoretical considerations (continuous gradients of current) and laboratory and field data. The differences in the two models lie in how they parameterize the vertical eddy viscosity, which is shown in Fig. 27. In the original GGM model, the eddy viscosity has a discontinuity at the height of the wave boundary layer $l^{\text {WBL }}$ whereas the modified GGM model has a continuous profile and a second slope change point, $l^{\text {Truss }}$, between the transition layer and the current boundary layer. One of our goals in this work to verify which of these models is most appropriate for the LEO-15 site and in general. Since we are doing this primarily using concentration measurements, let us briefly look at how these models predict the concentration field. 


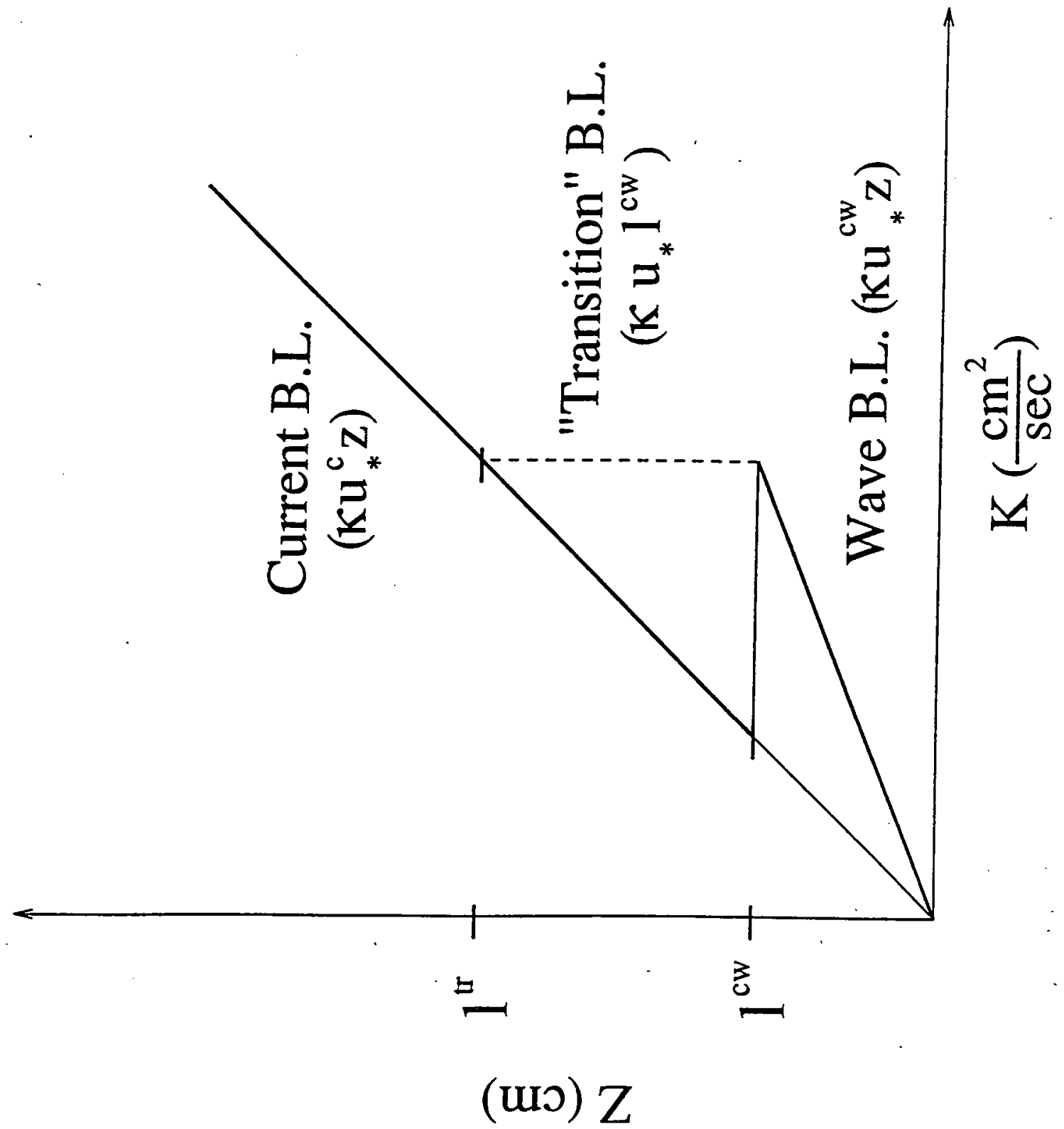
Modification of the GGM model of eddy viscosity vs height above bottom in
which the eddy viscosity does not decrease, thus insuring continuity of the vertical current
gradient.

Figure 27 
The basic quantities need in bottom boundary layer descriptions are the wave and current stresses and the bottom roughness. The turbulent current and combined wave-current stresses are conveniently expressed in terms of a "friction velocity", $U_{v}$, using the relation

$$
U_{.}=\frac{\tau}{\rho}
$$

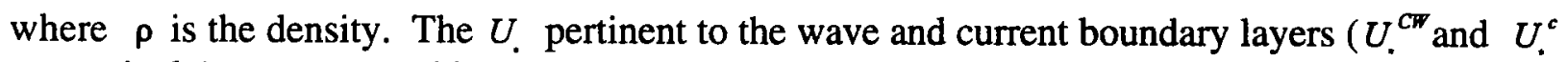
respectively) are computed in our present work from the $\mathrm{CM}$ data for waves and currents taken at $2 \mathrm{mab}$, which is then input to the GGM computer model. The model produces estimates of $U^{C W}, U^{c}$, and $z$, the bottom roughness., The estimates of $U^{C W}$ and $U^{c}$ are show in Fig. 28. It is seen that $U_{\text {. }}^{c}$ is of order $1-2 \mathrm{~cm} / \mathrm{sec}$, whereas the wave/current induced turbulence is of order 2-6 $\mathrm{cm} / \mathrm{sec}$, i.e. two to three times larger. Thus, it is not too daring to say that the waves, when present, dominate the turbulence, and thus the suspension of the sediments. While one can make this simple conclusion from our winter CM data, it would not do to push it too much further, as this data has limits. Due to the limited mechanical response of the instrument to the wave field, the exact fraction of the motional energy which is in currents and waves has a fair degree of error (perhaps up to 50\%). Also, due to being a point measurement at $2 \mathrm{mab}$, one cannot use the standard "log profile" for the currents to estimate $U^{C}$ and $z$, from a vertical string of current meters. Finally, we do not have from this data set a good estimate of the wave direction, so that the angle between the waves and currents, which in part determines how strong the nonlinear wave-current interaction is, was arbitrarily set to $0^{\circ}$, the maximum possible effect. All this notwithstanding, the estimates shown in Fig. 21 are still probably reasonable, and so will be used with some degree of confidence in the work that follows.

We next look at the heights of the wave and transitional boundary layers. From the GGM models, the wave boundary layer height is:

$$
l^{W B L}=\frac{2 \cdot K U_{.}^{C W}}{\omega}
$$

where $K$ is von Karmans constant and $\omega$ is the dominant wave frequency. Using our pressure sensor (e.g. Fig. 12) and current meter data (e.g. Figs. $6 \& 7$ ) to get $\omega$ and $U_{.}^{C W}$ respectively, we obtain the result shown in Fig. 29. As one would expect, the height of this layer is on the order of $1-10 \mathrm{~cm}$. Unfortunately, this is below the lowest OBS sensor, so that we have no direct observations of this layer for the winter deployment. However, we still have enough OBS sensors just above the wave above the wave boundary layer to try to make sense of the structure of the layer above it, and so we turn next to the transition layer and the current boundary layer. 


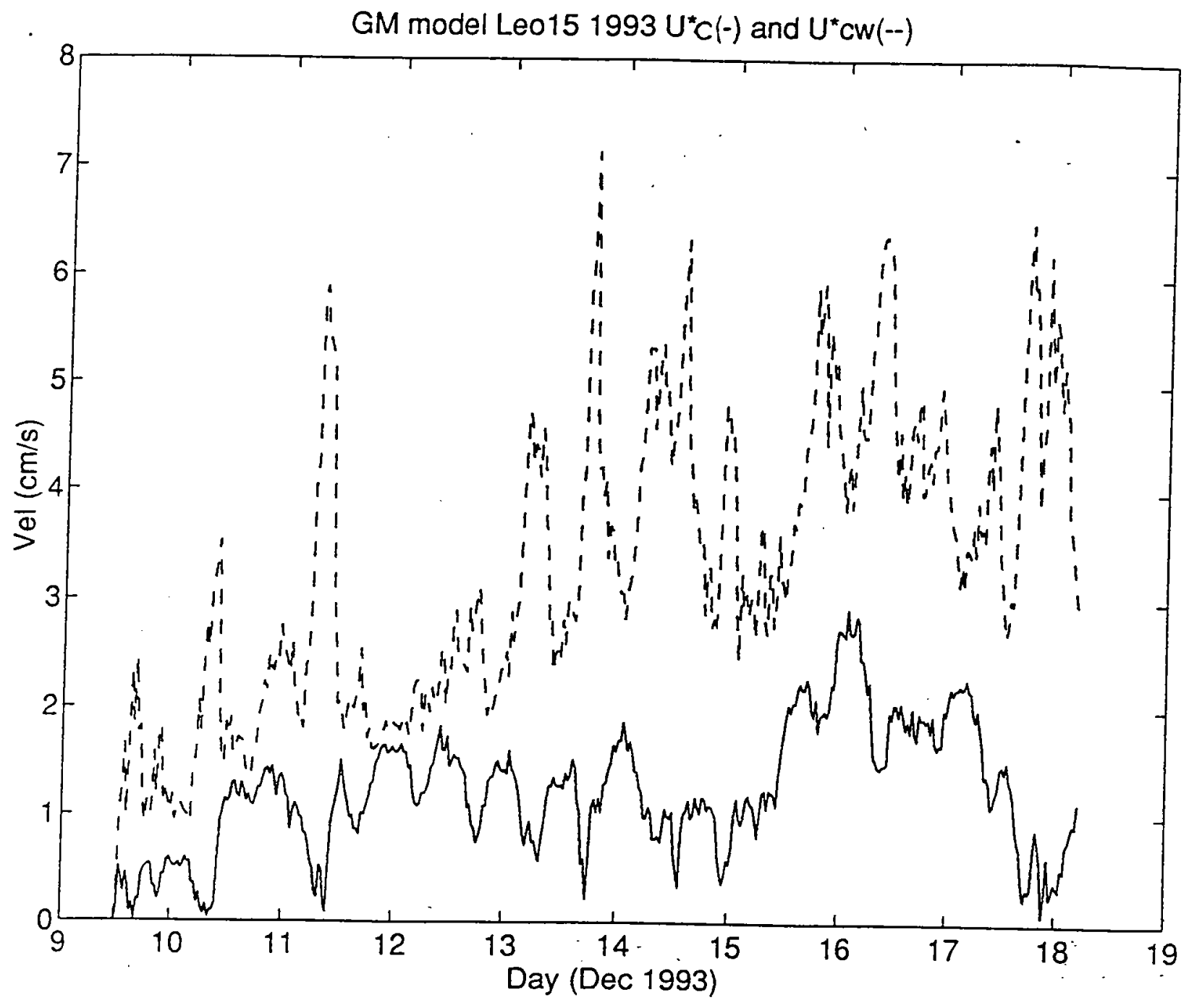

Figure 28. Output of GGM model for $U_{.}^{C}$ and $U_{.}^{c w}$. 


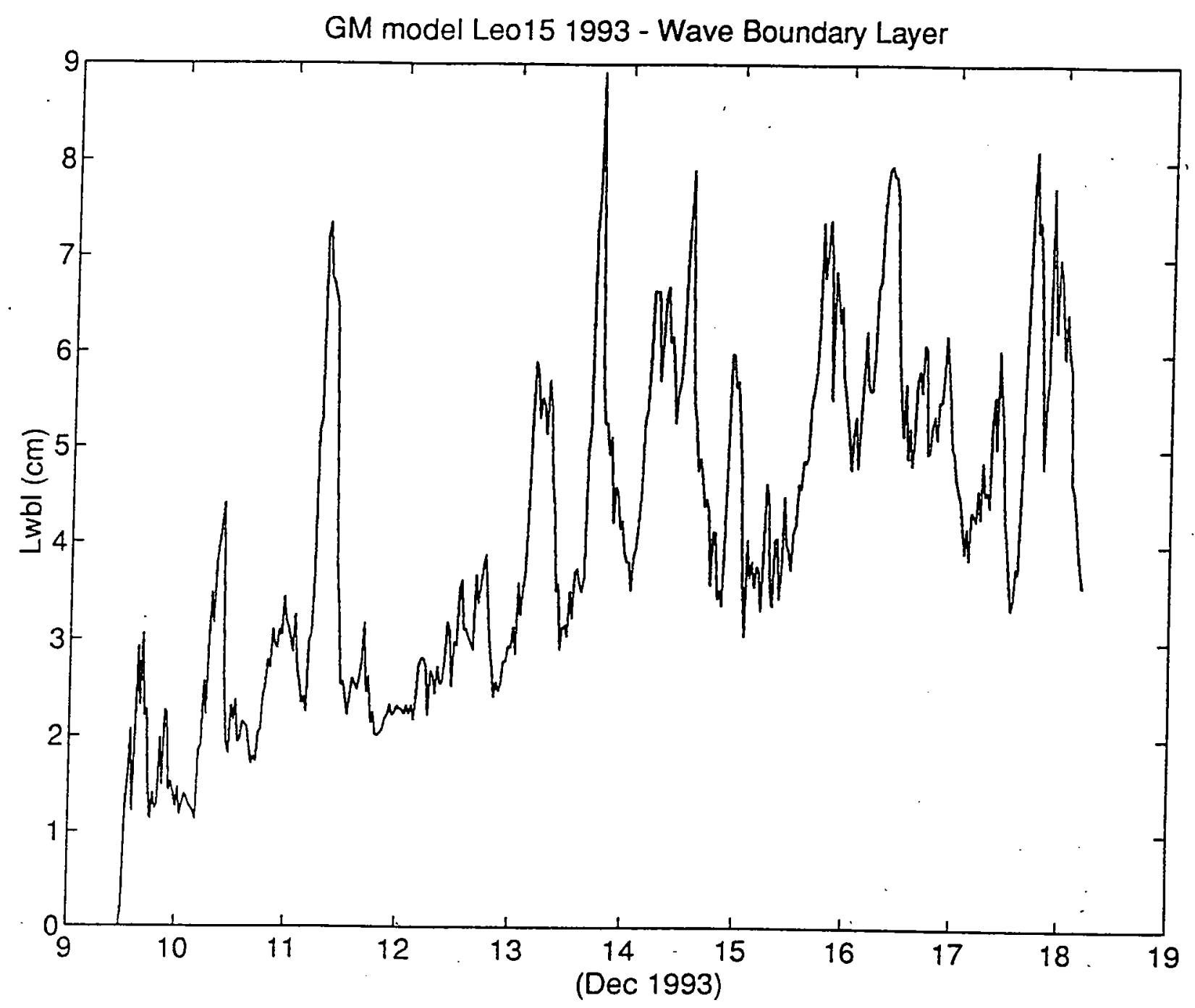

Figure 29. Wave boundary layer thickness calculated from the GGM model output. 
From the model in Fig. 30, one can simply calculate that the height of the transition layer is given by:

$$
l^{\text {TRANS }}=\frac{U_{\cdot}^{C W}}{U_{.}^{C}} \cdot l^{\text {WBL }}
$$

If one uses the $U_{.}^{C T}$ and $U_{.}^{C}$ estimates from Fig. 31, one obtains the result shown in Fig. 30. Based on our previous experience in the California coast STRESS experiments, we expect numbers on the order of 10 to $50 \mathrm{cmab}$ for $l^{\text {TRANS }}$; the peaks seen in Fig. 26 thus seem far too high. It is our belief that the algorithm by which the wave and current energies are separated for the VACM may be at fault here, at times subtracting from the (already small) current energy and putting into the wave estimate. Thus one would see occasional sharp spikes, as in Fig. 30. It is quite possible that a low pass filter time average of $U^{C W}$ and $U^{C}$ would give a better estimate of $l^{\text {TRANS }}$; however, we have no firm basis on which to support such a procedure for now, so we will leave this question open. From Fig. 30, however, we can say that for a number of "event periods", the transition layer should be considerably larger than the wave boundary layer, and thus one should see wave effects above $l^{\text {FBI }}$. We will explore this hypothesis next. To do this, we will have to look at the vertical concentration profiles as predicted by our boundary layer models and compared to the OBS data.

For the extended GGM model, one obtains for the concentration profiles vs. height:

$$
\begin{aligned}
& C_{n}(z)=C_{n}\left(z_{r}\right)\left(\frac{z}{z_{r}}\right)^{\frac{-w_{n}}{\mathbf{K} U_{l}^{*}}} \quad 0 \leq z \leq l^{n B L} \\
& C_{n}(z)=C_{n}\left(l^{\text {FBL }}\right) \exp \left[\frac{-w_{n}}{\mathrm{~K} U_{\cdot}^{c w} l^{\text {WBL }}} \cdot\left(z-l^{\text {WBL }}\right)\right] \quad l^{\text {WBL }} \leq z \leq l^{\text {TRANS }} \\
& C_{n}(z)=C_{n}\left(l^{\text {TRNS }}\right)\left(\frac{z}{l^{\text {TRANS }}}\right)^{\frac{-w_{n}}{\mathrm{k} U_{\cdot}^{c}}} \quad z \geq l^{\text {TRANS }}
\end{aligned}
$$




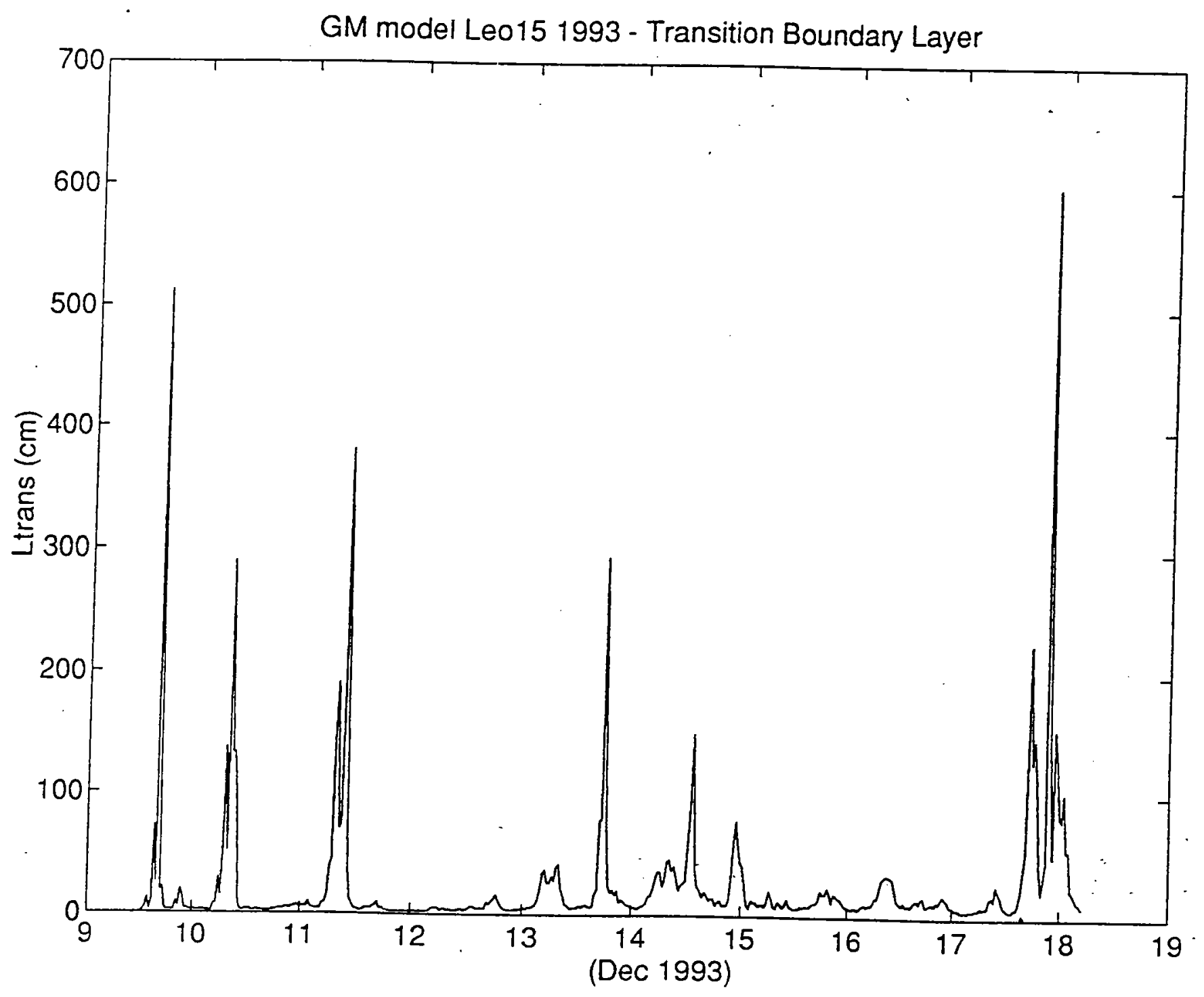
Figure 30 . Height of the "transition boundary layer" from the modified GGM eddy viscosity model
of Figure 27. 
These profiles assume an equilibrium balance between turbulent diffusion of the particles and gravitational settling; this is often but not always the case, as will be seen.

For the original GGM model, there are two simple logarithmic layers:

$$
\begin{aligned}
& C_{n}(z)=C_{u}\left(z_{r}\right)\left(\frac{z}{z_{r}}\right)^{\frac{w_{n}}{\mathrm{k} U_{*}^{* *}}} \quad 0 \leq z \leq l^{\text {FBL }} \\
& C_{u}(z)=C_{u}\left(l^{\text {FBL }}\right)\left(\frac{z}{l^{\text {WRL }}}\right)^{\frac{-w_{n}}{\mathrm{k} U_{.}^{c}}} \quad z \geq l^{\text {FBL }}
\end{aligned}
$$

To try to distinguish between the two models, we will do some simple calculations. (The data does not justify much more, in fact). Our approach will be to try to estimate, using the OBS data at $200 \mathrm{cmab}$ and each of the two boundary layer models, what the concentration seen at the 10 cmab OBS would be. If we examine the original GGM model first, we note that all the OBS sensors are then in the current boundary layer, and so one uses the simple logarithms form to extrapolate downward to the $10 \mathrm{cmab}$ sensor. Doing so, one obtains the result shown in Fig. 27. In this Figure, it is seen that during periods of low concentration, the estimate of the $10 \mathrm{cmab}$ sensor is rather good; this is just the time when current effects dominate the environment and the original GGM model is a good one! During "events", however, the current boundary layer extrapolation from $200 \mathrm{cmab}$ is poor, in that it overestimates the amount of sediment at $10 \mathrm{cmab}$. This is due to there being too much sediment at $200 \mathrm{cmab}$ for strictly current driven turbulence to explain! Only by adding wave effects, can one hope to do a better job of handling the event peaks in Fig. 31. We also note that on December 16, there is a peak which, counter to the others, is underestimated by the "purely current boundary layer" theory. This is because this peak is due to an upwelling event, which leads to a completely different vertical profile of concentration than those presented above.

We now turn to including the "transition boundary layer" and wave effects. Since we do not know very well from our winter data how far up the transition boundary layer extends, this poses somewhat of a challenge. To do a simple estimate of what wave effects are above the wave boundary layer, but not get into the (unknown) details of the exact shape and height of the transition layer, we took a simpler route. As an "upper bound" on wave effects above the wave boundary layer, one could simply extend the logarithmic wave boundary layer, i.e. use a $\log$ profile with $U^{\mathrm{CW}}$ as the appropriate turbulence factor. If one does so, one obtains the result in Fig. 32. In this figure, one sees again that the low energy region is fit well (as it should be, since $U_{.}^{C W} \rightarrow U_{.}^{C}$ as the waves vanish!), and that a few "events" are fit well, but some are underestimated. This is just what one would expect if our answer lie somewhere between a pure current and a pure wave 


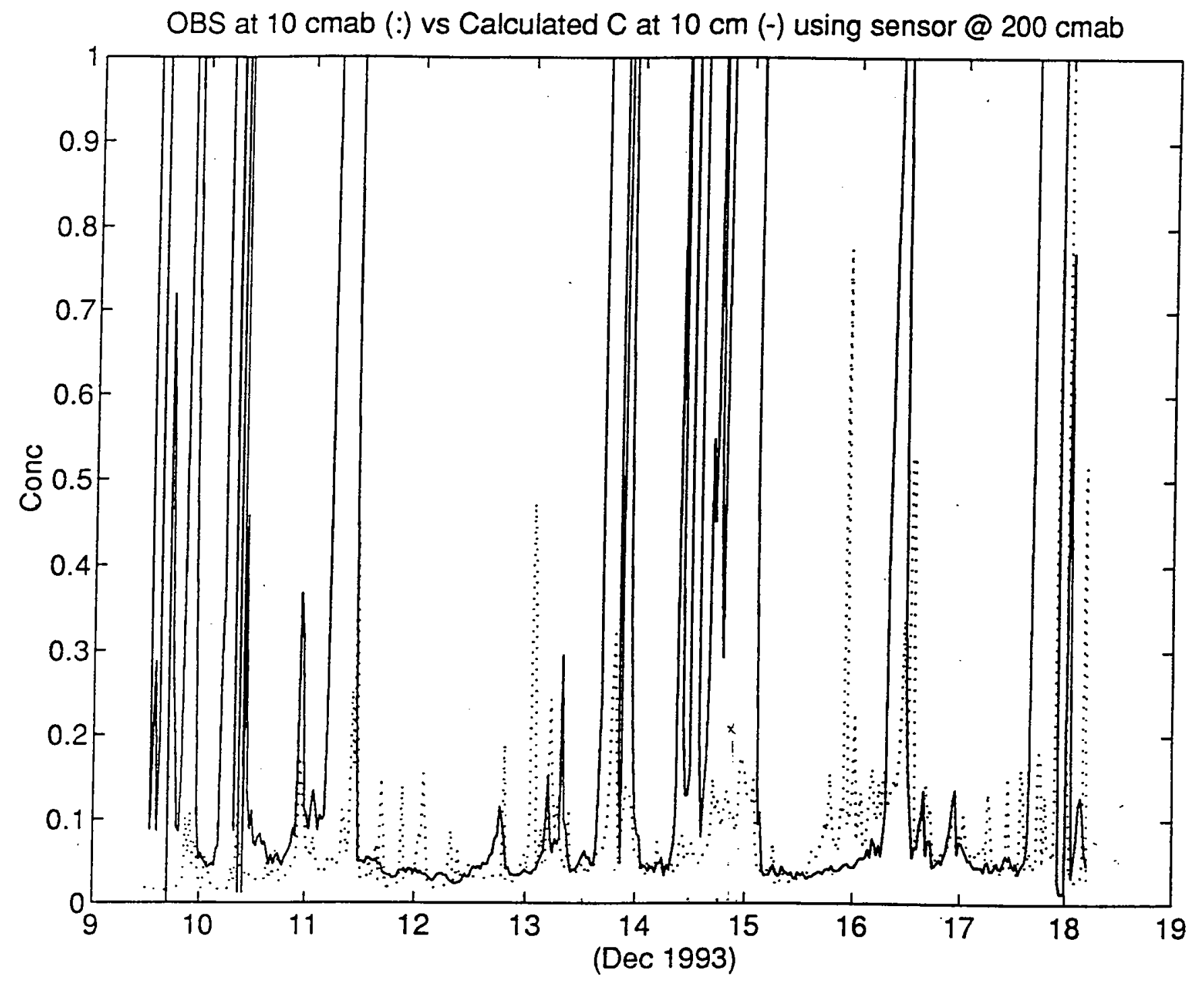

Figure 31 . OBS output at $10 \mathrm{cmb}$ vs $C$ calculated at $10 \mathrm{cmab}$ using $C(z)=C\left(z_{r}\right)\left(\frac{z}{z_{r}}\right)^{-\omega_{n} / K U_{.}^{c}}$ for $\mathrm{z}_{\mathrm{r}}$
$=200 \mathrm{cmab}$. (OBS output at $200 \mathrm{cmab}$ gace $\left.C\left(\mathrm{z}_{\mathrm{r}}\right)\right)$. 


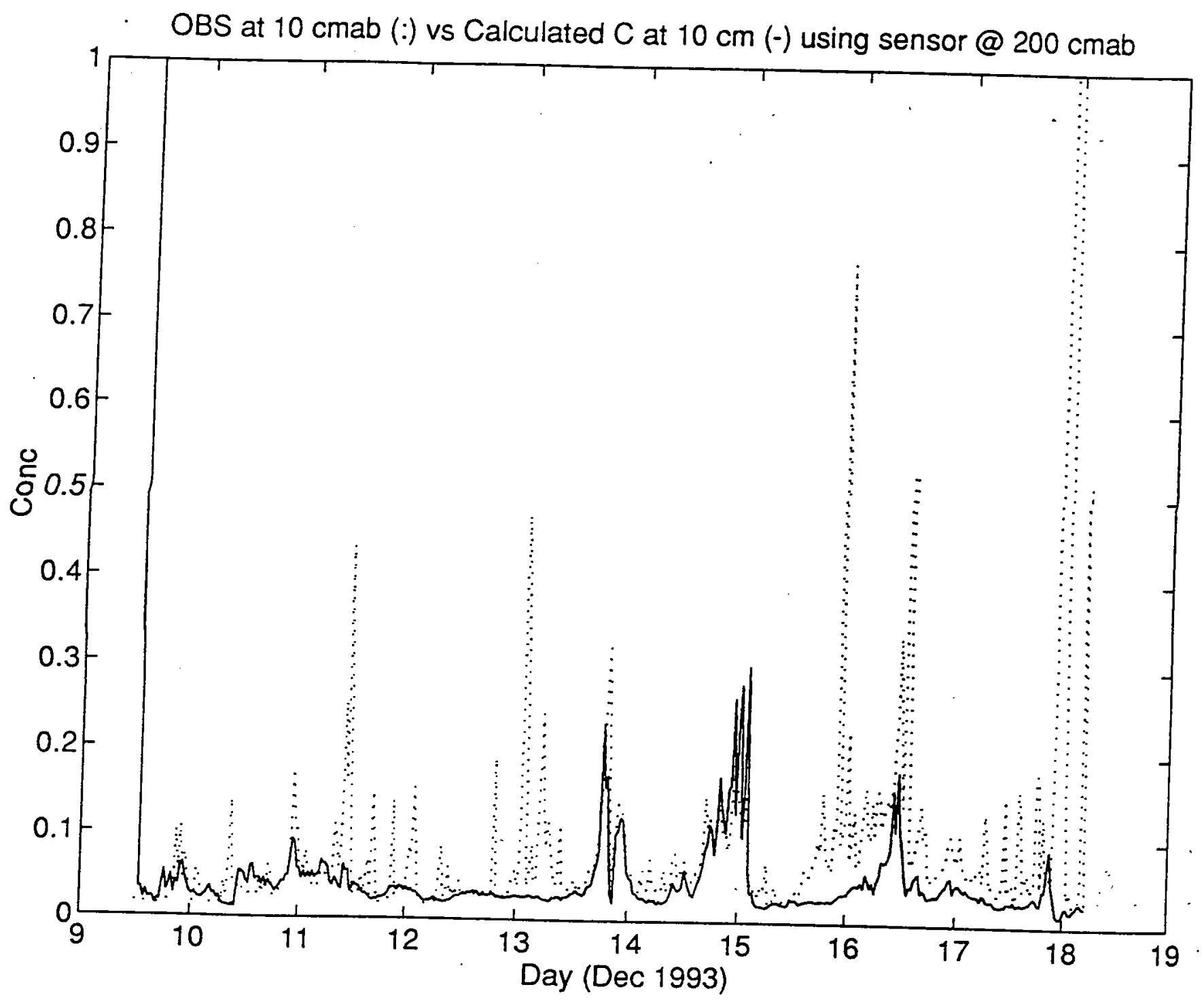

Figure 32. OBS output at $10 \mathrm{cmab}$ vs $C$ calculated at $10 \mathrm{cmab}$ using $C(z)=C\left(z_{r}\right)\left(\frac{z}{z_{r}}\right)^{-\omega_{n} / K U_{. "}^{o n}}$ for
$\mathrm{z}_{\mathrm{r}}=200 \mathrm{cmab}$. (OBS output at $200 \mathrm{cmab}$ gace $\left.C\left(\mathrm{z}_{\mathrm{r}}\right)\right)$. 
boundary layer, i.e., an "intermediate" layer with a current boundary layer above it. Unfortunately, given the sparse vertical OBS sampling and the quality of the VACM data, there is not much more we can say. We should also note that particle size distribution changes with height above the bed could also have some influence on the above results, and to address them we will turn to that topic next.

\section{B. Particle Size Effects}

Although we planned to have multifrequency acoustics and optics measurements to give us estimates of the particle size spectrum evolution versus time and height above the bottom, i.e., $C_{N}(z, t)$, we can still use the OBS data to give us a "first cut" estimate of particle size effects. This is done by looking at the measurements of the vertical profile of concentration made by the OBS's in conjunction with a model of the bottom boundary layer. since we are not entirely sure of what boundary layer model is most appropriate to use (as per the discussions in the last section), we will choose the simplest model, that of the current boundary layer, for our calculations. As noted, this assumption will probably break down during storm events, so that our particle size estimates from the vertical profile data during such periods will be suspect.

To use this technique, we note that for a single particle size class $n$, the slope of a plot of log $\mathrm{C}$ vs $\log \mathrm{z}$ is given by

$$
S=\frac{-W_{n}}{K U_{.}^{c}} .
$$

If we take $U^{c}$ from our measurements, and use the Stokes fall velocity law for a quartz sphere of density $\rho=2.7 \mathrm{gm} / \mathrm{cm}^{3}$, we then can simply relate the measured slope to the particle size. Of course, in reality we have a distribution of sizes suspended in the water column. However, if we assume that this distribution is unimodal and can be, in a simple picture, be replaced by its mean, then we can relate our concentration profiles directly to particle sizes. In doing this, we fit only the slopes of the highest three OBS's (30,100, and $200 \mathrm{cmab}$ ) since the lowest OBS was rather close to the wave boundary layer. Doing this, we obtain the result shown in Fig. 33. A preponderance of 10 to $30 \mu \mathrm{m}$ particles is seen, in reasonable agreement with the fine particle modes seen in the SPECTREX measurements shown in Fig. 19. This result also agrees with the average of the bottom sample taken during the deployment cruise. The peaks in particle size during the storm events are probably too high, due to using $U^{c}$. and our simple log layer model. By using the correct model, these peaks would probably be reduced by a factor of two, though they would still probably be larger than the "non-event" periods.

Obviously, we need better measurements to get at the size dependence of the transport. However, even these first look numbers can be of some use, especially in comparison with better data as it becomes available. 
Calculated Particulate Diameters for leo15 1993

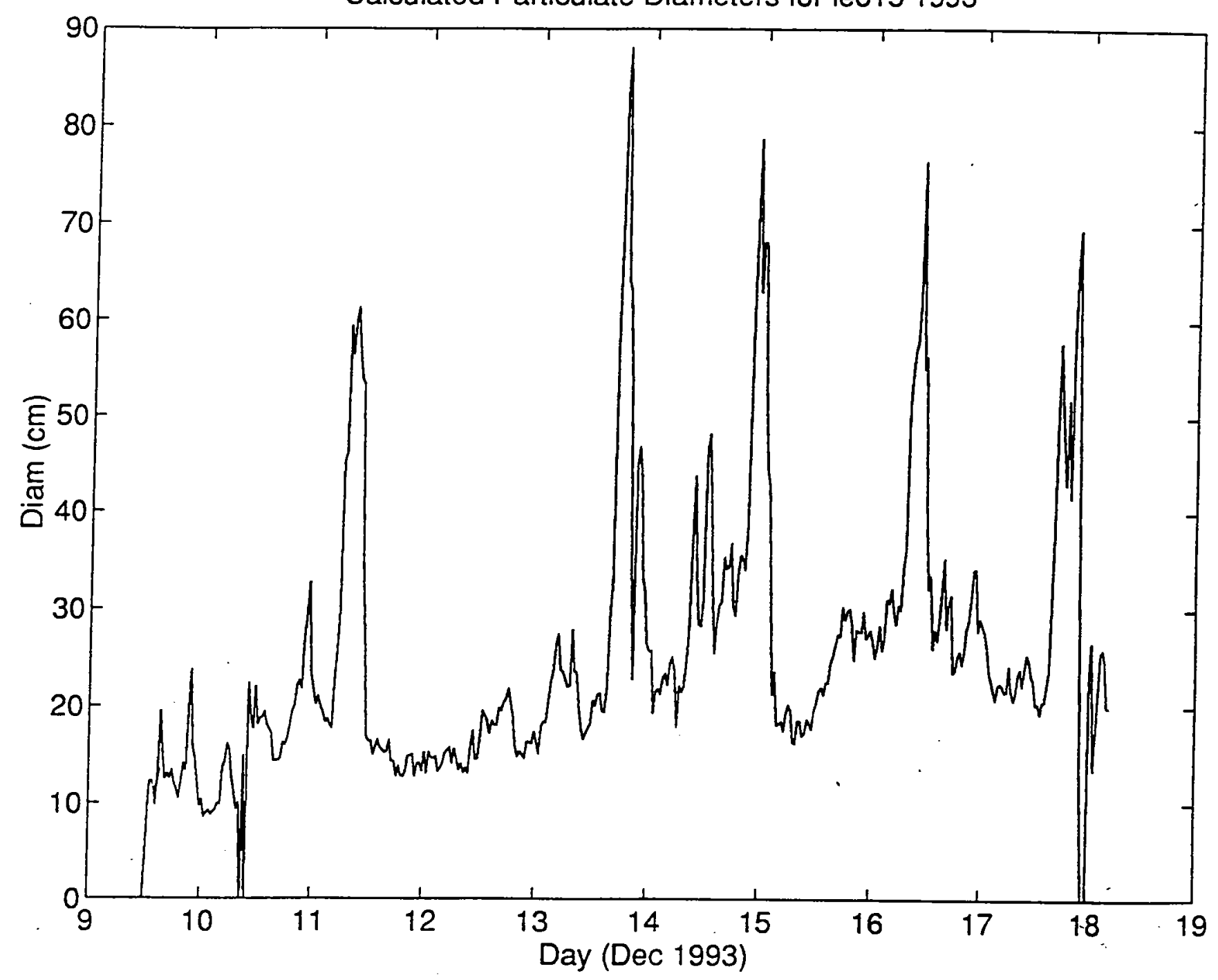

Figure 33. Calculated particale diamters for 1993 LEO-15 deployment using slope of Rouse profile fit to the 30,100 , and $200 \mathrm{cmab}$ OBS sensor's outputs. A Stoke's law fall velocity is assumed. 


\section{Conclusions/Recommendations}

In order to keep our conclusions brief, they are presented in short, "bulletized" paragraphs.

- Windstorm driven wave events and upwelling (or advective) events were the dominant processes affecting sediment suspension and transport. The former process is more likely, since all wind directions produce waves, but only winds from the south produce upwelling. Advection of suspended sediment most often occurs from offshore currents.

- Since waves are seen to be important, it follows that study of the effectiveness of the wave/current interaction for suspension and transport at the site and its environs will also be important.

- The frequency of events was (1/2.5 days) in the winter is very frequent! Our subsequent summer deployments (May, June 1994) show much less frequent events. As these events are wind driven to a large extent, study of the historical wind data should prove to be of great value to quantifying the seasonal/interannual variations in transport at the site. Long time series of waves and currents would also be quite helpful, if available. These should become available with the fiber optic cable and start of long term observations at the LEO-15 site.

- In addition to the historical data on wind, currents and waves, long time series observations of the suspension and transport at LEO and how it relates to the wave current and upwelling forcing are initially needed. Just knowing the dominant forcing is not enough how effective the forcing is in producing transport also needs to be well understood.

- The tidal and mean currents need to be better quantified at the site, as these strongly affect both suspension and transport. A vertical string of current meters (or an ADCP) to study baroclinic versus barotropic effects would be useful here.

- The wave measurements from the NDBC buoy 50 miles away are useful, but are perhaps not entirely adequate for the studies of transport at LEO-15. The wave field magnitude and direction can shift appreciably over this distance, and the errors incurred might be enough to affect transport modeling at LEO. This needs to be quantified; if the errors are appreciable, a separate wave buoy at LEO would be required in addition to the weather gathered at the Tuckerton Marine Station.

- The size dependence of the transport is a big issue. We see indications, both in our sensors (the high OBS near bottom concentration and the slopes of the OBS vertical profiles higher up) and from diver grab samples that the suspended particle size distribution has both strong temporal and strong vertical dependence. Transport is generally different for different sizes (both in mean path length and in amount), and in fact can be in completely different directions under certain circumstances. This points our the need for both high resolution measurements of the size spectrum (Yogi Agrawal's LISST laser diffraction sizer is a good instrument for this) and vertical profiles of the size distribution (combined acoustics and optics is a good way to do this).

- The model of the bottom boundary layer most appropriate for the LEO site needs to be better quantified. Data assimilating versions of these models will eventually be the way in which transport 
is described on a day to day basis; errors in the model will translate directly to error in our transport estimates. We are currently using 1-D eddy diffusion models, as they are the simplest approach. But, in these, we need to refine the model of the vertical profile structure, including perhaps the "transition" layer. Acoustic measurements of the vertical concentration profile and laser doppler velocimeter measurement of the near bottom current structure are perhaps the best means of getting at this.

- The finer scale variation in the bottom topography, i.e. transient ripple and megaripple features, is nearly a black box so far. This is unacceptable, as bottom roughness is crucial to transport studies! Divers reported megaripples after the winter storms, which lingered for a while and then eroded. Summer observations using the ABSS and ABS acoustic backscatter instruments showed up to $20 \mathrm{~cm}$ high ripples passing under our sensors. We are hoping to eventually have a sector scanning sonar to help us image this roughness at the LEO-15 site; studies by N. Psuty and others also help fill in this void!

- On a practical note, the stresses on the bottom are quite considerable in the winter, and the wave action toppled our tripod during the winter ' 93 deployment. Some serious consideration needs to be given to how to anchor the equipment even more firmly in the future or design instruments to work in these conditions.

- The winter '93 data was basically a "first look" at the transport issues at LEO-15. It was adequate to suggest what the priorities for future, more refined, measurements should be, but was not quite adequate, in our minds, to produce good transport estimates. The spring-summer ' 94 measurements should be more adequate in this respect, and we are now in the process of looking at this data. However, the guidance these winter measurements have given us has been very valuable, and we hope that future NOAA-NURP measurements at this site will benefit from our experience in this deployment. 


\section{REFERENCES}

Baldwin, K.C., J.D. Irish and H.J. Bokuniewicz, "Real-Time, In Situ Monitoring of Dredge Disposal Sites," Geotechnical Aspects of Ocean Waste Disposal, ASTM STP 1087, K.R. Demars and R.C. Chaney, eds., American Society for Testing and Materials, 76-86, 1990.

Beardsley, R.C., "A Comparison of the Vector-Averaging Current Meter and the New Edgetton, Germeshausen and Grier, Inc., Vector-Measuring Current Meter on a Surface Mooring in Coastal Ocean Dynamics Experiment I," Jour. Geophys. Res., 92, 1845-1859, 1987.

Brown, W.S., J.D. Irish and A.W. Bratkovich, "CODE-1: Moored Temperature and Conductivity Observations," WHOI Tech. Rept. 82-23, 83-118, 1983.

Brown, W.S., J.D. Irish and M.R. Erdman, "CODE-1: Bottom Pressure Observations," WHOI Tech. Rept. 82-23, 119-138, 1983.

Busse, D.W., "Quartz Transducers for Precision under Pressure," Mech. Eng., 109(5), 1987.

Downing, J.P., "An Optical Instrument for Monitoring Suspended Sediment Particles in the Ocean and Laboratory," Proc. Oceans'83, 199-202, 1983.

Glenn, S.M., "A Continental Shelf Bottom Boundary Layer Model: the Effects of Waves, Currents and a Moveable Bed, Sc.D. Thesis, 237 pp., Mass. Inst. of Tech., Cambridge, MA 1983.

Glenn, S.M. and W.D. Grant, "A Suspended Sediment Stratification Correction for Combined Wave and Current Flows," Jour. Geophys. Res., 92, 8244-8264, 1987.

Grant, W.D. and O.S. Madsen, "Combined Wave and Current Interactions with a Rough Bottom," Jour. Geophys, Res., 84, 1797-1808, 1979.

Grant, W.D. and O.S. Madsen, "Movable Bed Roughness in Unsteady Oscillatory Flow," Jour. Geophys. Res., 97, 469-481, 1982.

Irish, J.D., M.P. Woodbury and W.S. Brown, "The use of Microprocessor Technology for the Sampling of Intermittent Ocean Processes," Jour. Atm. and Ocean. Tech., 1, 58-69, 1984.

Irish, J.D., K.C. Baldwin, G.J. Needell, M.A. Martini, J. Wood and J. Mather, "Testing of a BottomMounted, Intelligent Instrument with Optical Sensors and Real-Time Telemetry for Monitoring Dredged Material Disposal Site, EOS Tech. Rept. No. EOS-90-TR01, 74 pp, 1990.

Irish, J.D., K.E. Morey, G.J. Needell and J. Wood, "A Current Meter with Intelligent Data System, Environmental Sensors and Data Telemetry," IEEE Jour. Ocean Eng., 16(4), 319-328, 1991.

Irish, J.D., "Deployment of a Bottom Monitor at a 30 Meter Deep Site in the New York Bight Apex During the Summer of 1993," Woods Hole Oceanographic Institution, Tech. Rept. No. WHOI-9343, $86 \mathrm{pp}, 1993$. 
Levine, M.D., "Dynamic Response of the VACM temperature sensor," Deep-Sea Res., 28A, 14011408, 1981.

Pederson, A.M., "An Accurate Low-cost Temperature Sensor," Trans. Marine Temperature Measurement Symp., 135-153, 1969.

Pederson, A.M. and M.C. Gregg, "Development of a small in situ Conductivity Instrument," IEEE Jour. Oceanic Eng., OE-4, 69-75, 1979.

Wearn, R.B., Jr. and N.G. Larson, "Measurements of the Sensitivities and Drift of Digiquartz Pressure Sensors," Deep-Sea Res., 29, 111-134, 1982. 


\section{ACKNOWLEDGEMENTS}

The authors would like to thank Divemasters and the crew of the R/V SOUTHBOUND and R/V ATLANTIC SURVEYOR for deploying and recovering the instrumentation. Excellent support was provided by Rose Petracca, and the divers and crew of the R/V CALETA for logistic support, anchoring the tripod to the bottom, attaching retrieval lines and collecting in situ sediment and water samples. This work was supported by NOAA though the Rutgers/SUNY National Underseas Research Program in the New York Bight under contract 4-25020. 


\section{DOCUMENT LIBRARY}

Distribution List for Technical Report Exchange - May 1995

University of California, San Diego

SIO Library $0175 \mathrm{C}$

9500 Gilman Drive

La Jolla, CA 92093-0175

Hancock Library of Biology \& Oceanography

Alan Hancock Laboratory

University of Southern California

University Park

Los Angeles, CA 90089-0371

Gifts \& Exchanges

Library

Bedford Institute of Oceanography

P.O. Box 1006

Dartmouth, NS, B2Y 4A2, CANADA

Commander

International Ice Patrol

1082 Shennecossett Road

Groton, CT 06340-6095

NOAA/EDIS Miami Library Center

4301 Rickenbacker Causeway

Miami, FL 33149

Research Library

U.S. Army Corps of Engineers

Waterways Experiment Station

3909 Halls Ferry Road

Vicksburg, MS 39180-6199

Institute of Geophysics

University of Hawaii

Library Room 252

2525 Correa Road

Honolulu, HI 96822

Marine Resources Information Center

Building E38-320

MIT

Cambridge, MA 02139

Library

Lamont-Doherty Geological Observatory

Columbia University

Palisades, NY z10964

Library

Serials Department

Oregon State University

Corvallis, OR 97331

Pell Marine Science Library

University of Rhode Island

Narragansett Bay Campus

Narragansett, RI 02882
Working Collection

Texas A\&M University

Dept. of Oceanography

College Station, TX 77843

Fisheries-Oceanography Library 151 Oceanography Teaching Bldg.

University of Washington

Seattle, WA 98195

Library

R.S.M.A.S.

University of Miami

4600 Rickenbacker Causeway

Miami, FL 33149

Maury Oceanographic Library

Naval Oceanographic Office

Building 1003 South

1002 Balch Blvd.

Stennis Space Center, MS, 39522-5001

Library

Institute of Ocean Sciences

P.O. Box 6000

Sidney, B.C. V8L 4B2

CANADA

Library

Institute of Oceanographic Sciences

Deacon Laboratory

Wormley, Godalming

Surrey GU8 5UB

UNITED KINGDOM

The Librarian

CSIRO Marine Laboratories

G.P.O. Box 1538

Hobart, Tasmania

AUSTRALIA 7001

Library

Proudman Oceanographic Laboratory

Bidston Observatory

Birkenhead

Merseyside L43 7 RA

UNITED KINGDOM

IFREMER

Centre de Brest

Service Documentation - Publications

BP 7029280 PLOUZANE

FRANCE 


\begin{tabular}{|c|c|c|c|}
\hline $\begin{array}{l}\text { REPORT DOCUMENTATION } \\
\text { PAGE }\end{array}$ & $\begin{array}{l}\text { 1. REPORT NO. WHOI-95-17 } \\
\text { WHO }\end{array}$ & 2. & 3. Recipient's Accession No. \\
\hline \multirow{2}{*}{\multicolumn{3}{|c|}{$\begin{array}{l}\text { 4. Titte and Subtitle } \\
\text { Winter } 1993 \text { Observations of Oceanography and Sediment Transport at the } \\
\text { LEO-15 Site }\end{array}$}} & $\begin{array}{l}\text { 5. Report Date } \\
\text { December } 1995\end{array}$ \\
\hline & & & 6. \\
\hline \multicolumn{3}{|c|}{ 7. Author(s) J.D. Irish, J.F. Lynch, A.E. Newhall, N. Witzell, P. Traykovski, S. Glenn } & $\begin{array}{l}\text { 8. Performing Organization Rept. No. } \\
\text { WHOI-95-17 }\end{array}$ \\
\hline \multicolumn{3}{|c|}{ 9. Performing Organization Name and Address } & 10. ProjectTaskWork Unit No. \\
\hline \multicolumn{2}{|c|}{$\begin{array}{l}\text { Woods Hole Oceanographic Institution } \\
\text { Woods Hole, Massachusetts } 02543\end{array}$} & & $\begin{array}{l}\text { 11. Contract(C) or Grant(G) No. } \\
\text { (C) } 4-25020 \\
\text { (G) }\end{array}$ \\
\hline \multirow{2}{*}{\multicolumn{3}{|c|}{$\begin{array}{l}\text { 12. Sponsoring Organization Name and Address } \\
\text { National Oceanic and Atmospheric Administration }\end{array}$}} & $\begin{array}{l}\text { 13. Type of Report \& Period Covered } \\
\text { Technical Report }\end{array}$ \\
\hline & & & 14. \\
\hline
\end{tabular}

This report should be cited as: Woods Hole Oceanog. Inst. Tech. Rept., WHOI-95-17.

16. Abstract (Limit: 200 words)

The NOAA National Underseas Research Program at Rutgers University is establishing a Long-term Ecosystem Observatory off New Jersey in 15 meters of water. As part of a bottom boundary layer study at this site, WHOI deployed a bottom instrument frame during the winter of 1993-94. The bottom instrument carried a current meter, a vertical array of optical backscattering sensors, temperature, pressure and conductivity sensors and an Acoustical Backscattering Sensor. The deployment was partially successful as the acoustic system failed. The other instrumentation worked well for 3 weeks returning data on winter conditions at the site. The extreme winter waves ended the experiment by tipping the instrument over on its side. The optical instrumentation was calibrated with sediment from the site, and the results from the experiment presented.

17. Document Analysis a. Descriptors

sediment transport

LEO-15

acoustic backscatter

b. Identifiers/Open-Ended Terms

c. COSATI Field/Group

18. Availability Statement

Approved for public release; distribution unlimited.

\begin{tabular}{|l|l|}
\hline $\begin{array}{c}\text { 19. Security Class (This Report) } \\
\text { UNCLASSIFIED }\end{array}$ & $\begin{array}{c}\text { 21. No. of Pages } \\
69\end{array}$ \\
\hline 20. Security Class (This Page) & 22. Price \\
\hline & $\begin{array}{l}\text { OPTIONAL FORM 272 (4-77) } \\
\text { (Formerly NTIS-35) } \\
\text { Department of Commerce }\end{array}$ \\
\hline
\end{tabular}

